\title{
Electoral Systems in Divided Societies: the Fiji Constitution Review
}





\section{Electoral Systems in Divided Societies: the Fiji Constitution Review}

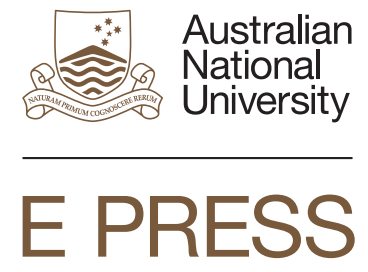




\section{ANU \\ E PRESS}

Published by ANU E Press

The Australian National University

Canberra ACT 0200, Australia

Email: anuepress@anu.edu.au

This title is also available online at http://epress.anu.edu.au

National Library of Australia Cataloguing-in-Publication entry

Title: Electoral systems in divided societies : the Fiji constitution /

edited by Brij V Lal and Peter Larmour.

ISBN: 9781922144508 (pbk.) 9781922144515 (ebook)

Subjects: Elections--Fiji.

Fiji--Politics and government--20th century.

Fiji--Constitution.

Fiji--Constitutional history.

Other Authors/Contributors::

Lal, Brij V.

Larmour, Peter.

Australian National University. National Centre for Development Studies.

Dewey Number: $\quad 342.9611029$

All rights reserved. No part of this publication may be reproduced, stored in a retrieval system or transmitted in any form or by any means, electronic, mechanical, photocopying or otherwise, without the prior permission of the publisher.

Printed by Griffin Press

First published by National Centre for Development Studies, 1997

This edition (c) 2012 ANU E Press 


\section{Contents}

Contributors

Abbreviations

vii

Map: the Republic of the Fiji Islands

viii

Introduction

Peter Larmour

1. Encouraging electoral accommodation in divided societies

Donald L. Horowitz

2. Fiji Constitution Review Commission recommendations for a new electoral system for Fiji

Brij V. Lal

3. Constitutional engineering and the alternative vote in Fiji: an assessment

Ben Reilly

4. Fiji's proposed new voting system: a critique with counter-proposals

D.G. Arms

5. Party cooperation and the electoral system in Mauritius Raj Mathur

6. The recommendations on the electoral system: the contribution of the Fiji Constitution Review Yash Ghai 


\section{Contributors}

David G. Arms is a linguist and a Catholic priest, a member of St. Columban's Mission Society. He has a longstanding interest in electoral systems and has conducted many elections for the Church using the Single Transferable Vote and Alternative Vote systems.

Yash Ghai is Sir Y.K. Pao Professor of Public Law at the University of Hong Kong. He was the Legal Advisor to the NFP-FLP coalition.

Donald L. Horowitz is James B. Duke Professor of Law and Political Science at Duke University. He has published and consulted widely on the problems of divided societies and policies to reduce ethnic conflict.

Brij V. Lal is Senior Fellow in Pacific Islands History in the Research School of Pacific and Asian Studies at The Australian National University. He was a member of the Fiji Constitution Review Commission.

Peter Larmour is Director of the Development Administration Program, National Centre for Development Studies, Research School of Pacific and Asian Studies, The Australian National University. He has published extensively on South Pacific politics and governance.

Raj Mathur is Associate Professor of Politics in the Faculty of Social Studies and Humanities, University of Mauritius. He has written extensively on the government and politics of Mauritius.

Ben Reilly is Programme Officer at International IDEA in Stockholm. He has previously worked as an adviser in the Department of the Prime Minister and Cabinet in Australia and as a research officer in the Australian Electoral Commission. 


\section{Abbreviations}

ANU

AV

$\mathrm{BV}$

$\mathrm{CBC}$

CRC

FLP

FPP

IDEA

MAV

MMP

MP

MV

NFP

NGO

PNG

PR

RAV

SAV

STV

SVT
The Australian National University

Alternative Vote system

Block Vote

Constituency Boundaries Commission

Constitution Review Commission

Fiji Labour Party

First-Past-the-Post system

Institute for Democracy and Electoral Assistance

Multiple Alternative Vote

Mixed-member Proportional system

Member of Parliament

Multiple Vote

National Federation Party

non-government organisation

Papua New Guinea

Proportional Representation

Repeated Alternative Vote

Single Alternative Vote

Single Transferable Vote

Soqosoqo ni Vakavulewa ni Taukei 


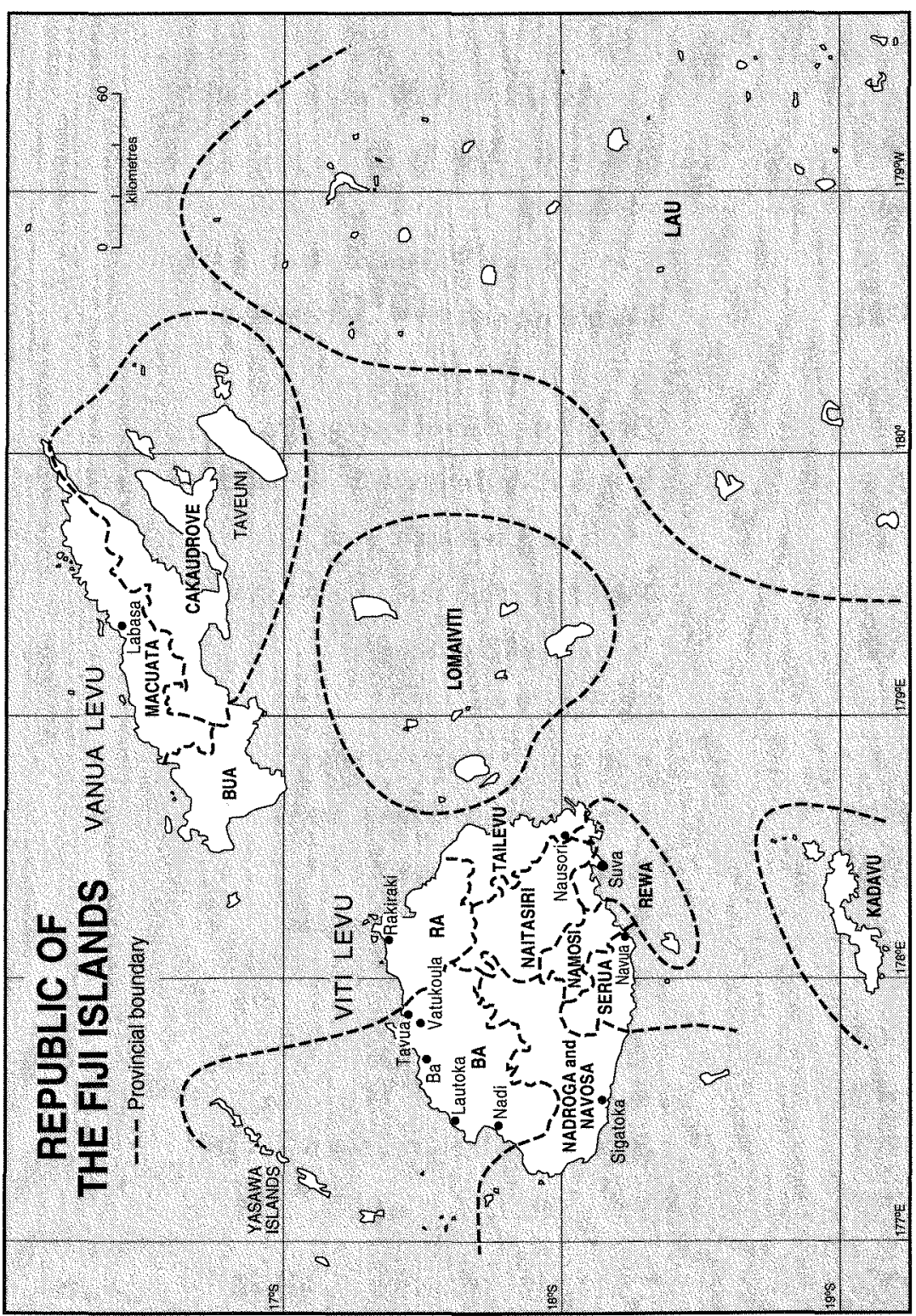




\title{
Introduction
}

\author{
Peter Larmour
}

In 1987, Fiji had its first change of government since the country became independent in 1970. In a general election, a coalition of the National Federation Party (NFP) and the Fiji Labour Party (FLP) won four more seats than the ruling Alliance Party. Dr Timoci Bavadra replaced Ratu Sir Kamisese Mara as Prime Minister. Both were indigenous Fijians, but most of the Coalition's electoral support was non-indigenous. A month later the new government was deposed by a military coup. A second coup, later in the year, forestalled implementation of a political compromise between party leaders. The country was declared to be a Republic, and was refused re-admission to the Commonwealth. The former Governor-General became President, and established an Interim Government.

A new Constitution was drawn up to replace the one adopted at Independence in 1970. Its preamble explained how the 'events in $1987^{\prime}$

were occasioned by a widespread belief that the 1970 Constitution was inadequate to give protection to the interests of indigenous

Fijians, their values, traditions, customs, way of life and economic well being (Fiji 1990:498).

The new 1990 Constitution contained provisions that its designers believed would protect and promote the interests of indigenous Fijians, including disproportionate parliamentary representation, more influence for the Great Council of Chiefs, affirmative action in the public service, and the reservation of the office of Prime Minister for indigenous Fijians. Its affirmation of indigenous rights attracted some sympathy from governments elsewhere in the region, but the Constitution was also criticised for its impact on non-indigenous 
Fijians, particularly the Indo-Fijians whose forebears had come as indentured labourers to the country during colonial rule. Emigration increased and investment fell. Constitutional change became the test for investor confidence and a return to the Commonwealth.

The 1990 Constitution contained provisions for its own review within seven years (Section 161). The Review was eventually commissioned in March 1995, and reported in September 1996. Parliament approved the following terms of reference

The commission shall review the Constitution promoting racial harmony and national unity and the economic and social advancement of all communities and bearing in mind internationally recognised principles and standards of individual and group rights.

Towards these ends the Commission shall

(1) Take into account that the Constitution shall guarantee full protection and promotion of the rights, interests and concerns of the indigenous Fijian and Rotuman people.

(2) Scrutinise and consider the extent to which the Constitution of Fiji meets the present and future constitutional needs of the people of Fiji, having full regard for the rights, interests and concerns of all ethnic groups of people in Fiji.

(3) Facilitate the widest possible debate throughout Fiji on the terms of the constitution of Fiji and inquire into and ascertain the views and opinions that may exist in Fiji as to how provisions of the Fiji constitution can be improved upon in the context of Fiji's needs as a multi-ethnic and multicultural society.

(4) Report fully on the above matters and, in particular, to recommend constitutional arrangements likely to achieve the objectives of the Constitutional Review as set out above (Fiji 1996:744-55).

The chairman of the Constitution Review Commission (CRC) was Sir Paul Reeves, a former Archbishop and Governor-General of New Zealand with an indigenous Maori background. Its other members were Tomasi Vakatora, an indigenous Fijian businessman and former cabinet minister, and Dr Brij Lal, an Indo-Fijian academic historian at The Australian National University (ANU).

The chapters in this book assess the CRC's recommendations about the system of electing members of Parliament. Although they are only one aspect of the CRC's report, they are a critical, and 
controversial, aspect of its approach to achieving cooperation between ethnic groups.

Ethnic divisions are typical of modern states (Smith 1995:86). Ethnic conflicts have become more salient since the end of the Cold War, but have always been a feature of the politics of developing countries like Fiji. Relations between indigenous people, and the descendants of migrants, are also a matter of constitutional debate in Fiji's neighbours, including Australia, New Zealand and New Caledonia.

\section{Background to the chapters}

The following chapters are based on papers presented at a workshop held at ANU's Research School of Pacific and Asian Studies in Canberra in January 1997. The workshop brought together the former Commissioners (Reeves, Vakatora and Lal, and their Counsel, Alison Quentin-Baxter), Professor Donald Horowitz, whose arguments about voting in ethnically divided societies had influenced the Commission, and other academics and students with interests in electoral systems and Fiji politics. Members of the Select Committee of the Fiji Parliament which was then reviewing the CRC report were invited to the workshop, and several were able to attend. It was organised by the editors of this book as part of a wider research project in the Research School of Pacific and Asian Studies on 'State, Society and Governance in Melanesia', funded from the ANU's own resources and the Australian Agency for Aid and Development (AusAID), and convened by Professor Ron Duncan of the National Centre for Development Studies.

Tomasi Vakatora, and Professor Yash Ghai, who were academic visitors to ANU in late 1996, helped design the workshop and identify participants. Professor Cheryl Saunders, of the University of Melbourne, Michael Maley of the Australia Electoral Commission, and Dr Marian Simms, Dr William Sutherland and Anthony Regan of the ANU contributed as rapporteurs and discussants. Ghai was adviser to the NFP-FLP, and he, Saunders and Larmour had been advisers at various times to the Citizens Constitutional Forum, a nongovernment organisation (NGO) that had held a number of workshops in Fiji on constitutional issues, and had made a submission to the CRC. Another NGO, the International Institute for Democracy and Electoral Assistance (IDEA), contributed to the 
publication of this book, through Ben Reilly, Programme Officer at IDEA and a PhD scholar in the ANU's Department of Political and Social Change.

\section{Electoral systems in Fiji, 1970-1997}

Under the 1970 Constitution, there were separate electoral rolls for Fijians, Indians and so-called General Voters (the rest). The country was divided into two kinds of constituency: 27 communal constituencies, in which voters from one ethnic group chose among candidates from their group; and 25 national constituencies, in which candidature was limited to members of one or other ethnic group, but all three groups voted. Thus any particular elector had four votes: one for a candidate from his or her own ethnic group, competing only for the votes of that group; and one each for a candidate from each of the three ethnic groups, competing for three national seats. The candidate with the largest number of votes in each seat won. There were no seats without ethnic restrictions on candidature and/or voting. However 'cross voting' in the national seats was meant to encourage accommodative behaviour. For example, the candidate in a Fijian national seat had to be a Fijian, but could seek support more widely from other ethnic groups. In ethnic terms the outcome was fixed, and balanced, in advance: there would always be 22 Fijian MPs; 22 Indian MPs; and 8 'General' MPs (who were thus over-represented compared to their numbers in the population).

Fijian and Indian leaders had agreed that the 1970 arrangements were not final, and that a Royal Commission would look again at the electoral system. The commission, chaired by Professor Harry Street, reported in 1975 and recommended retaining the 27 communal seats, but opening up the 25 national seats to any candidate, regardless of ethnicity. Elections to the open seats would be by Single Transferable Vote. The government did not act on the report (Lal 1986:78, Scarr 1988:20).

The Alliance Party held power under this electoral system for 17 years. The Alliance was formally a coalition of different ethnic organisations. Though it was dominated by its Fijian wing, it always attracted a substantial Indian vote. It faltered briefly in 1977, when it narrowly lost a general election. However, the opposition was so divided that they could not form a government and the Alliance was 
restored with a large majority in a second general election held later in the year. It faltered fatally in 1987, when the opposition coalition briefly took office, before being removed in a military coup.

The 1990 Constitution retained the separate electoral rolls of its predecessor, and created an additional roll for the indigenous people of the offshore island of Rotuma. It eliminated the cross voting national seats, and increased the total number of communal seats, but reweighed them to give the Fijian members an overall majority. Thirty-seven of the 70 seats were reserved for Fijians, 27 for Indians, 5 for General Voters and 1 for Rotumans (who had previously voted with Fijians). Thirty-two of the Fijian seats were filled from multimember, provincial constituencies. All elections were conducted via a First-Past-the-Post (FPP) electoral system.

When parliamentary government was restored after the first general election in 1992, the Alliance had been replaced by the Soqosoqo ni Vakavulewa ni Taukei (SVT) as the largest Fijian party. It was led by Sitiveni Rabuka, who had led the two coups in 1987. Ratu Mara, the former Prime Minister, became President. The SVT did not try, nor did it have any electoral incentives, to appeal outside Fijian constituencies, and claimed a special relationship with the country's chiefs. In the 1994 election it increased its number of seats.

Meanwhile, emigration had affected the demographic balance between ethnic groups. In 1966, indigenous Fijians had formed 42 per cent of the population. In 1986, just before the coups, they formed 46 per cent. By 1996 they were 50 per cent (Norton 1990 Table 1; Fiji CRC 1996: 790-91, Tables A and B). There had been a net outflow of about 40,000 Indo Fijians, compared to 5,000 people from other communities, since the coups (Fiji CRC 1996: 37, para 3.67).

\section{What the chapters say}

\section{Horowitz: the arguments for the Alternative Vote system}

Donald Horowitz's chapter argues from first principles, particularly that a politician's primary objective is to ensure election, and from the recent history of other, ethnically divided societies. He identifies several ways of reducing inter-ethnic conflict: by dispersing it; by encouraging conflict within rather than between groups; by creating incentives for cooperation; and by encouraging cleavages such as class or territory, that cut across ethnicity. 
Horowitz proposes that politicians will be more moderate on ethnic issues if they have to rely, to some extent, on the votes of people who are not members of their ethnic group. Their moderation is enforced by the votes, and the threat of withholding them, of voters from other ethnic groups. He contrasts this approach, which he calls 'vote pooling', with 'seat pooling', where candidates successful within their own ethnic group form a coalition with candidates from other ethnic groups after the election. These coalitions, he says, quickly break down without the backing of voters. He finds three conditions are required for pre-electoral coalitions in divided societies: party proliferation (so no party can govern alone); heterogeneous, or mixed constituencies (so that candidates cannot rely on the votes of their own group alone); and 'strong electoral incentives to make vote pooling politically profitable', particularly the Alternative Vote (AV).

Horowitz finds the CRC's arguments for the AV 'impeccable' but he disagrees with some of their detailed recommendations, particularly their way of adding preferences, and their proposal for multimember seats in which all candidates compete against all other candidates. He suggests other ways of counting preferences, and proposes that if large constituencies are necessary they need not be 'multimember': three members would be chosen by the same electorate, but candidates competing for one of the seats would only compete with other candidates competing for that seat, and preferences would be transferred only within single seats. Horowitz thus deals with the major concerns raised in the workshop against multimember AV.

Horowitz also includes 'discouraging words' about the relationship between the process of negotiation, and the outcome. Just because two sides can agree on something does not mean it will work. And things that are agreed to as transitional often later prove hard to dislodge (as the fate of the Street Commission shows). It is important to get things right at the start.

\section{Lal: the Commission's thinking}

Brij Lal introduces and summarises the Commission's thinking and recommendations about electoral systems. He sets out the logic of the Commission's approach: analysing the weaknesses of the 1970 and 1990 constitutions, comparing Fiji with other countries, giving 
priority to inter-ethnic cooperation, and then making recommendations to achieve it. Among these were the recommendation that all elections to both Houses of Parliament, and to the Presidency and Vice Presidency, should be by "the preferential system known as the 'Alternative Vote'" (Fiji CRC 1996:304).

The chapter treats the AV as a refinement of the FPP system, designed to ensure that the successful candidate receives a majority of the votes cast. The AV contrasts both with proportional systems, designed to ensure that the seats a party receives in Parliament are proportional to the number of votes it receives in the election. Importantly for the debate in the January workshop, the chapter argues that the Alternative Vote can be used in multimember as well as single-member constituencies.

The Commission evaluated these electoral systems according to their impact on inter-ethnic cooperation and multi-ethnic government. They studied the impact of electoral systems in other ethnically divided societies, including Mauritius (discussed in Mathur's chapter). They saw politicians and political parties as the significant actors, responding to incentives and restraints imposed by the electoral system. Provided that there were a number of political parties, and constituencies contained a mixture of ethnic groups, the Alternative Vote could encourage some politicians and parties to seek the second or third preferences of people from another ethnic group. If they wished to get re-elected, they would continue to take into account the interests of the voters who had given them their preferences.

The Commission went on to evaluate AV against their other criteria: representation of constituents; voter participation; minority representation; fairness between parties; effective government and effective opposition; provenness elsewhere; and legitimacy. The CRC recommended that 45 open seats in Fiji's Lower House should be filled by AV in 15 three-member heterogeneous constituencies. Boundaries would be determined by a standing, independent Constituency Boundaries Commission. Another 25 seats should be reserved for ethnic groups.

Lal's chapter concludes with his own comments, particularly to counter criticisms of the use of $\mathrm{AV}$ in multimember constituencies. Fiji already used multimember constituencies for Fijian seats, and the purpose of the CRC's recommendation was to achieve the ethnic 
State, society and governance in Melanesia

heterogeneity within the seats that was necessary for AV to encourage inter-ethnic cooperation.

\section{Reilly: the Alternative Vote in Australia and Papua New Guinea}

Ben Reilly's chapter follows Horowitz and Lal in granting a central place to electoral systems in shaping political competition, and the Alternative Vote in achieving accommodation. His contribution is to show in detail how AV works in Australia, and worked in its former colony, the ethnically divided state of Papua New Guinea. He disagrees with the $\mathrm{CRC}$, however, over the use of $\mathrm{AV}$ in multimember constituencies.

Reilly shows how AV can be seen as a refinement of the Single Transferable Vote system of proportional representation. The arguments for $\mathrm{AV}$ assume that politicians behave rationally, and strategically, taking into account the characteristics of the electorate, their bases of support, and their expectations of what other candidates will do. To 'pool' their own first preferences, and the second preferences of other candidates, politicians will, he says, tend to move to the centre. The Australian Labor Party's reliance on the second preferences of Green voters in the 1990 Federal election is a good example.

Reilly identifies three strategies adopted by candidates under AV in Papua New Guinea: candidates with a small base of first preferences sought the second preferences of other groups; candidates with a larger base sought secondary support from outside it; while others campaigned together, urging supporters to give their second preferences to each other. Preference distribution became increasingly important in deciding the outcome of successive elections (and, by implication, the highly competitive, and sometimes violent, style of campaigning in some parts of Papua New Guinea may be related to its adoption of FPP in 1975).

While the PNG evidence supports AV, Reilly faults the CRC's recommendation for $\mathrm{AV}$ in multimember constituencies, and their recommendations about the way second and third preferences should be counted. The Alternative Vote in multimember constituencies, he argues from Australian Senate examples, can produce highly disproportionate outcomes. He shows from a hypothetical example, that giving second and third preferences the same weight as a first preference may lead to the elimination of more 
popular candidates, and disproportional outcomes. He concludes that AV utilising single-member constituencies is the best option, but if multimember constituencies are needed to achieve ethnic heterogeneity, then Fiji should use the Single Transferable Vote.

\section{Arms: arguments for Proportional Representation}

David Arms dissents from the consensus among previous chapters in favour of the Alternative Vote. He goes back a step further to dissent from the priority that the CRC gives to multi-ethnic government. Instead, he argues, the electoral system should try to represent the whole spectrum of opinion in the electorate, including minority views, even if these are racist, or extreme. Arms is suspicious of deals, accommodations and engineering outcomes. People in Fiji, he suspects, will continue to vote on ethnic lines, and a system that tries to marginalise these expressions of opinion will only drive them outside it.

Arms is sympathetic to the use of AV when one official is being elected (for example, a President). However, when a number of representatives is being elected simultaneously (as in a parliament), he is concerned that a minority interest or viewpoint may be systematically unrepresented. (Supporters of AV might say they would nevertheless be able to influence the outcome through the use of their preferences.)

The first part of Arms' chapter uses examples to show how different electoral systems can deliver different results from the same initial distribution of votes. He notes Block Voting is already operating in some elections in Fiji, and generally finds it, and AV, to be hostile to minorities. He points out that the CRC has been sufficiently concerned about under-representation to allow the President to make appointments to the Upper House to compensate for it, and that the CRC is content to continue the over-representation. of General Voter and Rotuman minorities in the reserved seats.

Arms favours the Single Transferable Vote (STV) as a means of ensuring that parties, interests and viewpoints (including expressions of ethnic sentiment) are represented in parliament in proportion to their distribution among the electorate. Coalitions might then follow by a process of what Horowitz called seat pooling rather than vote pooling, but the electoral system is not enlisted to encourage them. The second part of the chapter engages point-by-point with the 
arguments of the $\mathrm{CRC}$, using its own criteria. He notes the stress that requirement for ethnic heterogeneity puts on the boundaries to be drawn by the Constituency Boundaries Commission. The third part advances Arms' argument for STV, and admits some mainly technical drawbacks.

\section{Mathur: accommodation without the Alternative Vote in Mauritius}

First-Past-the-Post (FPP) voting received short shrift in the CRC report, and in all the chapters reviewed so far. Raj Mathur shows how FPP has allowed dramatic disproportionality between seats and votes in general elections in Mauritius. Twice, the opposition has been wiped out, with a winning coalition obtaining 100 per cent of the seats with 64 per cent of the vote in 1982, and a different coalition achieving a similar clean sweep with 65 per cent in 1995.

Nevertheless, Mauritius has achieved ethnic accommodation, and national, rather than communal parties, in spite of FPP.

Mauritius uses a system of three-member constituencies in which the top three candidates, regardless of the percentage obtained, are elected (rather like the Block Vote described in Arms chapter, and used in most Fijian constituencies under the 1990 Constitution).

Disproportionality has been somewhat mitigated by the filling of eight additional 'Best Loser' seats. Four of these are awarded on ethnic grounds, by calculating which community is least represented, compared to its population. However, Mathur says that the system is associated with increasingly unwelcome entrenchment of ethnic differences.

The Constitution of Mauritius recognises the existence of different ethnic communities, but does not enrol them separately, or require that they vote separately, as does Fiji. All are descendants of migrants (whereas the conflict in Fiji is increasingly expressed in terms of relationships between indigenous people and immigrants, rather than races, or ethnic groups). Mauritian parties have learned ethnic accommodation and power-sharing. They enter into coalitions before or after the election, pooling votes and seats, and none has tried to govern alone. Parties have striven to become 'national' and now no party is ethnically-based. In terms of Horowitz's criteria, there is a 
proliferation of parties, so none can govern alone. Not all constituencies, however, are heterogenous (Hindus, we are told, predominate in rural constituencies). Nor are electoral incentives particularly strong, as candidates require only a plurality to win.

\section{Ghai: what the parties wanted}

Yash Ghai compares the CRC report with the submissions to it from the opposition parties and the governing SVT. He criticises the CRC for its commitment to a 'Westminster' system of government, and its reluctance to mandate power-sharing in the constitution.

The SVT submission supported the continuing political predominance of indigenous Fijians, reinforced by majority representation in a parliament of seats reserved for particular ethnic groups. Coalitions or power-sharing might not be excluded, but the constitutional system did nothing to encourage them.

The NFP-FLP submission favoured 'constitutionally mandated sharing of power' between parties and ethnic groups. Any party that received more than 20 per cent of the votes would be entitled to a similar proportion of seats in Cabinet. The Prime Minister would be required by the constitution to ensure that Cabinet membership was racially balanced. Electorally, the NFP-FLP recommended 40 open seats elected by proportional representation from party lists, treating the whole country as a single constituency. It also recommended continuing, for the time being, with 30 communal seats, elected from single-member constituencies by the Alternative Vote. Parties would be required to open their membership to all ethnic groups.

Ghai associates the CRC's preference for encouraging powersharing indirectly, through the electoral system, with their conservative endorsement of the Westminster system (in particular, he implies, the adversarial relationship between Government and Opposition). He questions whether the CRC's assumptions about Westminster, and the continuing vitality and proliferation of political parties, are valid. Generally, he concludes that while the CRC's proposals may work, there are too many uncertainties to rely on an untried electoral system, rather than constitutional mandate, to ensure power-sharing. 


\section{The issues raised}

\section{Achieving heterogeneity by multimember constituencies}

Horowitz was clear that $\mathrm{AV}$ would not encourage accommodative behaviour on its own. Constituencies also needed to be heterogeneous for candidates to see the need to make appeals outside their own ethnic group.

It was the difficulties in achieving heterogeneity that drove the $\mathrm{CRC}$ from the uncontroversial use of $\mathrm{AV}$ in single-member constituencies to its controversial use in multimember constituencies where, according to Reilly, 'the majoritarian features of the system become overwhelming'.

Can sufficiently heterogeneous constituencies be drawn up in Fiji? The answer depends on demography and what counts as sufficient. The CRC made its own calculations, finding

the choice between single-member and three-member constituencies did not affect the potential for heterogeneity in the more densely populated areas in the western Division, Macuata and the Greater Suva and Nausori area. Using three-member constituencies made it marginally easier to achieve a reasonable degree of heterogeneity by combining the less densely populated areas, such as the maritime provinces, with other areas having similar interests (Fiji CRC 1996:314, para 10.50)

The CRC was prepared to accept as heterogenous 'a mixed population ranging from more or less equal balance between Fijians and Indo-Fijians, to a proportion as high as 85-90 per cent of one community and 15-20 per cent of the other' (Fiji CRC 1996: 315, para 10.51). In the latter situations there might be few pickings for ethnic moderates.

Horowitz proposed a solution: that constituencies large enough to be heterogeneous need not be 'multimember'. Two or three members could be separately elected by the same large, heterogeneous, electorate. Candidates competing for one seat would compete only with each other, and preferences would not be transferred between the seats. However, some felt this might be confusing and was untried.

In either case, several contributors pointed out the stress that the use of the electoral system to achieve ethnic accommodation put on the Constituency Boundaries Commission. Careful calculations, 
independent judgements, and unfamiliar combinations of population would be required to achieve and maintain the heterogeneity that was required for the CRC's scheme to work.

\section{The priority of multi-ethnic government}

Arms' chapter questions the priority CRC gave to multi-ethnic government, and the subordination of other democratic values to it (though as Ghai points, the CRC was required to do so by the terms of reference Parliament gave it). Horowitz points out that the arguments for $\mathrm{AV}$ are quite different from the arguments that animate discussions about electoral systems in homogeneous countries (proportionality, party strength, relations with constituents, and seat bonus for FPP).

Some participants questioned the assumption that lay behind the CRC's priorities: that Fiji was, in fact, 'deeply divided' by race. They cited the amiable day-to-day relationships between members of different ethnic groups, or the importance of other social divisions such as class or region (see Sutherland 1992). Different views of the salience of ethnicity were also expressed in different interpretations of 'the events of 1987'. Were these the last gasp of colonially-inspired racism, or a mild precursor of the violence that might come if ethnic tensions were not addressed?

\section{The relationship between recommendations}

The Commission and several participants emphasised the interconnectedness of its recommendations. These chapters and the workshop focused only on the electoral system. Other recommendations, such as the proposal for a 'Compact', and those dealing with human rights or indigenous institutions were meant to reassure communities, and encourage accommodation between them. Seamlessness is particularly important for the electoral system which is enlisted by CRC to encourage power-sharing. The CRC's approach is self-consciously indirect, but Ghai worries that it put too much reliance on the electoral system to achieve power-sharing that might have been achieved directly. The system lacks the 'redundancy' of Horowitz's engineering metaphor. Inability to achieve heterogeneity in constituencies may weaken the electoral incentives on politicians which in turn may reduce cooperation in government. 
The evidence from Mauritius, with accommodation in spite of an electoral system that all the other chapters condemn, shows how many other factors may be important. These are difficult to disentangle in ad hoc international comparisons that are made to support a point in a domestic argument.

\section{Consociation and/or integration}

The Commission contrasted two approaches to encouraging interethnic cooperation: its own integrationist approach, that used the electoral system to encourage parties to seek support from more than one ethnic group; and the 'consociational' approach, which assumed communal voting, and sought to achieve accommodation between leaders. The two approaches follow Horowitz's distinction between vote pooling (which creates continuing electoral pressure on leaders to accommodate) and seat pooling (which he found to be unstable).

'Consociation' was defined classically by Lijphart (1977:25) in terms of four features: a grand coalition government; mutual vetoes to protect minority interests; proportional representation, employment and expenditure rules in the public sector; and community autonomy. There has been much written about the degree to which the 1970 constitution was consociational and the relevance of the model to Fiji (for example, Premdas 1986:118 and 1993). Horowitz argued that consociation had, in fact, failed to produce accommodation in countries that tried it. Leaders were easily tempted to abolish the restraints it imposed. Ghai suspected the CRC of a 'doctrinal objection' to post-election coalitions.

Taken as a whole, the CRC's report has consociational elements, such as the idea of a 'Compact among the people of the Fiji islands', separate Fijian institutions, reserved seats, and the proposal that the composition of the state services, including the army 'broadly reflect the ethnic composition of the population' (Fiji CRC 1996:472, para 14.26). The CRC argued that it did not favour its approach 'to the exclusion of relevant aspects of the consociational model' (Fiji CRC 1996: 312, para 10.38).

The NFL-FLP submission to the CRC had taken a consociational approach with its proposal for constitutionally mandated powersharing, though its proposals for thresholds to get into Parliament and Cabinet, and for ethnically inclusive parties, were more 'integrationist'. 
The issue in the workshop was whether the outcomes expected by the application of electoral incentives might not be guaranteed directly by constitutionally mandated power-sharing-at least for a transitional period. Such guaranteed outcomes would also, politicians pointed out, be easier to explain to their constituents. Horowitz pointed out that elections were intrinsically unpredictable, while institutions could only hope to reduce ethnic conflict, not eliminate it altogether.

\section{The interests of politicians and parties}

The interests of politicians and parties, rather than voters, are referred to positively and negatively at different points in the chapters. They are crucial to the CRC's scheme of enlisting the selfinterest of politicians to an achievement of accommodative behaviour. Heterogeneous constituencies and Alternative Voting guide the vote-maximising politician to take the interests of other ethnic groups into account.

Arms recognised that some politicians' behaviour might be expressive (for example of ethnic identity) rather than rational and instrumental. The CRC's scheme assumes that at least some politicians are rational, in the sense that they calculate the best way of maximising their votes and chances of re-election (even if this involves them appealing outside their ethnic group). Horowitz argues it would work if just some politicians are rational, hewing to the centre while leaving the fringes to the fundamentalists.

The CRC is comfortable with parties: 'in our view the formation of a government must continue to depend on the party system' (Fiji CRC 1996:79, para 5.48). The CRC's scheme requires that there be proliferation, so that no one can govern alone. While they would be bound by the Compact, the CRC does not seek to regulate specifically the parties' internal mechanisms for selecting candidates or admitting members (matters addressed, Ghai notes, in the NFPFLP submission). Arms sees parties as potentially obstructive of voters' wishes (for example, in dealing with criticism that minority parties may exercise undue influence, he points out that the real villain is party discipline). Good or bad, Ghai wonders if parties will in fact continue to play the central role they have in Fiji politics. They are much weaker elsewhere in Melanesia. 
Reilly's work on Papua New Guinea, however, suggests strongly that $\mathrm{AV}$ can encourage accommodative behaviour in heterogenous constituencies without parties. The calculations, deals, and swops involved in vote pooling are simply made by individual candidates relying on concentrations of support.

The relative importance that the CRC and others give to the electoral system is partly because it seems to be the most manipulable part of the political system, that most conducive to 'engineering', though the interests of the current generation of politicians may act as a dead weight on change. They may rationally resist choosing rules that would subject them to unwelcome incentives.

The interests of politicians were also involved in Horowitz's cautionary words about the outcomes of constitutional bargains, which might not lead to the best outcomes, and the dangers of transitional measures.

Several contributors also referred to the ability of politicians and parties using the system to learn. Reilly showed how vote pooling took hold over several elections in Papua New Guinea, while Mathur described politicians and parties learning from early conflict. Part of the historical thrust of the CRC's report is to learn from the failures of the past, both 1970 and 1990. Clearly an indirect system like the CRC recommended will need time, and several elections, to work.

\section{The possibility of democracy in Fiji}

Horowitz identifies limits on democracy in a deeply divided society. Democratic elections assume no permanent majority or minority, and that voters may switch between parties. In divided societies, people are assigned identities at birth, and parties tend to attach to them.

Much depends on what is implied by 'democracy': the CRC took it to mean 'governed by the people through their elected representatives' (Fiji CRC 1996:66, para 5.13), though the CRC also put great emphasis on human rights. The scheme of heterogeneous constituencies, party proliferation and AV may be valuable in moderating inter-ethnic conflict, but does not of itself enhance democracy. Other parts of the CRC's report, for example those dealing with human rights, expand the conditions for democracy in Fiji, but that is a secondary criterion for evaluating the electoral system, which is aimed at inter-ethnic accommodation. That was the basis of Arms' critique. 
Several contributors to the workshop questioned whether it was appropriate to talk about a 'return' to democracy in Fiji. Commentators from quite different points of view have questioned the earlier existence, and continuing possibility of democracy in Fiji's circumstances of Chiefly power, Fijian traditions, ethnic divisions, and a politicised military. For Ravuvu, 'Democracy was an illusion, a facade, a parting whim of a colonial power that had itself only practised dictatorship' (1991:87). Scarr concludes 'the independence constitution itself was not democratic at all' (1988:23). Lawson points to the system's intolerance of an opposition becoming the government (1991:287-8). Comparative research on the social conditions for democracy finds that landowners are generally resistant to democratisation. A linkage between constitutional and land issues is often made in Fiji (Larmour 1994).

\section{Other issues of 'state, society and governance in Melanesia'}

The relationship between the electoral system and ethnic conflict is of significance more widely in Melanesia (the scope of the project that sponsored the workshop). A return to Alternative Voting has been canvassed for Papua New Guinea, particularly by Tony Siaguru (Reilly 1997:6). Vanuatu provides an example of the use of a simple form of Proportional Representation to reassure linguistic minorities (Van Trease 1995a:145-50). The ethnic impact of voting systems and constituency boundaries is also an issue in New Caledonia, where a large indigenous minority coexists with the descendants of settlers, and recent migrants, in what is constitutionally part of France.

Conceptually, the CRC's indirect approach to achieving multiethnic government is consistent with new approaches to governance that rely less on restraints and more on incentives. Their approach assumes rationality - at least among sufficient voters and politicians - to elect an accommodative coalition. Such indirect approaches may be particularly relevant to so-called 'weak states' in other parts of Melanesia, but the analysis of the conditions for AV to achieve ethnic accommodation shows that it requires some strong institutions, particularly Boundaries Commissions. The political parties that play a central role in the CRC's scheme are also much weaker, or absent, in other parts of Melanesia, though Reilly showed that AV could nevertheless encourage accommodative behaviour between candidates themselves, regardless of the party system. 


\section{References}

Fiji 1990. Constitution of Fiji, Suva.

Fiji Constitution Review Commission 1996. The Fiji Islands. Towards a United Future, Parliament of Fiji Parliamentary Paper 34 of 1996, Government Printer, Suva.

Lal, B., (ed.), 1986. Politics in Fiji, Institute for Polynesian Studies and University of Hawaii Press, Hawaii.

Larmour, P., 1994. 'A Foreign Flower? Democracy in the South Pacific', Pacific Studies 17(1):45-76.

Lawson, S., 1991. The Failure of Democratic Politics in Fiji, Clarendon Press, Oxford.

Lijphardt, A., 1977. Democracy in Plural Societies: a comparative exploration, Yale University Press, New Haven and London.

Norton, R., 1990. Race and Politics in Fiji (Second edition), University of Queensland Press, St Lucia.

Premdas R., 1993. 'Balance and Ethnic Conflict in Fiji', in J. McGarry and B. O' Leary, The Politics of Ethnic Conflict Regulation, Routledge, London:251-74.

1986. 'Ethnic Conflict Management: a government of National Unity and some alternative proposals,' in B. Lal (ed.), Politics in Fiji, Institute for Polynesian Studies and University of Hawaii Press, Hawaii:107-38.

Ravuvu, A., 1991. The Facade of Democracy: Fijian struggles for political control, Reader Publishing House, Suva.

Reilly, B., 1997. 'The Alternative Vote and Ethnic Accommodation: new evidence from Papua New Guinea', Electoral Studies 16(1):111.

Scarr, D., 1988. The Politics of Illusion: the military coups in Fiji, University of New South Wales Press, Kensington, NSW.

Smith, A., 1995. Nations and Nationalism in a Global Era, Polity, Cambridge.

Sutherland, W., 1992. Beyond the Politics of Race: an alternative history of Fiji, Political and Social Change Monograph 15, Department of Political and Social Change, Research School of Pacific and Asian Studies, The Australian National University, Canberra. 
Van Trease, H., 1995a. 'The Election', in H. Van Trease (ed.),

Melanesian Politics: stael blong Vanuatu, Institute of Pacific Studies, Suva and Macmillan Brown Centre for Pacific Island Politics, Canterbury:119-58.

, (ed.), 1995b. Melanesian Politics: stael blong Vanuatu, Institute of Pacific Studies, Suva and Macmillan Brown Centre for Pacific Island Politics, Canterbury. 


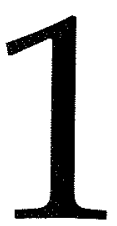

\title{
Encouraging electoral accommodation in divided societies
}

\author{
Donald L. Horowitz
}

The constitution recommended by the Fiji Constitution Review Commission is the result of a careful process of investigation and deliberation that produced an extraordinarily rich and well-reasoned report. One important aspect of the report that might otherwise go unnoticed requires mention at the outset. The Commission took its mission to embrace the need for a cross-national examination of constitutional possibilities for countries situated similarly to Fiji. The report includes serious consideration of the experience of other states and of international standards applicable to the matters within its terms of reference. In this respect, the report does not exactly break new ground, but it carries the effort to a new level of seriousness and sophistication. First and foremost, then, the Commission conceives of constitution-making as a comparative exercise. The Commission learned everything it could from experience elsewhere and made its recommendations in the light of that experience and Fiji's own experience. There is no doubt whatever, in view of practice elsewhere and of emerging standards of human rights, that the Commission was entirely correct to proceed as it did.

Like the Commission, I intend to set the electoral system issues that face Fiji in a comparative framework. I want to focus on the 
political institutions a polity like Fiji may wish to adopt and comment on some problems of process involved. Divided societies need special institutions to foster political accommodation, and they need a coherent, consistent set of them. The most powerful lever of political engineering for conflict reduction is the electoral system. Accordingly, I intend to evaluate the merits of various electoral systems and mechanisms for fostering accommodative coalitions and reducing conflict. Finally, I shall have some generally discouraging words about the relationship of negotiation to the institutions created by negotiation. As I shall show, there is a disjunction between process and substance that is likely to affect constitutional outcomes.

I start with three propositions

- institutions should aim not for love but accommodative behaviour

- it is important to get institutional arrangements right from the beginning

- it is best to build in incentives for participants to comply with the intentions of constitution-makers.

In severely divided societies, no constitution can make the contending groups love each other. What a constitution can do is to foster accommodative behaviour. It can reduce conflict by providing security for groups, including them in the political system, and decreasing the incidence of zero-sum outcomes. What it cannot do, except perhaps over a very long period of time, is transcend ethnic identity, create wholly new, supraethnic identities, or alter dramatically the feelings of group members about members of other groups. Fortunately, maximal goals of this kind are not necessary. That is my first proposition.

My second relates to prospects for correcting constitutional mistakes. The conventional wisdom, that if agreements are flawed at the outset they can be fixed later, is misguided. It is not usually possible to amend a system in mid-course. Interests quickly crystallise around whatever arrangements were initially adopted. As a result, even if the institutions fail in their public objectives, there are actors whose private success will depend on the maintenance of the arrangements. Electoral systems everywhere are difficult to change for exactly this reason. In a divided society, consensus on any institution is rare, much less consensus on truly apt institutions, and it is a fallacy that whatever the parties agree to will be not only 
acceptable but durable. An agreement only indicates what was acceptable to the parties concerned at a particular moment. The existence of an agreement is no evidence that it embodies the best arrangements or the most durable arrangements. It is a mistake to exaggerate the importance of reaching an agreement, at the expense of its substance and content. There is a need to choose apt arrangements and to do so at the outset.

The more enduring and effective arrangements for conflict reduction are those fortified by internal incentives rather than by external constraints. By constraints, I mean admonitions to do something, even if it is not in one's interest. By incentives, I mean principally those that operate on politicians and that harness their self-interest to the cause of conflict reduction, regardless of personal feelings. Such incentives make moderation pay. Institutions that tell political leaders what they should do or must do are less effective than institutions that make it in the interest of leaders to behave in an accommodative fashion.

\section{Mechanisms for conflict reduction}

Incentive-based institutions that give politicians a stake in moderation need to be put into a broader context of mechanisms that produce conflict reduction. There are at least four such mechanisms.

First, inter-ethnic conflict may be reduced by dispersing it. Proliferating the points of power may take the heat off of a single focal point. One way to do this is by scattering power among institutions at the centre, as the United States' political system does. If the capture of no single body or office will suffice for any ethnic group to gain complete power, then ethnic conflict may lose some of its capacity to inspire fear that the worst is about to come to pass. Dispersal may also take a territorial form, involving the creation of lower-level units with important policy functions. Either way, politics becomes a more diffused game than it is when all of power can be captured by capturing parliament alone.

Second, inter-ethnic conflict (between groups) may be reduced by arrangements that emphasise intra-ethnic conflict (within groups) instead. Intra-ethnic conflict is usually, though not always, less dangerous and violent than inter-ethnic conflict. If intra-ethnic conflict becomes more salient, this may reduce the energy available for conflict with other groups. 
Third, inter-ethnic conflict may be reduced by policies that create incentives for inter-ethnic cooperation. Electoral inducements for coalition may be one way to heighten the incentives for cooperation. Certain territorial arrangements may also do this. Inter-ethnic cooperation may be more likely where intra-ethnic divisions are present, since links may be easier to forge between portions of groups than between groups that are cohesive and undivided. Generally, intra-ethnic solidarity provides the leeway for inter-ethnic cooperation, but often not the incentives. Intra-ethnic competition provides the incentives but sometimes not the leeway. That is because political leaders who do not need to compete for the support of their group, since they have a monopoly position, are able to deal across group lines, whereas those whose position is vulnerable to competitive outbidding need to be cautious about making concessions to other groups. However, those who have monopoly support among their own group, especially if it is a majority group, do not need to cooperate across group lines, whereas those who do not have such a monopoly could usually enhance their support by such cooperation, provided their competitive position permits them to engage in such cooperation.

Fourth, inter-ethnic conflict may be reduced by policies that encourage alignments based on interests other than ethnicity. In deeply divided societies, it seems unlikely that non-ethnic lines of cleavage, such as those based on social class or territory, can be manipulated so as to displace ethnic cleavages. If they could, ethnic conflict would not be the intractable force that it is. But some measures may provide the impetus for non-ethnic lines of cleavage, like class or territory, to compete for attention with ethnic cleavages.

Mentioning these mechanisms implies no judgement of likelihood that any regime will seek to utilise any given mechanism. Nor does it tell us how to choose among these, although sometimes they are mutually reinforcing. Intra-ethnic divisions and inter-ethnic cooperation often go together. A divided group more often needs outside help. Where conflict is reduced, one of these mechanisms is generally involved.

Electorally, the way to induce politicians to be moderate is to structure voting arrangements so politicians must rely, in part, on votes delivered by members of a group other than their own. Such incentives are effective because those votes will not be forthcoming 
unless the candidates receiving them can be portrayed as being moderate on inter-ethnic issues. Consequently, any compromises achieved at the top will be supported by electoral incentives at the bottom. Politicians respond to them from a basic desire to be reelected. What I call vote pooling-the dependence, in part, on votes of members of groups other than one's own-works at the voter level, not at the level of an élite deal.

\section{Vote pooling}

To explain why vote pooling is so crucial, it is necessary to understand clearly the main difficulty of democracy in a divided society. Democratic results are difficult to attain with permanent, ascriptive (birth-based) majorities and minorities, such as 60 per cent $A$ and 40 per cent $B$. In a divided society, ascriptive minorities tend to be permanently excluded. Anyone who thinks two-party systems are always superior to multiparty systems ought to consider the implications of two-party politics when a great cleavage divides the As and Bs. Two parties overlaid on ascriptive majorities and minorities reinforce bipolar politics.

Democratic elections presuppose no permanent majority and minority. They assume the existence of floating voters, some fraction of electors who are not permanently committed to any party and who may therefore shift their votes and open the possibility of altering the electoral outcome. The problem of engineering democracy in a divided society entails coping with the dual problem of ascriptively defined groups and the propensity for parties to follow group lines and become ethnic parties. The only floating that takes place in a system where parties represent only their own groups is centrifugal. In response to compromise and moderation at the centre, some voters move to extremist parties, but they do not float across the ethnic cleavage.

What electoral incentives can be created for inter-group moderation? Is it enough that no party receives a majority of seats and therefore two or more than two parties must form a coalition in order to govern? If that is enough, then List-system Proportional Representation (PR) is a good system, because it helps proliferate parties. This system permits each party to put up a list of candidates. Each voter then votes for one or another party list, each of which is numbered in order of the party's preference for its own candidates. 
Candidates at the top of the list are elected first. Often no party secures a majority of seats, necessitating a coalition to form a government.

Unfortunately, however, the need to form a coalition is not enough to induce moderation on potentially divisive issues. In many severely divided societies, such coalitions have had to be formed, but they fell apart at the first divisive issue, leaving inter-group relations worse than before (for examples, see Horowitz 1985:369-78). A postelectoral coalition, formed merely to gain a majority of seats, generally does nothing for inter-group accommodation. What is needed is an incentive to compromise in the first instance, not merely an incentive to coalesce after the election. What is needed, then, is a pre-electoral coalition, formed to pool votes, not just seats.

Pre-electoral coalitions of parties representing more than one ethnic group do not form easily in severely divided societies. Three conditions are necessary to bring them into being

- party proliferation, so no one party can form a government alone

- heterogeneous constituencies, consisting of a mixture of members of each group, so candidates cannot be sure of election on the votes of their own group alone

- strong electoral incentives to make vote pooling politically profitable.

\section{Seat pooling}

Contrast coalition formation after elections, where parties merely pool seats to secure a legislative majority. Under seat pooling, if five ethnic parties each have 20 per cent of seats, any three can form a government by pooling seats. None needs to seek votes from voters outside its own group. And no inter-group compromise will result. If, however, there are strong incentives to vote pooling, candidates must appeal outside their group to succeed, in order to be elected to office. Politicians seek to pool votes before the elections rather than seats after. To be elected president of Nigeria in 1979, a candidate needed a plurality in the whole country plus at least 25 per cent of the votes in at least two-thirds of the then 19 states. The technique was based upon plurality plus distribution of the vote. Since territory was a proxy for ethnicity, a candidate whose vote was spread over many states necessarily had support from many groups. No one could be 
elected without being a pan-ethnic figure. The incentives continue if the politician wants to be re-elected. The mechanism is simple: a candidate cannot attract $B$ votes without attending to $B$ interests.

At independence, the Malaysians, without electoral engineering, stumbled into such a situation. For a variety of idiosyncratic (and non-replicable) reasons, one Malay and one Chinese party had formed a coalition to pool each other's votes in heterogeneous constituencies. To do so, they had to compromise. Those compromises saved Malaysia from becoming a truly deadly society for more than 15 years. The coalition was located at the centre of the party spectrum, flanked by extreme parties whose raison d'être was opposition to the coalition's compromises.

Once it was established, the coalition was locked into the centre position, committed to the compromises, because the centre parties could not compete with the extremes for the votes of extremists. Likewise, the extremes, which thrived on the sell-out argument, were not able to form a coalition with each other or with a centre party of the other group. The extremes were less attractive as partners to those in the middle. So the spectrum was divided into three: roughly 50 per cent in middle, and roughly 25 per cent on each flank. The parties on either flank could not form a government alone, while the centre coalition saw the continuing benefits of pooling each others' votes.

This may be a good model for Fiji-an accommodative centre coalition flanked by less accommodative parties. It is exactly what was wanted for Northern Ireland in the power-sharing experiments of 1973. Those elections came at a time when British government specified that no post-electoral government would be permitted to take office unless it was committed to power-sharing. That meant not merely inter-group accommodation but also actual participation of Catholic-based parties, as well as Protestant-based parties, in government. The basic idea of an accommodative inter-group coalition was certainly on the right track.

\section{Single Transferable Vote}

The problem in Northern Ireland was the electoral system, based on the Single Transferable Vote. It was thought conducive to proliferation of parties, so that coalition would be necessary. But the next set of assumptions, sound in principle, did not work out in practice. 
In the Single Transferable Vote, voters cast ballots for candidates, not parties, in order of voters' preference. In a multimember constituency, with 4 seats but 10 candidates, a voter might cast up to 10 preferential votes. This opens up possibility that some of those votes might be cast for candidates across the sectarian or ethnic divide. By contrast, List-system Proportional Representation requires that votes be cast for a single party list, so there is no way to transfer votes across group lines, if parties are ethnically based, as they tend to be in severely divided societies. The voter is locked within his ethnic party. The hope in Northern Ireland was that there would be intergroup vote transfers that would help elect people who were moderate on ethnic issues, because they had been elected on votes provided by voters of both groups.

The Single Transferable Vote requires multimember constituencies. To be elected a candidate must receive an appropriate quota of votes. The quota depends on the number of seats in the constituency: the larger the number of seats, the smaller the quota required. Once a candidate is elected, surplus votes (above the quota) cast for the candidate are transferred to the candidates who stand next in preference among the candidate's supporters. Here is how the quota is determined

$$
\text { Quota }=\frac{1}{\text { Number of seats }+1}+1
$$

Applying this formula in a three-member constituency, it takes only one-fourth of the total vote plus one to be elected. It is easy to win a seat and therefore easy to win a seat based on the votes of voters of one's own ethnic group alone. Under the Single Transferable Vote, as indicated, surplus votes (after a candidate has met his quota) get transferred. If candidates anticipated needing such transfer to get elected, agreements across the sectarian divide to secure them would have been made and would have fostered moderation, as vote pooling does.

The problem in Northern Ireland was that, because of the way the Single Transferable Vote works, it was relatively easy for candidates to get elected, and to get elected on votes of their own group members, so they did not need to negotiate for reciprocal transfers. 
The agreements were not made, and the transfers did not appear. A new Protestant party sprang up to oppose power-sharing. It and other Protestant parties opposed to inter-ethnic coalition secured 35 per cent of vote, compared to 27 per cent for the Protestant party committed to power-sharing. When the power-sharing cabinet took office, even the Protestant party committed to power-sharing, fearful of erosion of its support, rejected the arrangement, thereby dooming it. According to the assessment of Richard Rose

The electoral system offered parties no incentive to seek votes across the religious divide, because the chances of winning an extra seat by adding a few votes from the other community were much less than the chances of appearing 'soft' on the issues which were of central concern within the party's home community (Rose 1976:78).

The concept of vote pooling is sound, but the task is to change these calculations, by making it harder to get elected without agreements leading to vote transfers across group lines. It is the threshold for election that is the key. The Nigerians added a second requirement to having most votes: distribution. Distribution across territory was a proxy for distribution across ethnicity. Another way is to use a majority threshold. The need to get to a majority creates stronger incentives to make deals for inter-group vote pooling.

\section{Alternative Vote}

A more promising system is the Alternative Vote. It yields more proportionality than First-Past-the-Post but less than List-system PR. Its effectiveness lies in its being a preferential and a majority system. Voters list preferences in order, and each candidate needs a majority to win. Suppose a country is divided into two ethnic groups, the As, with 80 per cent of the population, and the Bs, with 20 per cent. The As, however, divide their support equally between two political parties, the A party and the $A_{1}$ party, whereas the Bs concentrate their support in the $B$ party. Under many electoral systems, competition between the $A$ and $A_{1}$ parties will centre on the issue of who is more pro-A and anti-B. Under Alternative Voting, which requires a majority threshold for victory, some A candidates and one of the A parties will find reason to behave more moderately toward the Bs, in order to secure their second preferences. With a majority threshold, they cannot be elected in any other way. 
The President of Sri Lanka is now elected this way, and a similar system has been used widely in Australia. The Sri Lankan system works as follows

- if there are more than 2 candidates, each voter may vote for 3 or 4 or however many candidates there are, in order of preference

- if no candidate receives a majority, the election commission determines who the two leading candidates are

- other candidates are eliminated

- the preferences of all those voters whose first preference was eliminated are reallocated between the two leading candidates

- second preferences then count as if they were cast as first preferences

- whoever then receives a majority wins the election.

That is one way to do the counting in an Alternative Vote system. Another is to drop off bottom candidates, one at a time, reallocating the second and subsequent preferences of the voters who supported them, until a single candidate receives a majority of votes, based on his or her own first preferences plus reallocated preferences of candidates who have been eliminated. This is the way the system works in Australia. Either way, for present purposes, the result is the same. The winning candidate owes his victory to the fervent support of his own supporters plus the more modest support of those whose more fervent support was given to candidates who were eliminated.

The Commission, it will be noted, chose a third way to tally preferences (Fiji CRC 1996:319, para 10.69)-a way that is, in my view, more complicated and less desirable than either of these two ways. It also recommended multimember seats, in which all candidates compete against all other candidates (Fiji CRC 1996:296, para 9.167), making the process of transferring preferences unusually cumbersome.

Those recommendations do not in any way impugn the validity of the Commission's reasoning about Alternative Voting, which is impeccably correct. The tallying technique recommended by the Commission can easily be discarded in favour of one of the more commonly accepted methods: it entails only one paragraph of the Commission's report. By the same token, there is no need to have multimember constituencies. Indeed, Alternative Voting works well 
in single-member constituencies. In multi-ethnic societies, however, those constituencies need to be significantly heterogeneous for Alternative Voting to foster inter-ethnic vote pooling. This suggests one of two possibilities: if significant heterogeneity is available at the geographic size level customary for constituencies in Fiji, then all that is needed is to draw the boundaries to maximise heterogeneity of the open seats. If achieving such heterogeneity requires much larger constituencies than Fiji has customarily had, then it would be possible to draw boundaries for larger constituencies, in which two or three separately-elected seats would be located. These would not be multimember seats; two or three members would have to be elected by the same electorate to fulfill the requirement of constituency scale for heterogeneity, but candidates competing for one seat would compete only with candidates competing for that same seat, and preferences would be transferred only within single seats. Neither of these solutions is in any way radical or difficult to implement. Alternative Voting would work smoothly with either.

What needs to be borne in mind is that the Commission was entirely on the right track in pursuing the goal of vote pooling. Alternative Voting, a modest modification of First-Past-the-Post, in that it substitutes a majority threshold for victory for a plurality threshold, is perfectly apt for this purpose in Fiji. It is an electoral system that meets the tests of simplicity of operation, lack of ambiguity in producing electoral results, and conduciveness to the goal of inter-ethnic accommodation. If there is party proliferation and if candidates cannot win the election on a plurality, then many contests will be decided on second, and possibly even third, preferences. That is the feature that induces candidates and parties to behave moderately toward those voters who are not among their most ardent supporters. The votes of those voters are still valuable.

How does this work out in a divided society? To illustrate how Alternative Voting would work and how it would produce conciliatory results, consider an imaginary conversation between party leaders seeking the presidency in Sri Lanka, where Alternative Voting is used. Suppose two Sinhalese candidates are contesting the election. The first estimates 40 per cent first preference support, and the second estimates 35 per cent. There is also a Sri Lankan Tamil candidate, who can count on perhaps 10 to 12 per cent of all first preference votes. A meeting is convened between the first Sinhalese 
candidate and the Tamil candidate. Since no candidate will have a majority of first preferences, the discussion centres on the subject of Tamil second preferences. The Tamil leader is asked whether he would be willing to urge Tamil voters to give their second preferences to the first Sinhalese candidate. He replies that his ability to do so depends on the Sinhalese candidate's willingness to be hospitable to Tamil aspirations. Otherwise, his appeal to Tamil voters to cast second preference ballots for a Sinhalese candidate would be futile. Before long, concrete policy issues are being discussed. By the end of the negotiations, the first Sinhalese candidate has emerged as decidedly more accommodating on Tamil issues than the second Sinhalese candidate. A compromise is reached.

Knowing of this bargain, the second Sinhalese candidate will probably seek to differentiate himself from the first, by becoming less accommodating on Tamil issues, in order to attract hardline defectors who are displeased by the compromise commitments of the first Sinhalese candidate. For this reason, accommodation of Tamil interests will lose the first Sinhalese candidate some Sinhalese first preferences. It will be noted that the first candidate cannot go overboard in accommodating the Tamils, if he is to have a net gain from the transaction. But he can compensate, to some extent, for the loss of hardline Sinhalese votes by appealing to the other minorities in Sri Lanka as well. They, too, can offer votes to conciliatory Sinhalese candidates. The 50 per cent threshold means that, every time there are more than two candidates, parties need to search hard for pockets of votes to reach a majority. If there were more than two Sinhalese candidates, the majority threshold would be harder to reach, the extreme Sinhalese vote would be more divided, and the votes of minorities would be both more valuable and less risky to attract. In an Alternative Voting system, then, inter-group compromise can become useful in getting elected, whereas in most other systems compromise makes it more difficult to get elected (Horowitz 1991:193).

Obviously, this system can work for each parliamentary seat as well, provided constituencies are heterogeneous. As the Sri Lankan example shows, party leaders will take over the job of arranging the exchange of votes between supporters of moderate candidates. Of course, not all of the incentives of Alternative Voting point to moderation. As indicated, there will be some votes to be had by being 
anti-Tamil and by being opposed to the first candidate's concessions to the Tamils as a sellout of Sinhalese interests (although, of course, it is not a sellout but merely a compromise). Alternative Voting does not narrow the party spectrum or draw all parties toward the moderate centre. It does create centripetal forces, to be sure, and the hope of inter-ethnic accommodation depends on them. But it also differentiates the spectrum into the moderate centre and, again, the extremes on the flanks. Under propitious conditions, one of the Sinhalese parties will be able to secure more votes under Alternative Voting by behaving moderately toward the Tamils, and that moderation, which induces vote pooling, is the price of winning the election.

Note that Alternative Voting is all incentives-there are no constraints at all, except the constraint of desiring election and the constraint of needing 50 per cent-plus- 1 to get elected. These mechanisms of vote pooling work at a mainstream voter level, not at the level of a deal among the élite over the voters' heads. Alternative Voting uses an electoral market to encourage compromise, and party leaders respond to the market in votes, not to mere exhortations that they should behave virtuously (compare Lijphart 1977).

Another virtue of these arrangements is that they put majorities and minorities into real participation in power, not in the sense of officeholding but in the sense of influence. There is often a tradeoff between officeholding and influence. For ethnic officeholding, Listsystem PR is best. For influence in plural societies, a system that builds in incentives for moderation is best.

To be sure, there is an undeniable lure to guaranteed officeholding in divided societies. A 40 per cent minority that is offered 40 per cent of the cabinet seats will be sorely tempted, for the alternative may be to win 40 per cent of the legislative seats and, because the majority party gets to form the government, none of the cabinet seats. More often than not, however, such guaranteed officeholding proves illusory. The victory of the 60 per cent party was not dependent on the votes of the 40 per cent party, and the strong tendency will be for the 40 per cent party's cabinet participants to be considered peripheral to government. If inter-ethnic disputes arise, those minority ministers are likely rather quickly to find themselves on the opposition benches again. In short, arrangements like these fail because they are not underpinned by political incentives that are likely to bind both sides, and they are not underpinned by votes. 
Consequently, in divided societies, officeholding is decidedly inferior to influence. On the other hand, it is much more difficult to neglect commitments made to members of groups other than one's own when those members are among the voters (albeit a minority of those voters) who were responsible for one's election. The best way to assure moderation, in short, is through floating voters. Floating voters are rare in divided societies, but their numbers can be increased through preferential electoral systems.

An important word about the difference between Alternative Voting and First-Past-the-Post (FPP). First-Past-the-Post is a plurality electoral system, and it often produces odd results. Very commonly, a party with less than half the total vote nonetheless receives more than half the seats in a plurality system, and sometimes a party may gain a majority of seats even if it wins fewer votes overall than a competitor party. These tendencies in FPP can cause very severe problems of governmental illegitimacy in divided societies. AV has none of these problems, for, by definition, it requires a majority to win each and every seat, and so it produces a majority consisting entirely of members supported, at some level of preference, by more than half of their electorates every time. Where political legitimacy is a rare commodity, this is an important advantage.

\section{Electoral literature and electoral engineering: implications for Fiji}

The standard academic literature on electoral systems emerged from studies in mainly homogeneous societies. Accordingly, it is concerned with issues that are, at best, marginally relevant to inter-ethnic accommodation. These are the questions that have been central to the literature

- Proportionality, which only matters if minority officeholding is more important than influence

- Strength or weakness of party organisations. List-system PR is conducive to strong party centres, while FPP gives more weight to constituency organisations.

- Relationship between legislatures and their constituents. List-system PR is inimical to constituency accountability.

- Seat bonus for FPP. FPP systems may provide stable governments by giving the winners a greater proportion of seats than votes, but at the cost of underrepresentation of 
minorities, and, as indicated, of frequently excluding a majority of voters from electing the government. In ethnic party systems, FPP simply facilitates minority exclusion, by providing a seat bonus to the largest party.

Some of these objections can be met by amending the electoral system, but in ways likely to discourage inter-ethnic cooperation. For example, if one mitigates the absence of constituent accountability in List-system PR by moving to constituency Proportional Representation, great harm will be done to the representation of dispersed minorities. With four seats to a constituency, a 15 per cent minority in that constituency could be ignored. The same applies to permitting voters to change the order of election on a list. In Sri Lanka, where this is possible in parliamentary elections, Sinhalese voters move Sinhalese candidates up and Tamil candidates down on the list. Likewise, Alternative Voting provides less proportionality than does list-system proportional representation, but that is much less important than its provision of strong incentives to vote pooling.

In summary, to obtain moderation, an electoral system needs to encourage vote pooling across group lines. Vote pooling in turn requires

- party proliferation, so that no party can necessarily form government alone

- heterogeneous constituencies, so that candidates cannot be sure of election on the votes of their own group alone, and

- electoral incentives that make vote pooling politically profitable, incentives such as the need to achieve a majority or the need to demonstrate support distributed across the country.

\section{Process and outcome}

Finally, I want to discuss the limits of compromise in constitutional design, including the design of electoral systems. There is a difference between a constitution and a contract, and there is a crucial disjunction between the mode of decision-making and the content of accommodative arrangements. Bargaining, reciprocity, and exchange are ways that groups agree to arrangements that may moderate their conflict. The outcome of these processes is compromise. In crafting institutions to facilitate inter-ethnic compromise, however, there is a need for something other than a compromise. There is a need for 
consistent, coherent institutions of accommodation that prevent backsliding into conflict. It would be better if there are several redundant institutions. To use an engineering analogy, if one measure fails, there will be a backup. In Nigeria, for example, the president was elected on a vote pooling formula, but the legislature was not. The latter, with its built-in incentives for conflict, overwhelmed the former. The presidential electoral system was alone in fostering accommodation. And it was not enough by itself. In 1983, the Second Republic was terminated by a military coup. Malaysia started with heterogeneous constituencies and vote pooling, but only some politicians were elected on such marginal votes from other groups. Each constituency delimitation produced fewer and fewer heterogeneous constituencies, and cooperative arrangements eroded. The disjunction between process and substance is very serious and difficult to overcome. Incentives to moderation need to be built in at every step, wherever there is an office to be elected. Unfortunately, however, the process of bargaining over a constitution is usually at odds with the coherence of the product.

Since this kind of consistent constitutional plan is so difficult to adopt, in most severely divided societies incentives to conflict outweigh incentives to compromise, and many of them have succumbed to the unfavourable balance of incentives. Fiji has a unique opportunity to create structures conducive to a future of inter-ethnic accommodation. The constitutional technology exists. The Commission has already drawn on much of it, and it has produced a quite coherent plan of the sort that would be very unlikely to emerge out of a process of bargaining. It would be a shame if that plan were fragmented into bits and pieces, some adopted, some rejected, so that the outcome was a set of institutions only some of which conduced to accommodation. It would be especially unfortunate because, with the Commission's work in place, all that is really required are some imaginative constitutional engineers prepared to build a strong system.

\section{References}

Fiji Constitution Review Commission, 1996. The Fiji Islands. Towards a United Future, Parliament of Fiji Parliamentary Paper 34 of 1996, Government Printer, Suva. 
Horowitz, D.L., 1991a. 'Electoral Systems for a divided society, in D.L. Horowitz, A Democratic South Africa? Constitutional Engineering in a Divided Society, University of California Press, Berkeley:163-203.

1991b. A Democratic South Africa? Constitutional Engineering in a Divided Society, University of California Press, Berkeley.

Horowitz, D.L., 1985. Ethnic Groups in Conflict, University of California Press, Berkeley.

Rose, R., 1976. Northern Ireland: time of choice, American Enterprise Institute, Washington DC.

Lijphart, A., 1977. Democracy in Plural Societies, Yale University Press, New Haven. 


\section{Fiji Constitution Review Commission} recommendations for a new electoral system for Fiji

\section{Introduced and summarised by Brij V. Lal}

An electoral system is a means to an end, not an end in itself. Nor is there a perfect electoral system, neutral in its content and implications, tailor-made to suit every occasion and every need. Very often, a country's electoral system is the result of historical accident or, in the case of the former colonies of the European powers, a legacy inherited at the time of independence. Although they may be inappropriate or unsuited, indeed even harmful to the larger interests of the country, politicians are often reluctant to discard them in favour of other more appropriate and relevant alternatives because of, among other reasons, habit, inertia or simply the dread of the unknown: better the devil you know than the one you don't.

Yet, electoral systems play a critical role in shaping not only the the nature and direction of the political process of a country but also the foundations of its political culture. They reward certain kinds of policies and strategies and punish others. They influence the composition of political parties and determine the nature of the relationship between them. They structure the relations between the voters and their representatives in parliament. They can reward the politics of moderation or they can encourage the politics of extremism, depending upon the incentives the system provides. In short, the stability of a political system depends greatly on the way its electoral system. 
functions. In divided societies, Donald Horowitz argues, the electoral system is a vital tool in the arsenal of constitutional engineering.

The Fiji Constitution Review Commission was clearly aware of these thoughts as it set out to review the 1990 constitution. The vision that underlies its work is spelt out in its report and captured in the subtitle, 'Towards a United Future'. The Commission revisited past efforts at constitution-making, tested the assumptions which informed both the 1970 as well as the 1990 constitutions and explained why, in its view, they were wanting or inappropriate. It concluded that the 1990 constitution was not only not a product of consensus among the people of Fiji, but did not meet their widely-shared desire for a system of government that took proper account of Fiji's multiethnic character. It encountered widespread and irrefutable evidence of mutual respect, trust and cooperation among the various ethnic communities in Fiji, and concluded that it was the country's 'constitutional arrangements [which] seem to make people's individual ethnicity a barrier to effective cooperation' (Fiji CRC 1996:5). The way forward for Fiji, the Commission concluded, was 'to encourage the emergence of multi-ethnic parties or coalitions' (Fiiji CRC 1996:5).

The choice of the electoral system that the Commission recommended was greatly influenced by this overarching objective: to foster multi-ethnic cooperation and a multi-ethnic government. The Commission was convinced that this objective was widely shared by the people of Fiji, though they naturally differed about how to attain it or the extent to which Fiji should move in the direction of multi-ethnic bridge-building in the political arena. In its report, the Commission made a number of recommendations that aim to achieve that goal. The Preamble it recommends acknowledges the culturally rich and diverse character of the country. The Compact provides a (non-justiciable) framework for the principles upon which the conduct of the government should be based, and the interests and values which need to be recognised in the formation of governments. Its recommendations on Affirmative Action emphasise the need for more non-racial inclusiveness, while taking proper account of the interests and aspirations of the communities indigenous to Fiji. Its recommendations on the functioning of branches of the public sector underline the importance of transparency and effective accountability. 
All this is to emphasise the overarching vision of the Commission and the need to look at its recommendations in their totality.

The Commission recommended the retention of a 70-seat Lower House, to be called the Bose Lawa. Forty-five of these seats would be elected from 15 three-member open, heterogeneous, constituencies made up of members of the different communities, with no constitutional restriction or reservation of race either for the voters or the candidates, and 25 reserved seats of which 12 would be for Fijians, 10 for Indo-Fijians, two for General Voters and one for Rotumans. The Upper House, to be called the Bose e Cake, presently a totally nominated body, would comprise 35 seats, of which 28 would be elected from the 14 provinces (two each), again with no constitutional restriction or reservation of race, one from Rotuma, and six appointed by the President on the advice of the Electoral Commission to represent groups (ethnic, cultural, religious, and the like) which are under-represented in the Bose Lawa. The President would also be elected, without debate, at a joint sitting of both houses of Parliament from a list of three to five names submitted to them by the Bose Levu Vakaturaga. All elections of candidates for seats in the Bose Lawa and the Bose e Cake, as well as the election of the President and Vice-President, would be held under the preferential system known as the Alternative Vote (AV). Citizens of Pacific island origin would again vote with members of the Fijian community rather than as general voters; and citizens of mixed descent would have the option of regarding themselves as members either of their father's community or their mother's community for voting purposes (but not for any other constitutional purpose, and without any effect on any matter relating to the ownership of land).

What follows now is the Commission's reasons for choosing the $\mathrm{AV}$ over other systems. To prevent distortions or misunderstanding and to keep intact the integrity and spirit of the report, the ensuing text, with only minor editorial interventions (in the interests of clarity and economy), is taken from the Commission's report. The aim is to lay before the reader as accurately as possible the Commission's thinking on the subject. This is not the place nor the time to respond to various comments and criticisms which have been made of the Commission's choice of the electoral systems, though I allude to some of them at the end of this text. 


\section{The choice of voting systems}

Fiji, like most other former British colonies, inherited the First-Pastthe-Post (FPP) system used in Britain, where the candidate winning most votes is the one who gets elected. This is a logical system when the choice is between only two candidates. But if the choice is between more than two candidates, the situation is different. Then, a plurality system may mean that the winning candidate receives less than 50 per cent of the votes-that is fewer votes than those received by the competing candidates when their votes are added together. If there are three candidates, A, B and C, who receive 45 per cent, 40 per cent and 15 per cent of the votes respectively, it is possible to imagine that some of the 15 per cent who supported $C$ might have preferred B to A, if it was impossible to elect C. A further disadvantage of FPP is that the number of successful candidates belonging to a particular party who are elected under FPP must be added up, to determine whether or not that party has a majority. Conceivably a party getting a majority of the votes in the election may not get a majority of the seats because its supporters are unevenly distributed through all constituencies. Their candidates will be elected only if they obtain more votes than any other candidate in the constituency for which each is standing.

Various ways of modifying the plurality system have been devised to ensure that the winning candidate gets an absolute majority (more than 50 per cent) of the votes cast. One is to hold an election under FPP, but if no candidate in the constituency obtains more than 50 per cent of the votes, a subsequent ballot is held between the two highest-polling candidates, or those who have received a specified percentage of the votes. AV is based on the same principle, but avoids the need for a second election at a later date. It is a refinement of the FPP system in that it requires voters to rank candidates in the order of their preference. To be elected, a candidate must have a majority of the votes cast. It will produce the same result as the FPP system if one or more candidates receive 50 per cent plus 1 of the first preference votes. If there is only one seat to be filled, the candidate who passes this threshold and has the greatest number of votes will be declared elected. Only if no candidate reaches the threshold when first preferences are counted, will it be necessary to count and allocate second and subsequent preferences. 
Then, if the election is for a single-member constituency, the candidate with the lowest number of first preferences is eliminated. In the second round of counting, the ballot papers giving a first preference to that candidate are re-examined, and votes are allotted to those of the remaining candidates for whom the voter has expressed a second preference. After the second preferences are added to the first preferences for the candidates still in the running, the candidate with the lowest number of votes is again eliminated, and so on, until one of the candidates has obtained the required quota. The Alternative Vote system can be used in multimember, as well as single-member constituencies.

Unlike the Single Transferable Vote (STV) system, which need not necessarily require voters to indicate preferences in respect of all candidates on the ballot paper, $\mathrm{AV}$ requires voters to indicate preferences in respect of all or most candidates. Otherwise, all ballot papers may be exhausted before any candidate obtains the quota. There must in any case be a fall-back provision under which the candidate with the greatest number of votes is elected, but if this happens regularly because voters have failed to indicate sufficient preferences, the advantages of AV as compared with FPP will be lost. Also, under the AV system, the election of the successful candidates does not, as in proportional representation (PR) systems, depend on the proportion of votes cast for the candidate. However, it is argued that, like PR systems, AV mitigates the winner-takes-all aspects of FPP and generally achieves better proportionality of seats-to-votes than the FPP system.

Plurality systems like First-Past-the-Post and majority systems like the Alternative Vote may be contrasted with proportional systems, where the seats a party receives in Parliament are broadly proportional to the number of votes it receives, either in all constituencies or in a separate vote treating the whole country as a single constituency. Of the three main types of proportional system, the Commission received submissions in favour of two: a system based on Party Lists and STV. The latter had been recommended for open seats by the Street Commission in 1975. The submissions expressed limited interest in the Mixed Member Proportional system (MMP) adopted in post-war Germany, and recently in New Zealand. The general inclination was to wait and see how that system operates in New Zealand. 
List-system PR allocates seats to parties in proportion to the number of votes won by the party using one of several recognised formulae. The party managers decide the names and the order in which they should appear on the lists. Frequently, this gives better opportunities than most systems to include women and members of minority groups sufficiently high on the list to win a seat, but it is often seen as giving too much power to the party and not enough to individual voters. If the system treats the whole country or major regions of a country as a single constituency, the List-system also fails to provide the important links between a voter and his or her member. Measures to reduce the size of the constituency represented through the list, or to open the list to variation by individual voters deprive the system of the simplicity and proportionality it would otherwise have.

Under the STV system, the constituencies must be multimember because the allocation is based on the range of preferences within the constituency. The greater the number of members, the greater the proportionality. As in the case of $\mathrm{AV}$, the voter numbers the candidates in order of preference. But under STV, the underlying principle is the distribution of fractions of a single vote. If any fraction of the vote is not needed to help elect the candidate of the voter's first choice, or cannot be used because the candidate has been eliminated, it is transferred at a discounted value to help elect the candidate of second choice, and so on. The quota needed to secure election is the lowest possible, taking account of the number to be elected. In a three-member constituency it is just over 25 per cent. If three candidates each get just over 25 per cent, no other candidate can get more.

\section{The criteria for choosing a voting system in ethnically divided societies}

Recent years have witnessed a proliferation of literature on the best voting system for ethnically divided societies. The Commission's work is not concerned exclusively with the relative merits of plurality systems, majority systems and proportional systems as ways of turning votes into seats. It focuses on the extent to which each is likely to bring about the representation of different ethnic communities and give them the opportunity to participate in 
government. The Commission had access to analyses of the advantages and disadvantages of the voting systems in use or proposed for use, in a number of ethnically divided societies, including South Africa, Malaysia, Sri Lanka, various African and Caribbean states, Lebanon, Cyprus and Northern Ireland, as well as the consociational democracies of western Europe like Switzerland, the Netherlands and Belgium.

Political scientists base their analysis of voting systems on the assumptions that politicians are motivated by the desire to be elected and re-elected. They see the voting system as probably the most powerful instrument for shaping the whole political system, because it encourages politicians to behave in ways that maximise their chances of electoral success. There is general agreement that, in an ethnically divided society, at least to begin with, political parties are likely to be ethnically based. The objective is to find ways of encouraging such parties to come together for the purpose of governing the country in a way that gives all communities an opportunity to take part. However, scholars disagree about the kind of voting system that will produce this outcome partly because of the differing perceptions about the importance of proportionality, as compared with other likely consequences of particular voting systems, and partly because of differences of opinion about the consequences of particular voting systems.

\section{Identifying and ranking the criteria}

In identifying the criteria for judging voting systems for use in Fiji, the Commission focused mainly on the voting system for electing candidates for the recommended 45 open seats in the Bose Lawa because it saw those seats as providing the main stimulus for the emergence of a multi-ethnic political culture in Fiji. The Commission recommended that a single voting system should be used, not only for the election of members in the Bose Lawa and the Bose e Cake, but also for the election of the President and Vice-President. Therefore the system chosen has to be suitable for all these purposes.

The criteria the Commission considered relevant included those set out in the New Zealand Report of the Royal Commission on the Electoral System (1986), suitably adapted where necessary to take account of Fiji's different circumstances. The Commission ranked the 
criteria in the order of their importance, while bearing in mind the Royal Commission's own conclusion about how a voting system. should be chosen

If a system is designed to achieve one particular objective, the likelihood of meeting together objectives may thereby be lessened. The best voting system for any country will not be one which meets any of the criteria completely but will be one which provides the most satisfactory overall balance between them, taking account of that country's history and current circumstances

The Commission's own list of the relevant criteria is as follows

- encouragement of multi-ethnic government

- recognition of the role of political parties

- incentives for moderation and cooperation across ethnic lines

- effective representation of constituents

- effective voter participation

- effective representation of minority and special interest groups

- fairness between political parties

- effective government

- effective opposition

- proven workability

- legitimacy.

\section{Encouragement of multi-ethnic government}

The consistent theme of the Commission's report is that the encouragement of multi-ethnic government should be the overriding objective of constitutional arrangements for the Fiji Islands. It must therefore appear at the head of the list of criteria. The voting system must be one which promotes the emergence of multi-ethnic governments. The Commission also sees political parties as playing a key role in the political process. The voting system should take full account of the fact that the goal of political parties is to be elected and to be re-elected. Everything in the experience of Fiji confirms that the nature of the voting system moulds the character of political parties. They respond to the forces which will determine their success or otherwise at the polls.

Political scientists differ about the best way of encouraging moderation and cooperations across ethnic lines. Some argue that, in 
order to come together in stable multi-ethnic coalitions or perhaps a multi-ethnic party, political parties must have strong electoral incentives to take account of the interest of other communities. The voting system can provide these incentives by making it in a party's interests to enter into arrangements not only for seat pooling, but also for vote pooling.

The pooling of seats refers to the formation of coalitions where parties that do not have enough seats to govern alone agree to cooperate to achieve a legislative majority while vote pooling refers to arrangements where parties exchange votes across party lines to secure the election of candidates who would not win otherwise. Parties will pool votes if sufficient candidates of each ethnically based party, or component of a party, are marginally dependent on the support of voters in other ethnic communities. A contrary view is that the voting system need not itself be directed to producing intercommunity accommodation. The consociational model assumes that people will continue to vote communally. Therefore, the voting system should ensure that, through its party or parties, each community is represented in proportion to its size. However, unlike the communal system of representation, the system should not channel members of communities into monolithic blocks, but allow the emergence of cross-cutting interests and identities, so that no one community gains sufficient electoral support to govern alone.

The parties representing different communities will still need to come together in a coalition in order to govern. Ideally, all ethnic parties will be members of an all-embracing 'grand coalition'. This, it is said, calls for sufficient willingness to compromise and accommodate each others' interests. The viability of the coalition should be reinforced by giving communities maximum autonomy, even veto power where necessary, in the things that concern them most. The difference between the two approaches is that the first uses incentives that are essentially self-serving in order to induce or reinforce accommodations, while the second uses agreements to cooperate, and constraints in the form of exclusive or veto powers. These rely for their effectiveness on the wisdom and tolerance of political leaders.

In the case of Fiji, the Commission considers that electoral incentives are necessary to reinforce accommodations among ethnic communities. The pre-1987 system focused on the need for their 
adequate representation, but this alone did not bring about multiethnic governments, reflecting perhaps an artificial solidarity within communities resulting from representation through communal seats elected from a communal roll. But because present realities require the retention for the time being of some reserved seats, it is important to induce political parties to exercise moderation and take initiatives to cooperate. A voting system that provides strong incentives would be a strong candidate for adoption. That does not mean favouring the incentives approach over aspects of the consociational model. The important interests of communities or groups should be safeguarded by veto powers. The Compact recommends principles and processes designed to secure respect for the interests of all communities, reassuring them 'that their rights and interests will be protected, even if changes are made to the electoral arrangements', and recording 'the peoples' recognition of the principles on which the conduct of the government is based' (Fiji CRC 1996:82). The value of farsighted leadership should not be discounted in reaching agreement to put new arrangements in place.

The criteria just discussed can be used to evaluate the AV system. In recognition of the role of political parties will play in bringing about multi-ethnic government, it is important to provide incentives for moderation and cooperation through the voting system. That objective can be attained better through the AV system than any of the other systems mentioned. For the AV system to work effectively, two preconditions must be met: a multiplicity of parties based in the various communities, and heterogeneous constituencies.

\section{A multiplicity of parties}

Ethnic communities in Fiji have never remained united in support of a single political party. Some parties are already committed to encouraging multi-ethnic membership. The willingness of members of the various communities to support such a party depends on whether it will take account of the interests of all communities. There is already a base for cooperation among communities and parties, which could be strengthened by electoral incentives for communities to cooperate rather than compete. Such incentives might lead to the formation of a widely-supported multi-ethnic party. But even if this did not happen, they would encourage cooperation among moderate parties based in the different communities. The spread of parties in 
Fiji suggests that not all may wish to reach out for multi-ethnic support. Some may remain ethnically based. But this disadvantage could be overcome if moderate parties based in another ethnic community are more attractive to some voters than more extreme parties within their own community. Exclusively ethnic parties still have a useful role in preventing multi-ethnic parties or coalitions from going too far in fostering the interests of any one community.

\section{Heterogeneous constituencies}

Heterogeneous constituencies are required because of the likelihood that the candidate or candidates of an ethnic party may be unable to succeed if supported only by members of that community, an outcome all the more likely if there is competition with other parties also based in that community. The design of constituencies deliberately to improve the chances of success of a particular party or community or social class or interest group is wisely condemned as 'gerrymandering'. Nonetheless, constituency design can also be a legitimate element of a voting system, specially in an ethnically diverse society; everything depends on the purpose for which constituencies are designed in a particular way.

The use of constituencies in Malaysia and Mauritius illustrates these points. In both these countries, the constituencies originally drawn by the British administrators were relatively homogeneous, to secure the representation of all ethnic groups in proportion to their size. It was assumed that each constituency would elect a member from the predominant ethnic groups. In Malaysia, enough constituencies nevertheless had a sufficiently mixed population to enable Chinese voters to influence the election of some Malay candidates. They could not dominate, but they could not be ignored. However, since the riots of 1969, constituencies have been more heavily weighted in favour of Malays, reducing the ability of Chinese voters to influence electoral outcomes. In Mauritius, every two of the original ethnically based constituencies were combined to form heterogeneous constituencies, each electing three members. Elections largely are contests between coalitions of ethnically based parties sponsoring a multi-ethnic slate of candidates in each constituency. Ethnicity has therefore become less important than political ideology in determining the outcome of elections and the composition of Parliament. 
The Commission asked whether, given the residential pattern of the different communities within Fiji, it would be possible to create heterogeneous constituencies, each having roughly the same number of inhabitants, within a tolerance of 10 to 15 per cent. The principle of equality may be departed from to the extent expedient

in order to take account of geographical features, the boundaries of existing administrative and recognised traditional areas, means of communication and density and mobility of populations (Fiji CRC 1996:314).

One exercise involved the drawing of 45 single-member constituencies and the other to producing 15 constituencies, each of which could be represented by three members. These exercises showed that the choice between single-member and three-member constituencies did not affect the potential for heterogeneity in the more densely-populated areas in the Western Division, Macuata and the greater Suva and Nausori area. Using three-member constituencies made it marginally easier to achieve a reasonable degree of heterogeneity by combining the less densely populated areas, such as the maritime provinces, with other areas having similar interests.

Heterogeneity within the constituency was understood as a mixed population ranging from a more or less equal balance between Fijians and Indo-Fijians, to a proportion as high as 85 to 90 per cent of one community and 15 to 10 per cent of the other. This last figure represented the limit of reasonableness in constituencies which included island populations consisting mainly of Fijians. The average distribution was 60 per cent of one community and 40 per cent of the other. It is entirely possible to draw constituency boundaries in Fiji to achieve a reasonable heterogeneity. The question now is how Alternative Voting, coupled with heterogeneous constituencies and a multiplicity of parties, can provide strong electoral incentives for cooperation among communities.

\section{The nature of the incentives}

Obviously, the best method of inducing vote pooling is to avoid interethnic competition. A multi-ethnic party or pre-election coalition can put up a multi-ethnic slate of candidates. Ethnic parties based in different communities can agree not to contest a particular seat in a 
constituency where one community is outnumbered, in return for a corresponding favour in another constituency where that same community predominates. Such arrangements are more likely between moderate parties than between more extreme ones. One way in which AV provides incentives for vote pooling is by requiring the winning candidate to obtain more than 50 per cent of the votes. In a heterogeneous constituency, this threshold increases the need for the winning candidate to have multi-ethnic support. The second is by requiring voters to rank candidates in the order of their preference. The candidates with the lowest totals of preferences at each level are eliminated and preferences at the next level are allocated to those still in contention until a candidate is found who has more than 50 per cent of the votes.

Although the successful candidate may not have been everybody's first choice, he or she must be broadly acceptable to over half the voters in the constituency.

The AV system allows parties to trade preferences. They may decide to put up competing candidates because their supporters may wish to give their first preferences to candidates of their own party and ethnicity. However, the party least likely to succeed may be willing to encourage its supporters to give their second or third preferences to the candidate of the other party, in return for reciprocal support, in the same constituency or in another where the ethnic balance is reversed. The effect of a preferential system like AV is to keep alive the value of second, third and subsequent preferences as the weakest candidate is eliminated after each round of preferences is counted.

Only moderate parties with conciliatory policies are likely to trade preferences and persuade their supporters to honour the agreement. The system therefore encourages the emergence of such parties. It may be feared that, in response to the perceived pressures created by open seats and heterogeneous constituencies, ethnically based parties may not be willing or able to cooperate across the ethnic divide, but may coalesce into single ethnically based parties, one or other of which might be able to win an outright majority. In the long run, however, such united positions would be a reversal of the evident tendencies for ethnic communities to divide their support among two or more parties based in that community. It would also 
run counter to the experience of some other ethnically divided countries. There is no actual experience of AV with open seats in heterogeneous constituencies in an ethnically divided country, but an analogy can be drawn from the experience of Mauritius and Malaysia, both of which have open seats under FPP. The Malaysian experience is relevant, even though there has always been a large Malay party in a dominant electoral position, and constituencies have become less heterogeneous since 1969. In neither country have small, ethnically based parties coalesced into larger ethnic parties. Even a large ethnic party like the main Malay party the United Malay National Organisation, which can govern alone, is committed to the perpetuation of the multi-ethnic coalition now called the National Front.

$A V$ 's potential to provide electoral incentives to moderation and cooperation may be contrasted with such incentives under other voting systems. Under FPP, a candidate can be elected with substantially less than 50 per cent of the votes. The voter has no way of indicating a second or third choice if the candidate who is the voter's first choice is unsuccessful. Some voters may, however, decide not to vote for their most preferred candidate, if that candidate has a very poor chance of success. They may feel that such a vote would be 'wasted'. Preferences may be expressed under some Proportional Representation systems, but their effect is quite different. The object is to elect a number of candidates in proportion to the number of votes received by the party. List-system PR requires that votes be cast for a single party list. Although some systems have been devised under which voters may make choices across party lists, it is argued that, if parties are ethnically based, there is no practicable way of inducing voters to exercise such an option. STV has the advantage of allowing voters to express second, third, or subsequent preferences for individual candidates the same way as AV does. But because STV is designed to be proportional in its outcomes, the quota that each candidate must obtain in a three-member constituency is just over 25 per cent. This may be compared with the just over 50 per cent required under $\mathrm{AV}$.

The overall effect of proportional systems compared with AV or even FPP is that, if people vote communally, ethnic parties can expect to succeed in getting a number of candidates elected in proportion to the number of their community members in the constituency, and 
therefore in the country. This is irrespective of whether they are moderate and seek to reach accommodation with the ethnic parties of other communities. If a party wishes to appeal to voters in other communities by putting up a multi-ethnic list, it has to calculate whether this will attract more voters from those other communities than the number it will lose from its own. Set alongside the reserved seats proposed to be retained in Fiji as a transitional measure, any proportional system would, in our view, offer few incentives to parties to become more multi-ethnic in their composition or more willing to take account of the interests of all communities.

In terms of the extent to which it provides electoral incentives for moderation and compromise, $\mathrm{AV}$ is to be preferred to either Listsystem PR or STV, the proportional representation systems advocated in some submissions. AV is also to be preferred to FPP, though FPP is more conducive to moderation and compromise than PR systems. For this reason alone the adoption of AV is favoured. Additionally, $\mathrm{AV}$ adequately meets the other criteria the Commission adopted for judging electoral systems.

\section{Effective representation of constituents and AV}

Experience in Fiji shows that voters expect close links and accountability between individual members of Parliament and their constituents. It is important for voters to see themselves as represented not only by the member elected to the seat reserved for their community, but also by the member for their open seat constituency. Communal representation has obscured the usual expectation that a member of Parliament serves all the people in the constituency whether or not they support the member's party, and does so regardless of the community to which they belong.

The AV system requires the election of candidates to represent territorial constituencies. It is suited to the recommended singlemember reserved seat constituencies and also the three-member open seat constituencies. In this respect it compares with FPP and STV (except that STV requires multimember constituencies). It is to be contrasted with List-system PR if, as suggested in one submission, the whole country were treated as a single constituency. Voters usually feel strongly that they want to know who their member is and to have access to him or her both individually and as a group with common interests arising from their residence in a particular 
geographical area. In 1995 when the Commission visited South Africa, there were strong indications that, for this reason, the Listsystem PR used as the only feasible way of conducting the first democratic election in that country was likely to be modified. (In its final form the constitution requires only that the electoral system must result, in general, in proportional representation, leaving the details of the system to national legislation).

The introduction of List-system PR in a Fiji-wide constituency might be acceptable if combined with representation through open seat constituencies, as under MMP, but if List-system PR were to be combined with reserved seats, the members for reserved seats would tend to be seen as people's 'real' representatives. It might be hard for List-system members to associate effectively with them, even though belonging to the same party, and it would be harder still if the member's ethnicity was different from that of the community to which the seat belongs. STV has the defect of allowing constituency representation to become a dominant preoccupation. Because the threshold is so low, each party is likely to nominate more candidates than there are seats. Therefore, each candidate is competing not only with candidates of other parties, but also with other candidates belonging to the same party. Consequently, members representing the same party in a particular constituency sometimes seek to outdo one another in their commitment to constituency work, to the neglect of other Parliamentary duties. They may also concentrate on obtaining reciprocal support for constituency projects, to the detriment of a national outlook.

Under AV, the problemsof intra-party competition in multimember constituencies can be avoided by adding first, second and third preferences together before the candidate with the lowest number of votes is eliminated. This facilitates the adoption of party slates under which the party may ask voters to give their first preferences to $A$, their second preferences to $B$ and their third preferences to $C$. As all preferences have equal weight when added together, it would be wrong to eliminate B or C before taking account of voters' second and third preferences, as well as first preferences. The Commission proposes that the AV system should be applied in this way in elections for the three-member open seats in the Bose Lawa. 


\section{Effective voter participation and AV}

If individual citizens are to play a full and active part in the political process, they should have a real choice among political parties and their candidates. They should feel that their vote will affect the outcome and will be of equal weight to the votes of other citizens. The voting system, and, in particular the ballot paper, should be one they can understand and use effectively in order to cast valid votes.

The $A V$ voting system would give citizens a considerable opportunity to affect the outcome of the poll by expressing preferences among individual candidates. It is sometimes argued that, by requiring voters to indicate preferences for all or most candidates, it forces them to give at least some support to candidates they would otherwise not be prepared to vote for. This is more of a philosophical than a practical problem, but to mitigate it we propose that votes should be treated as formal if voters express preferences for a least 75 per cent of the candidates. It is also possible to have rules preserving the validity of the ballot paper even if candidates accidentally fail to number preferences correctly beside the names on the ballot paper. For example, they may put in the same number more than once, or omit one number in the numerical sequence. To make sure that the election always produces a valid result, it should be provided that, if the requisite number of candidates has not reached the quota when all the preferences have been distributed, those with the highest number of votes should be deemed elected. Generally, the high level of literacy in the Fiji Islands will mean that few voters will have any difficulty in numbering the candidates in the order of their preference beside the names of particular candidates. Certainly, the Commission envisaged no difficulty in the elections of the single-member for each reserved seats. The number of names on the ballot paper is not likely to be more than three or four.

However, there are likely to be at least three times that number of candidates on the ballot paper for the three-member open seats. To assist people in marking the ballot paper, and also to encourage parties to exchange preferences and assist them in delivering them in accordance with the agreement, the Commission proposed that an 
'above the line/below the line' ballot paper should be used for elections to all seats. The ballot paper for the election of candidates for the multimember seats in the Australian senate provides a model. Voters wishing to vote on a 'ticket' basis need only tick the name or symbol of the party, coalition or independent candidate whose ticket they wish to support. The effect is to allocate that voter's preferences in the order predetermined by the party, coalition or candidate, and registered with the Electoral Commission. If the voter wishes to indicate a different order of preferences, he or she is free to do so by putting numbers beside the names of the candidates in the bottom part of the paper.

There should be a statutory requirement that the Electoral Commission must ensure that voters are given full information about the consequences of choosing a particular ticket. The Act should provide that, if a ballot paper is marked both above and below the line, it should not, for that reason alone, be treated as informal. If the preferences indicated below the line are otherwise formal, they should be regarded as the expression of the voter's intentions and counted accordingly. If, however, the preferences below the line are themselves informal, the vote for the party ticket, if formal, should be treated as expressing the voter's choice.

The principle of eliminating the lowest-polling candidate in each round of preferences and redistributing the preferences of the voters whose candidates are eliminated, until one candidate reaches the quota, is easily understood. Voters do not need to concern themselves with the mechanics of counting and distributing the preferences. These are relatively complicated and time-consuming. However, they are less complex then the allocation of surplus votes at a discounted value under STV, and training the requisite number of electoral officers for the purpose of conducting elections under the AV system can be arranged without too much difficulty. The process of vote counting and distribution is done openly. Candidates' agents will quickly understand and follow how it is done.

\section{Effective representation of minority and special interest groups and AV}

The voting system should ensure that parties, candidates and members of Parliament are responsive to minority groups and special interests. This is particularly important in those cases where 
the minority group is required to belong to, or is in competition with, a larger ethnic community for the purposes of political representation. AV does not have the same capacity as proportional systems to secure the election of representatives of every group in the country which chooses to organise politically and can win a minimum share of the votes. However, the need for a candidate to achieve an absolute majority means that no candidate can afford to neglect any small pocket of voters who might be willing to give their support in exchange for a policy which takes account of their interests. Just as AV encourages appeals across ethnic lines, so also it encourages appeals to women and to minorities with special interests. In this respect it is greatly superior to FPP. However, it is difficult to gauge whether, under $\mathrm{AV}$, parties would seek to gain wider support by nominating more women and members of minority groups as candidates then they do now under FPP. The evidence suggests that, under a proportional system, it is easier for candidates from disadvantaged or minority groups to win election. However, this advantage is outweighed in Fiji by the disadvantages of a proportional system.

\section{Fairness between political parties and AV}

When they vote at elections, voters are choosing between alternative party governments as well as alternative constituency members. The voting system should encourage competition between potential majority parties or pre-election coalitions, so that voters can make a clear choice about the identity of their future government. At the same time the voting system in its method of turning votes into seats should not have the effect of unfairly excluding the representation of small parties, provided they win a significant share of the vote.

However, the voting system does not need to allow for the representation of every small party with just enough votes to justify an allocation of a seat of a percentage basis -1.4 per cent in a house of 70 members. Carrying the representation of minority interests to extremes creates a danger that they will be able to exert pressure out of proportion to their number. It should also be kept in mind that some of the support for minority parties results from 'protest' voting. A vote for the small party may not represent the voter's expectation that it will become the government or even win a seat. Rather it may express unwillingness to support any of the larger parties which 
have a realistic chance of winning the election or at least obtaining representation. Finally, the voting system should not produce a consistent pattern of electing governments that have less than 50 per cent of the total number of votes cast in the election. In contrast to the position in New Zealand, that has not happened in Fiji. Most if not all governments that have taken office in Fiji since 1970 have received a majority of the total number of votes.

$\mathrm{AV}$ is not designed to secure the representation of political parties in proportion to their share of the total votes cast in the election. In this respect it has some of deficiencies of FPP, though not to the same extent, because of the need for a candidate to win majority support. Taking account of all preferences which become effective, it would be virtually impossible for a party to win an election without obtaining a majority of the overall votes. Some argue that $\mathrm{AV}$ has the same tendency as FPP to favour larger parties at the expense of smaller ones. They consider that this tendency is exacerbated when AV is used in multimember constituencies, as it was in the Australian Senate between 1919 and 1946. The AV system was then replaced by STV with the object of securing the fairer representation of all political parties in the Upper House. The question of encouraging the fair representation of ethnic communities was not at issue, so too much should not be read into the decision to make the change.

Even if the disproportionality of $\mathrm{AV}$ is greater in multimember seats than in single-member seats, multimember constituencies for open seats are nevertheless desirable. They are likely to encourage multiracial party slates, not only across the country as a whole, but also in individual constituencies. This seems likely to make individual voters more willing to cast their votes on the basis of party, not ethnicity. The encouragement of such a development is yet another essential building block in enabling parties to adopt moderate policies and to broaden their electoral support across ethnic lines. If the consequence is that, as not under FPP, smaller parties may not be represented in proportion to the number of votes they receive, that seems a small price to pay.

The Commission also considered the question of fairness to parties in the context of drawing constituency boundaries. It accepted that problems of fairness would not arise under a proportional system of representation. Under such as system, parties will get a number of seats in proportion to the number of votes they 
receive, regardless of the way in which boundaries are drawn. However, the advantages of putting in place heterogeneous constituencies for the open seats outweighs any difficulty that may arise in also being fair to parties. Any change in the voting system, including the transition from a system of exclusively communal seats to a mixed system of reserved and open seats, will require all parties to rethink their policies and to decide on the groups to which they will appeal. The situation is quite unlike that which can arise when boundaries under an existing system need to be revised. In those circumstances there may be real questions about interfering with the representation of areas from which particular parties have traditionally drawn support.

The initial drawing of new constituency boundaries will be an essentially political process calling for both fairness and compromise, if the essential objective of homogeneous constituencies is to be achieved. Once the new constituencies are in place, we envisage that the only major change in the distribution of the population would call for an adjustment of their boundaries. It is possible that the objective of heterogeneous constituencies may run counter to the instinct of parties that constituencies should bring together the groups that have traditionally supported them. That instinct will have to be resisted. The objective of heterogeneous constituencies will need to be agreed upon as part of the overall political settlement under which new constitutional arrangements are put in place.

\section{Effective government and AV}

The voting system should allow the election of Governments that have the support of a sufficient legislative majority to enable them to act decisively. In normal circumstances they should also be able to obtain Parliamentary approval of their budgets and defeat Opposition no confidence motions, so that reasonable stability is assured. The passage of other legislation should not normally be seen as an issue of confidence. The Government should have sufficient flexibility about the means of implementing its policies in legislation-if not the policies themselves-to allow the proposed Parliamentary select committee system to function effectively.

As a majoritarian, not a proportional system, AV is likely to encourage the emergence of a strong party or pre-selection coalition government. AV, with its requirement that candidates win majority 
support, not a mere plurality as under FPP, should mean that relatively small swings in the electoral support for particular parties will not have the effect of putting governments into or out of power. However, strong and stable government should not, in itself, be seen as an overriding goal of the voting system. Even if an ethnically based party were to win a majority of the seats in the Bose Lawa, it should not necessarily signal immediately its ability and willingness to form a government on its own. Under the Compact, it would be bound to consider the objectives of multi-ethnic government and the duty to take the interests of all communities into account. It would therefore need to consider whether other ethnic parties could and should be drawn into a coalition government.

Second, if a multi-ethnic pre-election coalition wins an election, it is still a coalition, though we believe it is likely to have a stronger base for remaining united than a coalition which comes into existence after an election because no party has the necessary majority to govern alone. Third, what cannot be excluded, even under $\mathrm{AV}$, is the need for parties, none of whom has a sufficient majority to govern alone, to form a governing coalition after an election. For some time to come, the people of the Fiji Islands will be juggling the two variables of party and ethnicity. It would be surprising if the introduction not only of a new voting system but also the reconstitution of both houses of Parliament took some time to settle down. But it can be said that AV is just as likely as FPP, and more likely than a proportional system, to produce strong and stable governments.

\section{Effective opposition and AV}

The voting system should ensure that, as well as effective government, there is also effective opposition. It should not be one under which relatively small swings in electoral support can have the effect of unduly reducing or eliminating the representation of the Opposition party or parties. It is difficult to foresee the character and composition of future Opposition parties if the goal of multi-ethnic government is achieved. However, AV is less likely than FPP to allow relatively small swings in voter support not only to bring about a change of government but also to give it an overwhelming majority. The equitable representation of Opposition parties is more assured under proportional representation, but, in the circumstances of Fiji, 
the greatest need is the encouragement of multi-ethnic government through the AV system in the manner described above.

\section{AV as a proven system}

The people of Fiji should adopt a voting system that has been successfully used elsewhere, preferably in the region. No unexpected problems would be likely to arise, and there would always be ready access to technical advice and help. AV is used for the election of candidates to single-member seats in the Australian House of Representatives and the lower houses of most Australian states. From 1919 to 1946 it was used in the Australian Senate to elect candidates to multimember constituencies. Apparently it is also used in multimember constituencies in Nauru. STV is used in electing the members of the Australian Senate, the lower house in Tasmania and the single chamber legislature in the Australian Capital Territory. New Zealand, in implementing MMP, is gaining experience with party lists. All three systems have shown themselves to be workable in actual operation in other countries over a considerable period.

\section{Legitimacy of elections under AV}

Under this heading the New Zealand Royal Commission said

Members of the community should be able to endorse the voting system and its procedures as fair and reasonable and to accept its decisions, even when they themselves prefer other alternatives (quoted in Fiji CRC 1996:327).

The Royal Commission saw this criterion as a test of whether the requirements of all of its proceeding criteria had been adequately met. In a society like Fiji, legitimacy means that the members of all communities must be able to accept election results as fair and needing to be upheld, even when they themselves would have preferred another outcome. On this basis, legitimacy as a criterion deserves a higher priority, but we have left it at the end of the list because it still measures the overall effect of the voting system.

This Commission's basic argument is that multi-ethnic government is in the interests of all communities in Fiji. If this is accepted, then the electoral arrangements must not be unfairly weighted in the interests of any one community. In any event, there is no guarantee that a weighted system will produce the desired result in all circumstances. If it does not, the reaction is to think that the 
electoral system has failed the interests of the community which sees itself as disadvantaged. Their likely response is that in order to remedy the situation, the system should be made even more lopsided. The electoral system should not favour one community more than another, but that this alone is not sufficient. If the goal was the certainty that all communities will be proportionally represented, there might be no reason to move away from a system under which all seats are reserved on a fair basis. But that would not in itself lead to multi-ethnic government.

Within a fair electoral system, the people of Fiji should adopt a voting system that helps to dissolve the present link between ethnicity and party. If all ethnic groups are adequately represented in the Government party or parties and in the Cabinet, then, so far as that outcome is facilitated by the voting system, that system should be seen as legitimate. The Commission concentrated on the election of candidates for the 45 open seats in the Bose Lawa, because the voting system will have its most important effect in that context, but it also saw AV as encouraging multi-ethnicity in the election of members to represent at least some of the provinces in the Bose $e$ Cake. In the election of the President and Vice President by the Electoral College constituted by the members of both houses, the need for an absolute majority under AV provides a necessary guarantee that the choice will have widespread support across the political spectrum. For that reason it will be regarded as legitimate.

This is not the first time that the AV system has been proposed for electing members for the reserved seats which need to be retained for the time being. The Street Commission made a similar recommendation in 1975. That body saw the need for the successful candidate for a reserved seat to obtain more than 50 per cent of the votes as an advantage, compared with the possibility of election by a minority of the votes cast in the constituency under FPP. AV will add to the legitimacy of the election of reserved seat members. The dynamics affecting elections for reserved seats will be changed, not only by the move to the AV system, but also by all the other changes affecting the composition of the two houses of Parliament and the election of their members. Overall, the incentives for moderation applying to the election of other members of Parliament will also affect the election of members for the reserved seats. 
The Commission concludes that all elections of candidates for seats in the Bose Lawa and the Bose e Cake, as well as the election of the President and Vice-President, should be held under the preferential system known as the Alternative Vote; that the 45 open seats in the Bose Lawa should be filled by voting in 15 three-member heterogeneous constituencies, that is, constituencies in which there is a mixed population made up of members of the different ethnic communities. The detail of conducting elections by the Alternative Vote should be provided for in an Electoral Act, which should, among other things, provide

- in elections for the 3-member open seats in the Bose Lawa, the first, second and third preferences given to each candidate should be added together, before the candidate with the lowest number of votes is eliminated

- votes should be treated as formal if voters express preferences for at least 75 per cent of the candidates

- there should be rules for preserving the validity of the ballot paper, so far as possible, even if candidates fail to number preferences in the correct numerical sequence

- if the requisite number of candidates has not reached the quota when all the preferences have been distributed, those with the highest number of votes should be deemed elected

- in the election for all seats, an 'above the line/below the line' ballot paper should be used. In the top part of the ballot paper voters should be given the opportunity to vote on a 'ticket' basis, indicating support for the candidates in an order of preference registered by a party, coalition of parties or independent candidate. If the voter wishes to indicate a different order of preferences, he or she should be free to do so by putting numbers beside the names of the candidates in the bottom part of the paper

- the Electoral Act should require the Electoral Commission to ensure that voters are given full information about the consequences of choosing a particular ticket

- the Act should also provide that, if a ballot paper is marked both above and below the line, it should not for that reason alone, be treated as informal. If the preferences indicated below the line are otherwise formal, they should be 
regarded as the expression of the voter's intentions and counted accordingly. If, however, the preferences below the line are themselves informal, the vote for the party ticket, if formal, should be treated as expressing the voter's choice.

\section{The determination of constituency boundaries}

The constituency boundaries for all seats in the Bose Lawa should be drawn so as to divide the Fiji Islands into the requisite number of territorial constituencies for each category of seats. So far as possible, each should contain an equal number of inhabitants of the relevant category, and should ensure that the inhabitants of every constituency can be effectively represented, taking into account geographical features, the boundaries of existing administrative and recognised traditional areas means of communication and density and mobility of population. In addition, the constituencies for the open seats should be required to be heterogeneous.

This recommendation departs from the criteria in section 48 of the 1990 Constitution by referring to 'inhabitants' rather than 'adult inhabitants'. The Commission proposes the change to reflect the principle that members of Parliament represent all inhabitants of their constituencies, regardless of age or eligibility to vote. Another relevant factor is that the census data relating to the distribution of the total population is readily available. The Constitution allows the principle of equality of the population to be departed from in order to take account of other relevant factors. We consider that, in principle, the variation should not be greater than 10 per cent on either side of the norm obtained by dividing the relevant population figure by the number of constituencies. However, we think it would be too restrictive to impose this target as a constitutional limit, particular in drawing the boundaries of the open seat constituencies which are required to be heterogeneous. That requirement is basic to the idea that the open seats should act as a catalyst for a move away from ethnic politics. If need be, we therefore see it as overriding the requirement for equality.

\section{Reserve constituencies}

There will need to be 12 reserved seat constituencies for Fijian voters, 10 for Indo-Fijian voters, 1 for Rotuman voters and 2 for general voters. The starting point will be the number and distribution of the 
members of the population regarded as belonging to a particular community for representation purposes. However, it would not be practicable to apply these rules when determining the distribution of the population belonging to each community. The Constitution should therefore refer to the distribution of inhabitants classified for census purposes as Fijians or Pacific islanders, Indo-Fijians, Rotumans, and persons not belonging to any of those ethnic communities.

\section{Open seat constituencies}

There will also need to be 15 open seat constituencies, each electing three members. Although the distribution of the ethnic communities will not be relevant for the purpose of applying the principle that constituencies should have an equal number of inhabitants, it will be relevant in fulfilling the requirement that open seat constituencies must also be heterogeneous. Again, account should be taken of the distribution of the population as classified for census purposes. It may not be feasible to specify the degree of heterogeneity required, but the open seat constituencies should be as heterogeneous as possible. In some cases this criterion may need to be fulfilled in innovative ways, for example, by placing more weight on lines of communication than on traditional ties. Through their elected members in the reserved and open seats in the Bose Lawa and the provincial seats in the Bose e Cake, all the people of Fiji will have the opportunity to be represented in a variety of ways which will take full account of their range of interests.

\section{Constituencies for the election of the members of the Bose $e$ Cake}

There will be no need to determine the boundaries of constituencies for the purpose of electing members of the Bose e Cake. The boundaries of the provincial constituencies should be the provincial boundaries prescribed under the Fijian Affairs Act. The boundaries of Rotuma should be those referred to in the definition of 'Rotuma' in the Rotuma Act.

\section{Constituencies Boundaries Commission}

The task of determining the boundaries of constituencies for the election of members of the Bose Lawa should continue to be carried out by a Constituency Boundaries Commission. The Constitution 
should require the Constituency Boundaries Commission to determine the initial boundaries of all constituencies on the basis described above. It should also require the Constituencies

Boundaries Commission, in the year following each census, to review the boundaries of all constituencies and decide whether or not they require revision to take account of changes in the distribution of the population as a whole, or of the members of any community. The Constitution should also empower the Constituency Boundaries Commission to review and redetermine all or any constituency boundaries at any other time during the intervals between each census (at present 10 years), if it has reason to think that such a review and redetermination might be desirable on those grounds. After the Constituency Boundaries Commission has reviewed constituency boundaries on any occasion, it should be required to report its findings to Parliament with an explanation of the reasons why it has decided either to redetermine boundaries or not to do so.

The procedures to be followed by the Constituency Boundaries Commission in determining or redetermining constituency boundaries should be prescribed by Act. Such an Act would require the Constituency Boundaries Commission to give notice of its proposed determinations and hear objections before making a final determination. Once made, the boundaries should continue to be final. They should not be subject to appeal, but judicial review should be available to test whether the Commission has acted within its powers and in accordance with the prescribed procedures.

Although the Constituency Boundaries Commission will only need to exercise its functions periodically, we consider that it should be a standing Commission. Otherwise there is a risk that constituency boundaries will not be reviewed as and when necessary. Its membership should be entirely separate from that of the Electoral Commission. The functions of the two bodies are quite distinct. The composition of the Constituency Boundaries Commission should take account of the fact that, although constituency boundaries should be drawn as impartially and fairly as possible and in accordance with the constitutionally prescribed principles, any determination of boundaries inevitably has political implications. The Commission should therefore consist of three members holding office for terms of three years. The Chairperson should be a person who is, or is qualified to be, a judge of a superior court in the Fiji 
Islands, and should be appointed by the President acting in his or her own deliberate judgement, after consultation with both the Prime Minister and the Leader of the Opposition. The two other members should be appointed by the President on the nomination of the Prime Minister and the Leader of the Opposition respectively.

No qualifications should be specified for members other than the Chairperson, but no person should be qualified to be a member of the Commission if at any time during the four years preceding appointment he or she has been a member of Parliament or an elected member of the council of any municipality, as defined in the Local Government Act (Cap. 125). A serving member of the public sector, the police or the military forces should also be disqualified. The Constituency Boundaries Commission should also be subject to the general principles and rules applying to all Commission established by the Constitution.

\section{The names of constituencies}

It is fair to say that not much imagination has been shown in naming constituencies in Fiji. The names of the main cities and the provinces have been used, with the addition of a reference to the relevant point of the compass if it was necessary for a geographic area to be subdivided. In addition, the designation of a member for a communal seat has included a reference to his or her community.

The names of the provinces and Rotuma should be used exclusively to describe the constituencies for election to the Bose $e$ Cake. As now, the members for a particular providence will each be entitled to use the designation 'Senator for Rewa', or whatever the province might be. However, the constituencies in the Bose Lawa will take account of, but will not be based on, provincial boundaries. Although some seats in the Bose Lawa will continue to be reserved, the member should no longer be identified by reference to his or her community. This not only puts undue emphasis on communal identity, but will also become less practicable in the light of our recommendations for identifying the voters belonging to each community for voting purposes. Fiji should do what is done in other countries and give constituencies distinctive names that prevent them from being confused with areas that have recognised geographic boundaries. Constituencies for all the seats in the Bose Lawa might be named after well-known physical features, like 
mountains or rivers, or after local flora and fauna. By way of example, the following list of names might be considered.

\section{Suggested Bose Lawa constituency names}

\section{Open seat constituencies}

1. Uluiqalau (Cakaudrove)

2. Seatura (Bua)

3. Babasiga (Macuata)

4. Veiyanuyanu (Lau-Lomaiviti-Rotuma)

5. Tebara ni Siga (Tailevu)

6. Vunivadra (Rewa)

7. Korobaba (Rewa)

8. Waimanu (Naitasiri South)
9. Medrau Sucu (Naitasiri North)

10. Toma ni Ivi (Ra)

11. Suka (Ba-Lautoka)

12. Dobu (Ba-Tavua)

13. Naloto (Nadi Yasawa)

14. Voma-Cakaubalavu (Namosi-Serua-Kadavu)

15. Maseki (Nadroga-Navosa)

\section{Reserved seat constituencies}

Fijians including other Pacific islanders (local flowers)
1. Mocelolo
6. Seniuci
2. Kukuwalu
7. Tomole
3. Lagakali
8. Buasala
4. Cevuga
9. Maba
5. Kurukoto
10. Saku

Indo-Fijians (local fish)
1. Babale
6. Ulavi
2. Saqa
7. Walu
3. Kawago
8. Kanace
4. Kawakawa
9. Nuqa
5. Kurukoto
10. Saku

General voters (local fruit trees)
1. Dawa
2. Kavika

\section{Rotumans}

1. (To be chosen by Rotumans)

\section{The right to be entered on reserved seat consistency}

A number of submissions expressed concerns about the existing rules governing registration on the various communal rolls. First, a number of Fijians raised questions about linking registration in the Vola ni Kawa Bula, which is a register of customary rights in land, with the classification of a person as a 'Fijian' for voting and other 
constitutional purposes. The Commission agrees that this link puts too much strain on the integrity of both systems and should be removed. The Constitution should deal only with the right to be entered on a roll for a Fijian reserved seat constituency. It should not define a 'Fijian' for any other purpose. For example, it should not be concerned with the question of who is a 'Fijian' for the purpose of being eligible for nomination as President-a matter safely can be left to the Bose Levu Vakaturaga-nor with the duty of the government to establish programs promoting ethnic justice for 'Fijians'. If necessary, the requisite Act can set out exactly who is eligible to benefit from a particular program.

Second, many members of the various Pacific island communities in Fiji expressed unhappiness about the fact that the 1990 Constitution had removed them from the Fijian roll and included them on what is usually called the 'general' roll. They considered that they had little community of interest with most of the other voters on that roll. None of them had succeeded in being selected to a seat belonging to the general voters' community. One suggested solution was the allocation of a communal seat to their community, an idea the Commission was unable to accept. Alternatively, they suggested that they should be restored to the Fijian roll, on the ground that many of them were vasu $u^{1}$ and lived closely with the Fijian community. Because we view the retention of the reserved seats as a transitional measure, we consider this solution is the better one. We therefore propose that Pacific islanders should be eligible to vote in the Fijian reserved seat constituencies.

Third, a number of submissions from members of all communities expressed unhappiness about the fact that persons have always been classified as 'Fijians' and 'Indians' for constitutional purposes by reason of patrilineal descent. The only exception allowing for descent to be traced through the mother has been if the identity of a person's father is not known. In those cases where persons of mixed descent have been brought up in their mother's community rather than their father's, the provision has inflicted personal hardship by requiring people to vote as members of a community to which they do not belong.

Rotumans are not affected in the same way, because section 156(b) of the 1990 Constitution classifies a person as Rotuman if of Rotuman descent through either the father or the mother. This gave persons of 
mixed Rotuman and Fijian or Indian descent through the father a choice of rolls. The original 1970 provisions were unduly preoccupied with having clear roles which could be applied automatically. Recognition of descent through the father was acceptable to Fijians because the customary right to land is usually based on descent through the father rather than the mother. However, as proposed above, the right to vote in a Fijian reserved seat constituency should not depend on having a customary right to land.

By returning Pacific islanders to the Fijian roll, many persons descended from an indigenous Fijian through their mother will acquire the right to vote in Fijian reserved seat constituencies. It would be unfair if other citizens also descended from an indigenous Fijian through their mother were not given the option of voting as members of the Fijian community. The Commission proposes that a person should be allowed to be registered on the roll for a Fijian reserved seat constituency if descended, through either the male or the female line, from an indigenous inhabitant of the Fiji Islands (other than Rotuma) or any other island in Melanesia, Micronesia or Polynesia. Similarly, a person should be permitted to register on the roll for an Indo-Fijian reserved seat constituency, if descended, through either the male or the female line, from a person who was originally from the subcontinent of India. A person who is descended, through either the male or the female line, from an indigenous inhabitant of Rotuma should have the right to be entered on the roll for the Rotuman reserved seat constituency.

A reference to 'the male line or the female line' would allow descent to be traced back though the generations on either side of the family, obviating any question of discrimination on the ground of a person's sex and give persons of mixed descent a choice. People will only want to change their present registration if it cuts across their sense of personal identify. The number is likely to be very small.

The right to be registered on the roll for a general reserved seat constituency should remain residual, so that registration is open to all persons who have no other options or, if they have the option of registering on another roll by reason of descent through the male line or the female line, but not both, have chosen not to exercise it.

No one may be registered on the roll for more than one reserved seat, open seat or provincial consistency. The Commission's 
proposals will foster a stronger sense of shared identity among all those who are registered on the roll for a particular constituency.

\section{Some concluding comments}

I now close this contribution with some comments of my own. The electoral recommendations of the Commission have been subjected to some criticism. Some of the comments have been illuminating, providing the basis for informed and vigorous discussion of the topic. Contributions to the Workshop ${ }^{2}$ and chapters in this volume fall in that category. But some criticisms have been unnecessarily strident and petty, and some driven by political considerations or other personal agendas. That is to be expected, I suppose, given that the Commission's recommendations represent a significant shift away from the electoral system currently in Fiji. At the Workshop a number of views were aired. Perhaps the most persistent criticism concerned the Commission's recommendations for electing members on AV from multimember constituencies. The system had been abandoned in number of countries, it was said. Others feared that $A V$ in multimember constituencies would throw up unpredictable results. Yet others pointed out the supposed superior qualities of other electoral systems. In response, it was said that Fiji already had multimember constituencies for the Fijian seats, and the fear of capricious results were exaggerated, even unfounded. Tomasi Vakatora reiterated the Commission's consideration that the AV in multimember constituencies was the best way to realise the vision that underlay its work: the attainment of multi-ethnic government in Fiji. If, however, there was a reluctance to go that route, then, but only then, it might be adopted in single-member constituencies. That system is widely practiced, including in Australian federal elections. $\mathrm{AV}$ in single-member constituencies would delay the achievement of the Commission's vision, but it was still far preferable to proportional representation systems.

I return to the point I made at the beginning. An electoral system is a means to an end, and not an end in itself. The most important objective, perhaps the overriding objective endorsed by the Commission, was to encourage the formation of multi-ethnic parties (or coalitions) and governments in Fiji that broadly reflected the multi-ethnic character of the country, that fostered nation building, 
reinforced the value of integration and cross-ethnic cooperation, rather than accentuating divisions in society, that put the national interest ahead of communal interests. The Commission's considered view, a view that I have found absolutely no reason to change, was that the Alternative Vote was the electoral system best likely to achieve that objective: of taking Fiji towards a united future for all its people.

\section{Note}

1. Vasu means the mother's brother's son, who has a right known as vasu in his uncle's village to take whatever he wants from his uncle's goods.

2. 'Electoral systems in the goverance of divided societies: the report of the Fiji Constitution Review Commission', 17 January 1997, National Centre for Development Studies, The Australian National University, Canberra.

\section{References}

Fiji 1990. Constitution of Fiji, Suva.

Fiji Constitution Review Commission 1996. The Fiji Islands. Towards a United Future, Parliament of Fiji Parliamentary Paper 34 of 1996, Government Printer, Suva. 


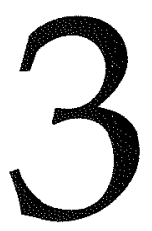

\section{Constitutional engineering and the alternative vote in Fiji: an assessment}

\section{Ben Reilly}

The single most important institutional issue for encouraging the development of peaceful multi-ethnic politics in Fiji is the design of the new electoral system. Electoral systems have long been recognised as one of the most important institutional mechanisms for shaping the nature of political competition-first because they are, to quote one electoral authority, 'the most specific manipulable instrument of politics' (Sartori 1968:273)-that is, they can be purposively designed to achieve particular outcomes-and second, because they structure the arena of political competition, offering incentives to behave in certain ways, and rewarding those who respond to these incentives with electoral success. The great potential of electoral system design for influencing political behaviour is thus that it can reward particular types of behaviour and place constraints on others. In terms of ethnically divided societies, for example, where ethnicity represents a fundamental political cleavage, particular electoral systems can reward candidates and parties who act in a cooperative, accommodative manner to rival groups; or they can punish these candidates and instead reward those who appeal only to their own ethnic group. Unfortunately, most academic studies of electoral systems are largely silent on the potential for electoral systems to produce these kinds of incentives. ${ }^{1}$ 
It is therefore a pleasure to assess the report of the Fiji Constitution Review Commission (CRC), which deals directly and comprehensively with these issues (Fiji CRC 1996). The Commission's report puts forward a compelling argument for utilising the electoral system to promote multi-ethnic politics in Fiji. In doing so, it presents a well-reasoned intellectual case for the virtues of 'vote pooling' for future Fijian elections, via the use of a preferential electoral system known as the Alternative Vote. Despite some technical misjudgements (which, I argue, can be corrected relatively easily), the overall depth and quality of the report make it a significant contribution to the field of constitutional engineering, and it deserves to be widely read and acted upon in the years ahead.

This chapter provides an assessment of the Commission's electoral system recommendations. First, I will show how the Alternative Vote (AV) works to promote accommodative behaviour both in Australia, where it is a well established feature of elections at the national and state level, and how it worked when used in another South Pacific state, the then Territory of Papua New Guinea, between 1964 and 1975. This second example is particularly important, not only because it represents the only example of the use of AV in a plural society, but also because an analysis of the three elections held under AV rules in Papua New Guinea provide detailed evidence of how AV influences campaigning strategies and promotes accommodative and cooperative behaviour in an environment with some similarities to Fiji.

Second, I will turn to the Commission's specific recommendations for $\mathrm{AV}$ in Fiji, which involve a departure from the type of AV used in Australia and Papua New Guinea towards a confused hybrid model. This hybrid model of electoral system represents the Commission's major 'technical misjudgement' mentioned above. I will show how and why this proposed hybrid model cannot and will not work in Fiji (or anywhere else, for that matter) and how it may instead, if adopted, deliver unpredictable and even nonsensical results which will not promote inter-ethnic accommodation. Essentially, I am arguing that the Commission got the big picture decision of which electoral system to use right, but then got some of the details wrong. While this is understandable in what can be a highly technical area, it nevertheless means that the specific system recommended by the 
Commission will, if adopted, produce the opposite of the effects intended. I will show why this is so.

Third, I will make some recommendations, within the framework of the Commission's report, for what systems will work to produce the conciliatory multi-ethnic politics advocated by the Commission. These are actually very close to the Commission's own recommendations: either conventional AV in single-member districts, or the Single Transferable Vote if multimember districts are required. I will argue that the key question to be addressed is whether, in the Fiji context, it is possible to draw single-member districts which are sufficiently ethnically mixed-heterogeneous-to allow meaningful cooperation between ethnic groups to take place. If it is, then I would recommend straight, single-member AV, as used in Australia. If multimember electorates are required to ensure sufficient heterogeneity, then I would recommend the use of STV in small, three-member districts. These recommendations will be based on my experience as a consultant to governments in the electoral systems field and on my research into the effects of particular electoral systems in divided societies in the Asia Pacific (Reilly 1997a, 1997b).

\section{The Alternative Vote in action}

The Alternative Vote (AV) was first developed as a modification of the Single Transferable Vote (STV) system of Proportional Representation (PR) - the system recommended by the Street Royal Commission of 1975 for Fiji-which would enable preferential elections to take place in single-member districts, rather than the large multimember electorates required for Proportional Representation (Reilly and Maley 1996). Both STV and AV oblige voters to rank-order all candidates in order of their preference from 1 onwards. The difference between the two systems is manifested in the way votes are translated into seats. Under STV, candidates must gain a 'quota' of votes for election-usually defined as the number of votes divided by one more than the number of seats to be filled, rounded up to the next whole number. In a case where three candidates are to be elected, the quota for election will thus be just over a quarter of all votes. The AV, by contrast, applies this same formula to the election of only one member, so that the quota for election is much higher: 50 per cent plus one. This requires a 
candidate to receive an absolute majority of votes in order to win election, and it is thus rightly classified as a 'majoritarian' system. Under AV, if no candidate has an absolute majority of first preferences, the candidate with the lowest vote total is 'eliminated' and his or her ballots are re-examined for their second preferences, which are assigned to the remaining candidates in the order as marked on the ballot. This process is repeated until one candidate has over 50 per cent of all votes, and is declared elected.

The argument for the accommodative effects of AV are premised on the assumption that politicians are rational actors who will do what needs to be done to gain election. Under AV, 'what needs to be done' varies considerably depending on the makeup of the electorate. Where one candidate is confident of achieving an absolute majority of first preferences, they need only focus on maximising their own vote share from their own supporters in order to win the seat. In cases where no candidate has outright majority support, however, the role of second and later preferences becomes crucial to attracting an overall majority. Those candidates who successfully 'pool' both their own first preferences and the second preferences of others will be more successful than those who fail to attract any second-order support. To 'pool' votes, candidates need to attract the support of groups other than their own, and this is usually achieved by their moving to the centre on policy issues to attract floating voters, or by successfully accommodating 'fringe' issues into their broader policy. There is a long history of both these types of behaviour in Australian elections (Reilly 1997a).

\section{The Alternative Vote in Australia}

The Alternative Vote was introduced by the Nationalist government in Australia in 1918 to replace the existing First-Past-the-Post system after it became clear that several aligned conservative candidates all standing in the same electorate could split their vote between them under First-Past-the-Post, thus handing victory to the less popular but more disciplined Labor Party forces. Its introduction was thus intimately related to the need to counter the possibilities of vote splitting and to encourage and reward collaboration or coalition arrangements between parties (Graham 1968). This ability to aggregate aligned interests, rather than divide them, has long been a (largely unrecognised) feature of Australian electoral politics. The 
most graphic example of this process in action occurred at the 1990 federal election in Australia, where the incumbent Australian Labor Party was polling badly and looked to be heading for electoral defeat, and where voter support for left-of-centre parties such as the Australian Democrats and Greens reached its height. The then Prime Minister, Bob Hawke, went on national radio to campaign directly for the second preferences of these parties' supporters, offering policy concessions on key issues (for example, the environment) and arguing that the Labor Party was far closer to their interests than the major alternative, the Liberal/National coalition (Hughes 1990). This strategy was markedly successful: with minor party support levels at an all-time high of around 17 per cent, the ALP was the beneficiary of around two-thirds of all preferences from Democrat and Green voters-a figure which probably made the difference between it winning and losing the election (Papadakis and Bean 1995). This was thus a 'win-win' situation for both groups: the ALP gained government with less than 40 per cent of the first preference vote, while the minor parties, who did not win lower house seats, nonetheless saw their preferred major party in government and committed to favourable policies in their areas of concern.

Analyses of the effects of AV in Australia have tended to concentrate almost exclusively on its partisan impacts. Some commentators have seen the system as an instrument for maintaining the dominance of the two major parties, the ALP and the Liberal/National Coalition, and for restricting the role of minor parties in the lower house to one of influencing the policies of the major parties rather than gaining election themselves (Papadakis and Bean 1995). Others claim that it can enhance the power and position of minor parties, especially if they have the potential to hold the balance of power between two major parties (Aitkin et al. 1989:150). There is widespread agreement that AV has facilitated coalition arrangements such as that between the Liberal and National parties, and that it works to the advantage of centre candidates and parties, encouraging moderate policy positions and a search for the 'middle ground' (Bean 1986:65). The sometimes fiery and aggressive rhetoric of Australian politics has often distracted observers from recognising just how much cooperative behaviour there is between parties-via preferenceswapping deals, for example-and how close the major parties are on most substantive policy issues. There is little doubt that the AV 
electoral system provides a significant institutional incentive for these tendencies.

Despite the fact that Australia is one of only two countries which currently uses AV to elect its national legislature, most of the interest in the system in recent years has been international in origin. ${ }^{2}$ The potential benefits of AV for encouraging collaboration and accommodation between competing interest groups saw it recommended as the most suitable electoral system for postapartheid South Africa (Horowitz 1991a). The former Australian Territory of Papua New Guinea, which used AV until independence in 1975, has been the site of a long-running campaign for the reintroduction of $\mathrm{AV}$, with much attention focused on the potential of the system to encourage moderate campaigning, reduce candidate numbers and nullify the effects of 'vote splitting'. In addition, another ethnically divided polity in the Asia Pacific region, Sri Lanka, has used a form of preferential voting to elect its president since 1978. Details of these cases and others can be found elsewhere (see Reilly 1997a). For the purposes of this discussion, I want to briefly focus on how AV worked in Papua New Guinea, because I believe this is by far the most illuminating example for those interested in Fiji.

\section{The Alternative Vote in Papua New Guinea}

We have seen above how AV can work to encourage the aggregation of common interests, via the exchange of preferences, in the case of a stable western polity, Australia. While the circumstances in ethnically divided societies are very different, the same broad approach can be used to induce inter-ethnic bargaining and promote accommodative behaviour. At the core of this approach is the need, as Donald Horowitz has argued, 'to make politicians reciprocally dependent on the votes of members of groups other than their own' (Horowitz $1991 \mathrm{~b}: 471)$. The most reliable way of achieving this aim, naturally enough, is to offer sufficient electoral incentives for campaigning politicians to court voter support from other groups. In deeply divided societies, this can be very difficult to achieve. Under conditions of primarily ethnic political identity, for example, policybased cleavages are considerably less salient than ethnic or linguistic identities, and almost nothing will convince a member of one ethnic group to cast his or her vote for a member of a rival group. However, 
under $\mathrm{AV}$ a voter can give a first preference vote to a member of his or her ethnic group, but then use lower-order preferences to indicate secondary choices. Where a candidate needs the support of other ethnic groups to gain election, there is a powerful incentive for him or her to reach out to these groups in search of these second preferences. There is thus an inbuilt centripetal spin within AV: those candidates and parties who are broadly attractive to others will tend to be rewarded, those who have polarised support will generally not. Ideally, candidates who are elected will be dependent on the votes of groups other than their own for their parliamentary positions, and can be expected to serve the needs of these groups as well as their own ethnic group if they are to establish their positions and gain reelection.

The only time that these theories have been properly tested have been in pre-independence Papua New Guinea (PNG), which held elections in 1964, 1968 and 1972 under AV rules. The Constitution Review Commission mistakenly claimed that there is no actual experience of AV...in heterogeneous constituencies in an ethnically divided country' (Fiji CRC 1996:316). The PNG case represents just that. Papua New Guinea is a Melanesian society in which political affiliation rests predominantly on an exceptionally diverse ethnic and linguistic basis of several thousand 'clans' - ascriptive extended family networks which are the primary, and often the only, unit of political and social loyalty. With over 800 separate languages and several thousand tribal groups, this clan-based level of ascriptive ethnic identity means that Papua New Guinea is one of the world's most heterogeneous societies.

We are fortunate that all of Papua New Guinea's elections to date have been the subject of major book-length election studies (Bettison et al. 1965; Epstein et al. 1971; Stone 1976; Hegarty 1983b; King 1989; Oliver 1989; Saffu 1996). These studies provide a wealth of comparative information on political behaviour in the context of an electoral contest. Crucially, they detail numerous instances of accommodative vote pooling and preference-swapping activities under AV; and increasingly violent, zero-sum campaign behaviour since the replacement of AV with First-Past-the-Post in 1975. Essentially, there is significant evidence that accommodative vote pooling behaviour was encouraged by the incentives presented by $\mathrm{AV}$, and further significant evidence that behaviour became markedly less accommodative upon 
the introduction of First-Past-the-Post, under which the incentives for electoral victory are different (Reilly 1997b).

Under AV, vote pooling took place in three primary ways, all of which were predicated on the assumption that most voters would invariably give their first preference to their own clan or 'home' candidate. The most common and successful method of vote pooling was for a candidate who had a limited 'home' support base to campaign widely for second-level support amongst rival groups. This required a range of techniques, such as translating campaign speeches and travelling widely throughout an electorate, with the essential request being not for a first preference vote but for a second preference. This enabled electors to cast their primary vote for their 'home' candidate-an essential element in cases of ascriptive ethnic identity-but to also indicate their second choice if their ascriptive candidate was not elected. For this strategy to succeed, candidates needed to be able to sell themselves as a good 'second-best' choicewhich meant, in general, someone who would look after all groups, not just his own. At the first AV elections in 1964, for example, Bill Bloomfield in the Kaindi electorate emerged as the winner of the seat after the preferences of seven candidates had been distributed. Without a strong local support base or home area, Bloomfield campaigned extensively, translated his speeches into local dialect and emphasised that if electors did not want to give him their first preference 'then give me number two'. This was a highly effective strategy which saw him carry a seat that he would have had no chance of winning on first-preferences. Similarly, the contest for the seat Henganofi provided a classic example of the way disciplined preference-swapping amongst a group of aligned candidates can overcome a single dominant plurality winner (see Table 3.1). Candidate Bono, with massive support from his own region but negligible support elsewhere, lost to candidate Ugi, situated in the centre of the electorate and attracting a smaller clan block vote but a considerably broader range of support. Ugi was well behind on first preferences, but gained the majority of all other candidate's preferences to win the seat. 
Table 3.1: Allocation of preferences in Henganofi Electorate, 1964

$\begin{array}{lccccc}\text { Candidate } & \text { 1st count } & \text { 2nd count } & \text { 3rd count } & \text { 4th count } & \text { final count } \\ \text { Forapi } & 787 & - & - & - & (787) \\ \text { Posi } & 1758 & 12 & - & - & (1770) \\ \text { Punupa } & 3708 & 73 & 41 & - & (3822) \\ \text { Bono } & 8028 & 12 & 35 & 224 & 8299 \\ \text { Ugi } & 3295 & 667 & 1362 & 3274 & 9228 \\ \text { Exhausted }^{a} & - & 23 & 334 & 324 & 681\end{array}$

Note: ${ }^{\text {a }}$ An 'exhausted' vote comprises a ballot under an optional preference marking system in which preferences have not or cannot be assigned to a continuing candidate, hence 'exhausting' before the full distribution of preferences.

Source: Chief Electoral Officer, 1964. Statistical returns showing the voting within each open and special electorate in relation to the General Election for the House of Assembly, 1964, Government Printer, Port Moresby.

A second strategy for victory under $\mathrm{AV}$ was for candidates with significant existing support bases to reach out to selected allies for secondary support. Traditional tribal contacts and allegiances, for example, could be utilised to create majority victors. This similarly necessitated a commitment to behave positively towards those groups if elected. In the Dei Open Electorate at the 1972 elections, for example, tribal leaders of previously hostile clans made deals with each other for preference support. The winning candidate forged particularly close connections with a traditional ally tribe via 'intensive ties of ceremonial exchange', urged his supporters to cast their preferences for a member of a hostile rival tribe as well as for himself, and consequently received a generous proportion of that opponent's second and later preferences to win the seat.

A third strategy, and increasingly common by the time of the third AV election in 1972, was for groups and candidates to form mutual alliances, sometimes campaigning together and urging voters to cast reciprocal preferences for one or the other. This necessitated a strong cooperative approach to electoral competition, in stark contrast to the zero-sum attitudes that have prevailed at elections since independence in 1975, when Papua New Guinea changed to a FirstPast-the-Post system. At the first post-independence election in 1977, David Hegarty found that vote splitting and other 'anti-system' 
tactics 'heightened tension between clans and groups and in some cases polarized electorates to the point of violent conflict...this situation contrasted markedly with campaigning styles in previous elections where opposing candidates often toured their electorates together urging voters to cast preferences' (Hegarty 1983a:15).

Despite problems of literacy and numeracy, the percentage of voters in Papua New Guinea utilising preferences increased with every election between 1964 and the last preferential voting election in 1972, where 70 per cent of all seats were decided on preferences. In addition, the incidence of preference distribution deciding outcomes increased over time. By 1972, 16 per cent of seats returned different members than would have been the case under a straight First-Pastthe-Post contest. These are much higher rates of preferences being counted and results being changed than has ever been achieved in national elections in Australian, the 'home' of AV, and reflects the way AV works in situations of highly fragmented support.

There is thus a considerable accumulation of hard evidence that AV did serve to encourage cooperative and accommodative political strategies and behaviour in Papua New Guinea. There is also considerable evidence for the obverse: that is, that when incentives for cooperation were removed, ethnic groups reverted to their traditional hostilities. This return to conflict was considerably enhanced by a new set of incentives for non-accommodative behaviour inherent under a First-Past-the-Post, which rewarded vote splitting and appears to have contributed to zero-sum campaigning styles. Attempts since 1975 to constrain these activities have generally proved unsuccessful: candidates have reacted to the electoral incentives of the First-Past-the-Post by focusing their energies on maximising their own clan vote, and in many cases by restricting the campaigning of opposition candidates, via threats of violence, to their own home areas (Standish 1996; Dinnen 1996). This has led to candidates being elected on increasingly minuscule pluralities, and to ever-increasing numbers of candidates standing for election: the higher the number of candidates, the smaller the total vote needed to gain a plurality and hence win the seat (Reilly 1996).

The significance of the PNG example for Fiji is clear: it provides detailed evidence of how and why AV promotes inter-ethnic 
accommodation. And Fiji, as a part Melanesian country, does itself have many social structures in common with Papua New Guinea within its indigenous population. There are two crucial differences, however. One is that the ethnic division in Fiji is a bipolar one between the native Fijian and Indian populations, rather than fractionalised between many different groups, as it is in Papua New Guinea. Second, the combination of the communal electoral system and the mixture of Polynesian and Melanesian elements in indigenous Fijian society-such as the existence of traditional chiefs, for example-means that there has traditionally been less intense competition for elected office in Fiji than in other Melanesian countries, and thus that the lessons of the PNG case may not hold true in Fiji. To assess the way AV will work in Fiji realistically, we must first assess the CRC's specific proposals, and it is to this subject which I will now turn.

\section{The CRC's recommendations}

The recommendations for an AV electoral system in Fiji are set out in detail in chapter 10 of the CRC's report (and summarised in Chapter 2 of this book). The Commission argues-persuasively I think-that AV would encourage multi-ethnic government, would fit in well with Fiji's existing multi-party system, would provide incentives for moderation and cooperation across ethnic lines, and would effectively represent constituents. They noted the appropriateness of using AV in single-member constituencies, but went on to argue that $\mathrm{AV}$ could also be used effectively in multimember constituencies by adding first, second and third preferences together before eliminating the candidate with the lowest numbers of votes. These two recommendations-that multimember rather than single-member electorates be used, and that first, second and third preferences be added together before the elimination of lower-placed candidates begins-represent a significant departure from $A V$ as used in Australia and Papua New Guinea which (with one exception which I will discuss below) have always utilised single-member districts and counted each preference separately. As I will show, the combination of the recommendation that $\mathrm{AV}$ be used in multimember districts, and the recommendation that first, second and third preferences be 
combined when counting votes, together represents a crucial error in the CRC's reasoning.

\section{AV in multimember districts}

The only time that $\mathrm{AV}$ has been used in multimember districts was in the Australian Senate between 1919 and 1946. In contrast to the CRC's claims that $A V$ can be used successfully in multimember constituencies, this experience was anything but a success, producing winner-take-all outcomes and extremely lopsided parliaments. This was because when $\mathrm{AV}$ is used in multimember districts, the majoritarian features of the system become overwhelming. In effect, each vacancy was filled by a separate election, but with the same electorate voting at each. This showed a strong tendency to produce an outcome under which the same party grouping won every seat, and produced such sustained periods of single-party dominance that on a number of occasions the Senate was scarcely workable as a legislative body, let alone as a house of review. In the period from. 1947 to 1950, for example, there were only three opposition Senators-a leader, a deputy leader, and a whip-facing 33 government Senators (Reilly and Maley 1996). This level of system dysfunction meant that the electoral system itself was primarily responsible for the erosion of public confidence in, and the legitimacy of, half the federal Parliament; some have argued that it increased popular opposition to any strengthening of the federal government's powers (see Goot 1985:226). Multimember AV was replaced with the Single Transferable Vote in 1948 which, having been designed for multimember constituencies, has operated in a far more logical way.

The inappropriateness of multimember AV evidenced by the case of the Australian Senate was such that no proposal for multimember $\mathrm{AV}$ has ever again been forthcoming in Australia. Horowitz did propose that multimember AV may have to be used to ensure sufficient electorate-level heterogeneity in the case of South Africa, and it is notable that most critiques of his proposal focused on the unworkability of multimember AV as one of their major criticisms (Lijphart 1991; Reynolds 1995).

\section{Combining first, second and third preferences}

So the first major problem with the CRC's proposal is the recommendation that a majority-style method be used in a situation of choosing 
three, rather than one, representatives-a situation which requires some form of proportional system to work well. The experience of multimember AV elections for the Australian Senate-which also utilised three-member districts-resulted in the most disproportional electoral results ever experienced at any Australian elections. This, however, is not the only problem with the system as proposed by the $\mathrm{CRC}$. The CRC also suggested that, to avoid problems of intra-party competition

in elections for the three-member seats in the Bose Lawa, the first, second and third preferences given to each candidate should be added together, before the candidate with the lowest number of votes is eliminated (Fiji CRC 1996:329).

This is the most unusual aspect of the CRC's electoral recommendations, as it introduces a completely new approach to the counting of preferences which has never been used anywhere else. Essentially, the effect of this recommendation is to count a second and third preference as being of the same value as a first preference. This will, according to the Commission, result in party slates where members are not competing with each other for votes-thus, presumably, strengthening internal party solidarity. Unfortunately, as I will show, whatever positive effects this may have are overwhelmingly outweighed by the capricious and often arbitrary results that this provision will deliver.

The easiest way to demonstrate the problems caused by counting the first three preferences together is to conduct a hypothetical count. I have taken the sample ballot paper produced at p. 321 of the Commission's report, which consists of a hypothetical three-member election in the Vunivadra Open constituency contested by the Viti Liberal Party, the Fiji First Party, the National/Republic Coalition and some independents (see Table 3.2). I have assumed that there are 11,000 voters in the constituency, that there is a slim overall indigenous Fijian majority of electors, that electors vote along ethnic and party lines, and that support for the parties stands at 15 per cent for the Viti Liberal Party, 40 per cent for the Fiji First Party and 35 per cent for the National Republican Coalition, with Independents making up the remaining 10 per cent.

As you can see, most voters follow the party's suggested ordering of candidates - that is, most give the first candidate on the party list their first preference, the second candidate on the list their second 


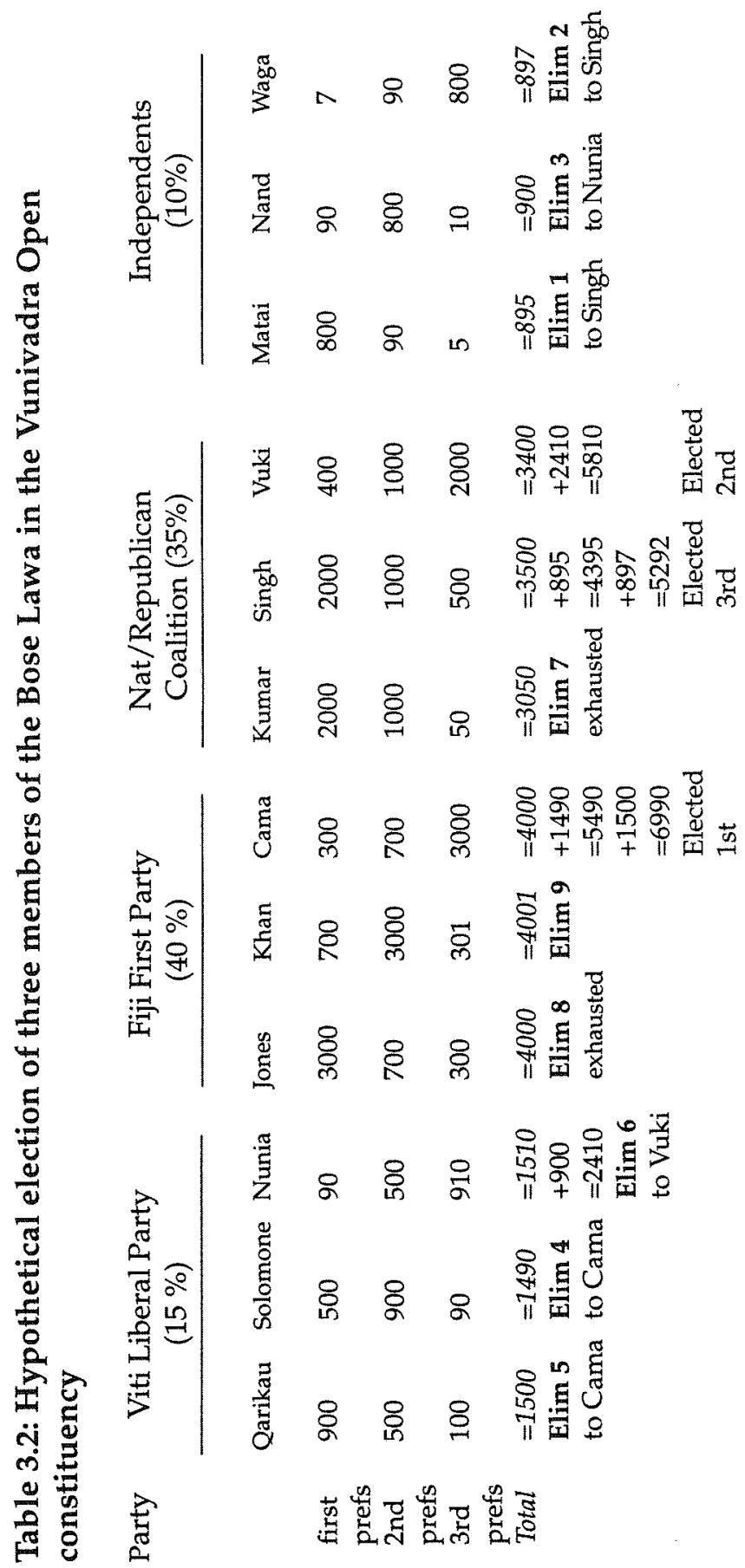


preference, and the third candidate their third preference. Because these are added together, most party candidates end up having very similar vote totals when the first, second and third preferences are aggregated (see the row marked 'Total'). This is the first problem we can see: that the adding together of preferences takes away one of the reasons for using a preferential system in the first place, which is to enable voters to register support for their favoured candidates in order of their choice. The system proposed dilutes this almost to the point of being meaningless. Candidate Jones of the Fiji First Party, for example, is by far the most popular candidate overall, with 3,000 first preferences, but when these are aggregated with second and third preferences he has a total of 4,000 votes - the same as the third placed Fiji First candidate, Cama, who gained one-tenth of the number of first preferences that Jones did. To assume that a third preference and a first preference can be aggregated in this manner is thus to undermine one of the most basic rationales of the Alternative Vote, which is that voters are registering the intensity of their preference when they give someone a first rather than a second or third preference, and that the more first preferences a candidate can gain, the better he or she should do.

This becomes even more apparent when we start the process of eliminating lower-placed candidates and transferring their preferences. The first candidate to be eliminated is the independent candidate Matai, who has 895 total votes (and who gained more first preferences than the other independents, but fewer second and third preferences). Let us assume that all of Matai's preferences go to candidate Singh, the second-placed candidate on the National/ Republican Coalition list. Singh now has 4,395 votes. Candidate Waga, the next to be eliminated, also passes on all his preferences to Singh, who now has a total of 5,292 votes. The preferences of the third independent candidate, Nand, all go to the third Viti Liberal candidate, Nunia, who now has 2,410 votes.

We have now eliminated the three independent candidates, but still have nine candidates left in the race. Six more will have to be eliminated. The next lowest-placed candidate is Solomone of the Viti Liberal Party, who has 1,490 votes. He is the next to be eliminated. This illustrates a second problem with aggregating first, second and third preferences. We are assuming, as the Commission did, that most voters will choose between members of one party with their 
first three preferences before they register their next choice-in other words, that they will be disciplined party voters. In this case, most of the electors who gave their first preference to Solomone would have given their second and third preference to other members of the Viti Liberal Party. However, because we are aggregating first, second and third preferences before we eliminate lower-placed candidates, these preferences have already been counted and we need to look at Solomone's fourth preference to see where the votes should be transferred. In most cases, it will be this fourth preference that determines which candidate will receive a transferred vote. Or, to put it another way, most vote pooling, on which the Commission is relying to encourage inter-ethnic accommodation, will have to take place as requests for fourth-level preference support-which does not augur well for its prospects.

In this case, all of Solomone's fourth preferences go to candidate Cama of Fiji First. So do Qarikau's, who is eliminated fifth. Candidate Cama now has over 6,990 votes. We still have more candidates remaining in the count than available seats, so we need to go on eliminating candidates. The next to go will be Nunia of the Viti Liberal Party, who has 2,410 votes. All his fourth preferences go to Vuki of the National/Republican Coalition. By now it is clear that the election is going to be fought out between the two major parties, who are the only ones left in the race. However, because they did not receive any preferences from the eliminated candidates, the next lowest placed candidates is Kumar of the National/Republican Coalition (3,050 votes) and Jones (4,000 votes) of Fiji First. Jones, you will remember, was the most favoured candidate from any party, gaining 3,000 first preferences, and Kumar was the second most favoured with 2,000. Because, however, first preferences count for the same as third preferences under the Commission's scheme, both are now eliminated. And here we see another capricious paradox of the proposed system. Let us assume that Kumar's supporters gave their fourth preferences to friendly independents, who have all now been eliminated. Similarly, let's assume that most Fiji First voters gave their fourth and later preferences to the Viti Liberal Party or the indigenous Fijian independents. Because both of these groups have also now been eliminated, neither Kumar's nor Jones's votes can be passed on to any continuing candidate. And, because first, second and third preferences have already been aggregated, they cannot 
even be passed on to a running mate. These votes are thus said to 'exhaust', meaning there is no one left in the count to transfer them to. Under a rational preferential vote system, like the Alternative Vote or the Single Transferable Vote, Jones would at least have been able to pass his votes on to his party colleagues Khan or Cama, ensuring that one of them was elected. Under this system, however, these votes are now essentially dead.

There are now four candidates left in the count-Cama with 6,990 , Vuki with 5,810, Singh with 5,292 and Khan with 4,001. Khan is the lowest placed of these and is thus finally eliminated. The final election result is thus Cama elected first, Vuki elected second and Singh elected third. As well as electing the less favoured candidates, it can easily be seen then that the National/Republic Coalition, with only 35 per cent of the vote, was able to gain two-thirds of the seats; the Fiji First Party with 40 per cent of the vote could gain only one, and the overall Fijian majority of electoral support translated into a clear minority of seats. This happened because of the quirks of the preference aggregation system, which counted votes for less popular candidates at the same value as those for more popular candidates. Wily political operators will already have observed the potential for destabilising opposition parties by strategic voting techniques-for instance, instructing your supporters to give their lower preferences to a low-ranked member of an opposition party, thus ensuring that an inferior opposition candidate is elected.

This brief hypothetical example of the system proposed by the CRC should be sufficient to indicate that the aggregation of first, second and third preferences is a questionable practice when applied to a preferential electoral system. It should also demonstrate that the use of a majoritarian system like AV in a multimember context which demands a proportional system is a similarly bad idea. The consequences of such a system can be highly disproportional results-such as the one, in the example above, which gave 67 per cent of the seats to the National/Republican Coalition even though they could only gain 35 per cent of the vote. If replicated in an actual election, this level of disproportionality could well undermine the perceived legitimacy of key institutions of government such as the parliament and the electoral system - the very institutions which most need public support and confidence in Fiji in the years ahead. 


\section{Conclusion}

If the system proposed by the CRC will not produce satisfactory results and promote inter-ethnic accommodation and compromise, then what will? My answer comes straight from the CRC's report, which argued that

the people of Fiji should adopt a voting system that has been used successfully elsewhere, preferably in the region. No unexpected problems would be likely to arise, and there would always be ready access to technical advice and help (Fiji CRC 1996:326).

I strongly concur with these wise words. And, as I have already argued, there is substantial evidence that a preferential electoral system can work to promote inter-ethnic cooperation and harmony, rewarding the centre and promoting broadly-based coalitions. There are two preferential systems with long histories of successful operation: AV in single-member districts, and STV in multimember districts. As the Commission noted, AV in single-member districts is widely used in Australia, at both the federal and state level and, as we have seen, has already been successfully used in Papua New Guinea. STV is used to elect members of the Australian Senate, legislatures in Tasmania and the Australian Capital Territory, and farther afield in Ireland and Malta. I would strongly recommend that the final electoral system chosen for Fiji be one of these two systems.

The choice of which system to adopt comes down to the simple question of whether single-member districts can achieve sufficient diversity in enough electorates to ensure meaningful vote swapping across ethnic group lines, or whether multimember electorates are needed to achieve this. This question was addressed directly by the CRC themselves, who noted the crucial importance of heterogeneous constituencies in facilitating the type of conditions favourable to interethnic vote pooling. The more heterogeneous a constituency, the more likely it is that no one group or party will command an overall majority, and thus the more likely it is that meaningful vote pooling will take place. In most ethnically divided countries, however, members of the same ethnic group tend to cluster together, meaning that the relatively small, single-member districts which are a feature of AV will result in ethnically homogeneous rather than heterogeneous constituencies. The CRC looked at whether, given the distribution of the different communities within the Fiji Islands, it 
would be possible to divide the country into heterogeneous constituencies-that is, one in which there is a reasonable mixture of indigenous Fijians and Indians. They concluded that the choice of 45 single-member or 15 multimember districts 'did not affect the potential for heterogeneity in the more densely-populated areas' but that 'three-member constituencies made it marginally easier to achieve a reasonable degree of heterogeneity' in the less populated areas. They concluded that, for both single and multimember districts, it is 'entirely possible to draw constituency boundaries in Fiji in a way that achieves reasonable heterogeneity' (Fiji CRC 1996:314-15).

If this is correct, then I would recommend the use of singlemember $\mathrm{AV}$, in 45 single-member constituencies. The advantages of this system are clear. It is simple to understand and to operate, it requires an overall majority of support to get elected (thus favouring the political centre and penalising extremes) and, importantly in a rural-based country like Fiji, it enables single-member representation. As the Commission noted, 'voters usually feel strongly that they want to know who their member is and to have access to him or her both individually and as a group with common interests arising from their residence in a particular geographic area' (Fiji CRC 1996:318)a need that, as Joel Barkan has shown, is particularly strongly felt in agrarian societies (Barkan 1995). The other advantage of using AV is that its vote pooling properties work just as well when ethnic divisions transform into other, less destructive cleavages (for example, labour vs capital, for example), as the Commission clearly hopes they will. In this context it is worth noting that, because party support from both major ethnic groups is divided between several parties, even relatively small numbers of one group can present an opportunity for vote pooling. Take, for example, the case of a division in which the population is 80 per cent indigenous Fijian and only 20 per cent Indian. If there is one monolithic Fijian party, then there is no incentive for vote pooling to occur. If, however, there are several parties all bidding for the Fijian vote, as is actually the case in most parts of Fiji, then the majority requirement for election under $A V$ puts the 20 per cent Indian community in a much stronger position, because the Fijian party that gains their support (in the form of second and later preferences) will be more likely to win the seat than others. To do this requires attracting the Indian voters somehow-by 
behaving moderately on ethnic issues, or by offering policy proposals that appeal to the Indian community. Of course, it is also possible to go the other way - for the Fijian parties to 'outbid' each other by being more and more anti-Indian-but such extremism will tend to be punished by AV rather than rewarded. The disadvantages of the system are that, because of the majority threshold, it can underrepresent minor parties and can thus be disproportional-although not as disproportional as the existing First-Past-the-Post system. Overall, the potential of the system for promoting inter-ethnic accommodation would seem to outweigh these drawbacks in the Fijian case.

However, it may be that, contrary to the Commission's expectations, it is not possible to create sufficiently diverse electorates from 45 single-member constituencies. The outer Fijian islands are almost entirely indigenous Fijian, so vote pooling there will have to take place on issues other than ethnic ones, if it takes place at all. The situation on the main islands and in urban centres is more mixed. Some commentators have argued that, even in urban areas, 'ethnic residential self-selectivity' occurs, rendering districts either predominantly Indian or Fijian (Premdas 1995:12). If this means that heterogeneity is impossible in single-member districts, then multimember districts will be necessary. But if multimember districts are necessary, then it is imperative that STV rather than AV be used. STV is similar to AV, but is a system of proportional representation, not a majority system. How proportional it is depends on how many members are chosen. If the Commission's favoured three-member districts are used, then the quota for election is just over 25 per cent, considerably lower than the overall majority required for election under AV. For this reason, the Commission concluded that STV would not work to break down ethnic communal voting to the same extent as AV, as most ethnic groups would be represented in the legislature in the same proportion as their numbers in the general community (Fiji CRC 1996:317). But this only tells half the story. If the hypothetical three-seat election at Table 3.2 had been held under STV rules, for example, the first seat would most likely have gone to the most popular indigenous Fijian supported party, the second to the most popular Indian supported party, and the third seat would most assuredly have been decided on the basis of vote pooling. This would be the case in nearly all three- 
member divisions, provided they were drawn to ensure ethnic heterogeneity. Looked at in this way, a system of 15 three-member constituencies, as proposed by the Commission, would have the advantage of not just encouraging but often requiring vote pooling to take place, at least for the third seat in each district. STV can also be used in two-member districts, where the quota for election becomes quite high-33 per cent-making it more like a majoritarian system than a proportional one. In ethnically mixed constituencies, this would also have the advantage of usually electing one Indian and one Fijian candidate in each district. A further possibility is to use a mixture of single-member seats elected by AV and multimember seats elected by STV, as first recommended by the Street Commission twenty years ago.

So, in conclusion, it seems to me that the two most feasible systems are the ones identified by the Commission itself - but in the form in which they are used elsewhere, rather than the unusual variant proposed by the Commission. Both have their specific advantages-AV is simpler and maintains single-member representation, STV is more complex but also more proportionalbut their similarities outweigh their differences and, in fact, one is a variant of the other. Both have been tried and tested elsewhere. The choice of which electoral system to choose is, of course, ultimately and properly a decision for the Fijian parliament and the Fijian people. I can only conclude by offering the services of International IDEA in this process: as an independent international body established specifically to deal with questions such as these, we would be happy to assist this process in any way we can.

\section{Notes}

1. Notable exceptions include the chapters on electoral systems in two seminal works by Donald L. Horowitz $(1985,1991$ a). See also Sisk (1996).

2. The tiny Pacific micro-state (and former Australian Territory) of Nauru inherited the preferential voting system from Australia but, in a unique departure from the Australian model, combines the preferential counting system with multimember constituencies. Preferences are counted as fractional votes (that is, a second preference is worth half a vote, a third preference is worth a third of a vote and so on). 


\section{References}

Aitkin, D., (ed.), 1985. Survey of Australian Political Science, George Allen and Unwin, Sydney.

Aitkin, D., Jinks, B. and Warhurst, J., 1989. Australian Political Institutions, Longman Cheshire, Melbourne.

Barkan, J., 1995. 'Elections in Agrarian Societies', Journal of Democracy 6(4):106-116.

Bean, C., 1986. 'Electoral law, electoral behaviour and electoral outcomes: Australia and New Zealand compared', The Journal of Commonwealth and Comparative Politics 24(1):57-73.

Bettison, D.G., Hughes, C.A. and van der Veur, P.W. (eds), 1965. The Papua-New Guinea Elections 1964, The Australian National University, Canberra.

Fiji Constitution Review Commission 1996. The Fiji Islands. Towards a United Future, Parliament of Fiji Parliamentary Paper 34 of 1996, Government Printer, Suva.

Dinnen, S., 1996. 'Violence, security and the 1992 election' in Saffu, Y. (ed.), The 1992 PNG Election: change and continuity in electoral politics, Department of Political and Social Change, Research School of Pacific and Asian Studies, The Australian National University, Canberra.

Epstein, A.L., Parker, R.S. and Reay, M. (eds), 1971. The Politics of Dependence: Papua New Guinea 1968, The Australian National University Press, Canberra.

Goot, M., 1985. 'Electoral Systems', in D. Aitkin (ed.), Survey of Australian Political Science, George Allen and Unwin, Sydney: 179-264.

Graham, B.D., 1962. "The choice of voting methods in federal politics, 1902-1918', Australian Journal of Politics and History 8(2):164-79.

Hegarty, D., 1983a. 'The 1977 National Elections in Papua New Guinea-an overview' in D. Hegarty (ed.), Electoral Politics in Papua New Guinea: studies in the 1977 National Elections, University of Papua New Guinea Press, Port Moresby.

Hegarty, D. (ed.), 1983b. Electoral Politics in Papua New Guinea: studies in the 1977 National Elections, University of Papua New Guinea Press, Port Moresby.

Horowitz, D.L., 1985. Ethnic Groups in Conflict, University of California Press, Berkeley. 
Horowitz, D.L., 1991a. A Democratic South Africa? Constitutional Engineering in a Divided Society, University of California Press, Berkeley.

Horowitz, D.L., 1991b. 'Making Moderation Pay: the comparative politics of ethnic conflict management' in J. Montville (ed.), Conflict and Peacemaking in Multiethnic Societies, Lexington Books, New York.

Hughes, C.A., 1990. "The rules of the game' in C. Bean, I. McAllister and J. Warhurst (eds), The Greening of Australian Politics: the 1990 Federal Election, Longman Cheshire, Melbourne.

King, P., (ed), 1989. Pangu Returns to Power: the 1982 elections in Papua New Guinea, Political and Social Change Monograph 9, Department of Political and Social Change, Research School of Pacific Studies, The Australian National University, Canberra.

Lijphart, A., 1991. 'The Alternative Vote: a realistic alternative for South Africa?', Politikon 18(2):91-101.

Oliver, M. (ed.), 1989. Eleksin: the 1987 National Election in Papua New Guinea, University of Papua New Guinea, Port Moresby.

Papadakis, E. and Bean, C., 1995. 'Independents and minor parties: the electoral system', Australian Journal of Political Science (special issue) 30:97-110.

Premdas, R., 1995. Ethnic Conflict and Development: the case of Fiji, Avebury, Aldershot.

Reilly, B., 1996. 'The Effects of the Electoral System in Papua New Guinea' in Saffu, Y. (ed.), The 1992 PNG Election: change and continuity in electoral politics, Department of Political and Social Change, Research School of Pacific and Asian Studies, The Australian National University, Canberra.

Reilly, B., 1997a. 'Preferential voting and political engineering: a comparative study', The Journal of Commonwealth and Comparative Politics 35(1):1-19.

Reilly, B., 1997b. 'The alternative vote and ethnic accommodation: new evidence from Papua New Guinea', Electoral Studies 16(1):1-11.

Reilly, B. and Maley, M., 1996. The Single Transferable Vote and the Alternative Vote Compared, paper presented to conference on 'Elections in Australia, Ireland and Malta under the Single Transferable Vote', organised by the Centre for the Study of Democracy, University of California, Irvine, 14-15 December 1996, unpublished. 
Reynolds, A., 1995. 'Constitutional Engineering in Southern Africa', Journal of Democracy 6(2):86-99.

Saffu, Y., (ed.), 1996. The 1992 PNG Election: change and continuity in electoral politics, Department of Political and Social Change, Research School of Pacific and Asian Studies, The Australian National University, Canberra.

Sartori, G., 1968. 'Political Development and Political Engineering', Public Policy 12:261-98.

Sisk, T., 1996. Power Sharing and International Mediation in Ethnic Conflicts, United States Institute of Peace Press, Washington DC.

Standish, W., 1996. 'Elections in Simbu: towards gunpoint democracy?' in Y. Saffu (ed.), The 1992 PNG Election: change and continuity in electoral politics, Department of Political and Social Change, Research School of Pacific and Asian Studies, Australian National University, Canberra.

Stone, D., (ed.), 1976. Prelude to Self-Government: electoral politics in Papua New Guinea 1972, Research School of Pacific Studies, The Australian National University and University of Papua New Guinea, Canberra and Port Moresby. 


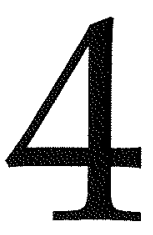

\section{Fiji's proposed new voting system: a critique with counter-proposals}

\section{D.G. Arms}

While the Fiji Constitution Review Commission (henceforth the CRC) has made many excellent recommendations, its proposals for a new electoral system are controversial. If I stress the negative aspects of the CRC's proposals, it is because they tend to vitiate many of the good points made. This chapter will consider in particular

- the problem in principle with the CRC's position

- the need for a transparently fair electoral system

- difficulties with the latter part of Chapter 9 of the CRC's Report, which deals with Parliament

- difficulties with the early part of Chapter 10 of the CRC's Report, which deals with elections

- counterproposals, in particular, the use of the Single Transferable Vote system (henceforth STV) of proportional representation (henceforth PR) for both Houses of Parliament.

\section{A flawed foundation}

The CRC recommends 'that the revised arrangements should be designed in such a way as to meet the following objectives

- they should encourage the emergence of multi-ethnic governments 
- they should comply with the international standards by applying the principle of equal suffrage

- they should be based on a more open system of representation

- they should provide a gradual but decisive means of moving away from the present constitutional arrangements (Fiji CRC 1996:290).

The CRC also states that 'the main thrust of this report is to encourage the emergence of multi-ethnic parties or coalitions' (Fiji CRC 1996:79). We also find the following set of criteria

- encouragement of multi-ethnic government

- recognition of the role of political parties

- incentives for moderation and cooperation across ethnic lines

- effective representation of constituents

- effective voter participation

- effective representation of minority and special interest groups

- fairness between political parties

- effective government

- effective opposition

- proven workability

- legitimacy (Fiji CRC 1996:310).

These objectives and criteria are commendable, but if they are ranked and given precedence over other values, injustices and inconsistencies could flow from them.

In particular, putting 'encouragement of multi-ethnic government' as top priority in choosing an electoral system is against the international standards the CRC says it wishes to uphold. The Universal Declaration of Human Rights provides

The will of the people shall be the basis of the authority of government; this will shall be expressed in periodic and genuine elections which shall be by universal and equal suffrage and shall be held by secret vote or by equivalent free voting procedures (Article 21.3).

However, it cannot be assumed that the will of the people and the CRC's feelings about multi-ethnic government are one and the same. The internal logic of Article 21.3 is that universal suffrage should 
determine the will of the people as accurately and fairly as possible. It implies that one should choose a system where every vote has the same effect. However, for the CRC

The concept of 'equal suffrage' means that, within reasonable limits, every vote is to be given the same weight. It does not imply that every vote must have the same effect in electing members of Parliament. Therefore it does not mandate a particular system for translating votes into seats (Fiji CRC 1996:47).

Thus, the CRC has not put the people first. It has put the encouragement of multi-ethnic government first, the role of political parties second, and incentives for multi-ethnic moderation and cooperation third. The people speak through their votes. No one has the right to try and twist the content of those votes towards a particular objective, no matter how noble that objective may be. If the people opt for mono-ethnic parties rather than multi-ethnic ones, that is their right. The CRC, however, wants to advantage multi-ethnic parties and penalise those which are not. It explicitly opposes PR systems because they are fair to both. It clearly believes the system it advocates will not provide ethnic parties with the representation their support would warrant.

While I would prefer that Fiji's political parties were more multiethnic in composition, there can be no justification for trying to weight the electoral system to achieve this. Ethnically based parties have a right to exist. To advocate a system that will force them into a coalition that will mute their effect, or that will deprive them of their due representation, is a dangerous choice. It tends to force such groups to seek redress outside the democratic system.

If the objective is to penalise ethnically based parties as being 'extremist', other 'extreme' positions too will be forced into coalitions. Not all 'extremists' are bad. Some extreme views fall by the wayside, others end up becoming mainstream positions. For instance, environmentalists and feminists were once regarded as extreme, and possibly still are in Fiji. In many places however, their influence, originally small, has pervaded the political scene. The electoral system is not capable of differentiating between one sort of 'extreme' position and another.

In addition, it may also be unnecessary. It is feasible for a number of mono-ethnic parties to work in a cross-ethnic coalition, and to 
provide the Opposition with a real say in things. The current 'winner-takes-all' is not the only workable model.

The CRC's position regarding ethnically based parties is also inconsistent. The CRC itself recommends ethnically-defined reserved seats in the Lower House, and presumes that some of the presidential appointees in the Upper House will also be selected on an ethnic basis (Fiji CRC 1996:300). In addition, it supports affirmative action on ethnic grounds, for example in Sections 8.68 (Fiji CRC 1996:240) and 8.79 (Fiji CRC 1996:243) and the notion of protected ethnic rights (Fiji CRC 1996:chap 17). In other words, the CRC concedes there are legitimate political interests that may pertain to a particular ethnic group as such.

By its willingness to sacrifice fairness, the CRC may anger those most likely to lose out by the system. And by advocating such a system, the CRC does nothing to allay the fears of many people, especially Fijians. It has allowed a political objective to take precedence over a moral one. How can it then appeal to politicians to take into account the opinion of all groups when considering the Report? Most serious of all, the CRC has unwittingly given a justification for staying with the electoral status quo. If it is alright to be unfair and go against the international instruments for one good purpose (multi-ethnic government), why is it not alright to be unfair and go against the international instruments for another (the progress of the indigenous people)?

\section{Voting systems}

There is more than one 'good' electoral system to choose from, although it is not an unlimited field. We can more easily evaluate the workings of the Alternative Vote system that the CRC recommends if we consider it in relation to other possible voting systems.

\section{First-Past-the-Post}

The system most familiar to Fiji is the First-Past-the-Post (FPP) system. In this system, the candidate who gains the relative majority of votes as between all contenders is declared the winner. In a situation where A gets 40 votes, $B$ gets $35, C$ gets 15 and $D$ gets 10 , candidate $A$ will be declared the winner. In ethnic terms if $B, C$, and $D$ are Fijian parties and $A$ an Indo-Fijian party, $B, C$, and D may prefer that one of themselves be elected, rather than A. However, 
because their supporters have divided their votes among the three parties, and are not reconsulted as to their second choice, none of the three Fijian parties gets their candidate elected. The undivided minority Indo-Fijian party (40 per cent) wins the seat.

When electing a number of people to a body simultaneously, it is better to elect them in groups rather than singly. In multimember constituencies, parties are likely to run a much larger variety of candidates, including women, younger people, and members of ethnic minorities. Wishing to pick up the votes of a wide crosssection of the electorate, they will appeal to many different groups. In single-member constituencies on the other hand, parties tend to run the safest candidates who will appeal only to the largest group, or widest-held viewpoint. Multimember constituencies in a place like Fiji have the other obvious advantage that parties can clearly express, through the range of candidates they run in each constituency, whether they are ethnically based or multi-ethnic.

\section{Multiple Vote}

One system using multimember constituencies is the Multiple Vote (MV), also known as the Block Vote (BV). The rules for such an election are the same as for FPP except that each voter votes for as many candidates as there are places to be filled. It was used in Fiji's national elections under the 1990 Constitution for most Fijian seats. ${ }^{1}$ It is also used for municipal elections. However, the Multiple Vote system is even worse than FPP in the unfair results it usually produces.

Voters nearly always vote for their party candidates as a block. Thus in a three-member constituency, supporters of party A will tick the three candidates of party A, supporters of party B will tick the three candidates of party $B$, and so on. Taking the example above again, party $A$ will win because each of its candidates gets about 40 votes. The other candidates get only about 35 votes (Party B), 15 votes (Party C) or 10 votes (Party D) respectively. The win for Party A, however, no longer consists of just one candidate, but three. With 40 per cent support, Party A takes all three seats and the 60 per cent are left without any representation at all. Even where the winning party has an absolute majority (more than 50 per cent), the system is still unfair, as the minority is without representation. We see this anomaly very clearly in the recent Western Division municipal 
elections where the NFP won all the seats on a few councils. While the NFP may rightly have won a majority, surely residents of other political persuasions deserve to be represented.

So the two systems actually used in Fiji for single-member or multimember constituencies-the FPP and the MV systems respectively-are poor systems. Let us first try to improve on the system for single-member consituencies.

\section{Alternative Vote}

The Alternative Vote system (AV) builds on a notion mentioned above. In the example, supporters of parties B, C, and D-a majority of the voters-would probably have had something more to say if they had been reconsulted. In some countries, for instance in France, voters are literally reconsulted in that a second round of elections is held. This is a costly exercise. However, in the AV system voters can be reconsulted without their having to go a second time to the polls. They indicate their preferences amongst the various candidates by writing 1 beside their first choice, 2 beside their second choice, 3 beside their third choice, and so on.

In tallying the results, the first step is for all the first preferences to be counted. Let us say the results were as discussed above. The next step is to eliminate the candidate with fewest votes-candidate D. The scrutineers in eliminating D reconsult D's supporters, as if asking 'Your candidate doesn't really have much of a chance, so if he or she is out, whom would you like to vote for?' The answer is written as a second preference on those votes. The scrutineers transfer those votes to their second preferences. We will pretend that 5 of D's 10 votes went to $B, 4$ to $C$, and 1 to $A$. The result of the counting at this stage is: A 41, B 40, C 19. Now C, holding fewest votes, has to be eliminated. The scrutineers first look at the second preferences of the 15 votes $C$ first received. If they show a preference for $A$ or $B$, the scrutineers give them to those candidates. If they show a preference for $D$ (who is already eliminated), they look further down the vote to the third preference and assign it accordingly. They also look at the third preferences ${ }^{2}$ of the 4 votes transferred to $C$ in the last round. Let us say C's 19 votes divide up as 3 for $A$ and 16 for $B$. The final results are thus: A 44, B 56. Since 51 is the minimum number of votes a candidate must get to be unbeatable, $B$ is declared the winner. 
The result of the above election is much fairer than the result under FPP. Candidate B enjoys more overall support than candidate A (who only has 44 per cent). True, candidate B was not the first choice of quite a few voters, but that is no reason for saying he or she is not the preferred candidate. If they had wanted $A$, those voters could easily have put $A$ as their second preference. The Alternative Vote is as good a system as there is for electing a single candidate. ${ }^{3}$

If the AV system is so good, need we look any further? The AV system is only good where there is justification for electing a single candidate, such as a committee chairman, a director, a mayor, a president. Where a number of representatives are being elected, the AV system suffers from very similar defects to FPP. All it does is guarantee that for each constituency, at least 50 per cent of the voters support the candidate. This may seem fair, but it is by no means impossible for one party to hold 51 per cent or more of the votes in every constituency. If it did so, this would mean that 49 per cent of the populace would get no representation at all.

Such extreme cases do occur in practice. For instance, in Alberta (Canada) in 1948, Social Credit took a clean sweep of seats with only 58 per cent of the vote. In Victoria (Australia) in 1967, the Liberals received fewer first preferences than Labor, but secured three times as many seats (Lakeman 1970:65). AV allows great imbalances of representation to occur once we move beyond the single vacancy situation. Furthermore, AV is even less fair to minority groups than FPP. Let us say there is an extreme party which can secure between 10 per cent to 20 per cent of the national vote but which is not popular enough to draw many second or third preferences. Some candidate of the party (the leader, say) may be able to muster 40 per cent in his or her constituency, but no more. If the remaining 60 per cent of the vote is divided, then this candidate is likely to get elected under FPP, thus providing this minority party with some representation. Under AV however, this will not happen, as no candidate of the party will be able to draw enough preferences to reach the required 50 per cent. When talking of electing a number of representatives, we have to start thinking in terms of multimember constituencies.

\section{Single Transferable Vote}

Extending the virtues of $\mathrm{AV}$ in single-member constituencies to multimember constituencies is done by the system known as the 
Single Transferable Vote (STV). The principle behind the system is that, as for $\mathrm{AV}$, the winners are the candidates who reach the minimum required to warrant a place. Where there is only one candidate to be elected, as for the AV system, that minimum is 51 per cent of the vote. ${ }^{4}$ Where there are two to be elected, the minimum for election is 34 per cent, because if two people get 34 per cent, no one else can beat them-the most such a challenger can get is 32 per cent. Where there are three to be elected, the minimum for election is 26 per cent, and so on.

The use of this minimum (or 'quota', as it is called) ensures that there will be fair representation of various groups. The voting paper is just like that for the AV system. Voters are asked to give their preferences by writing numbers beside their choices.

Let us look again at the example used earlier where the results of the first count were A 40, B 35, C 15, and D 10. Since there are three places to be filled, the quota is 26 votes. From the first count two candidates are elected immediately: A and B. However, they have more votes than they need. Rather than waste these votes, the system requires them to be transferred to further candidates. A's surplus 14 votes are transferred first. Let us say there are 4 for $C$ and 10 for $D$. The counting now stands at: A 26, B 35, C 19 and D 20. Now B's surplus of 9 votes has to be transferred. Let us say there are 6 for $C$ and 3 for D. The distribution of votes will now stand at: A 26, B 26, C 25 , and D 23. Neither $C$ or $D$ has yet reached the quota of 26 , so the lowest is eliminated. We end up then with $A, B$, and $C$ being elected.

We have here a very fair result-much fairer than the Multiple Vote which gave all three seats to $\mathrm{A}$. We indicated earlier how $\mathrm{A}$ is the minority party, holding only 40 per cent of the votes, and that $B, C$, and $D$ are subdivisions of another viewpoint that holds 60 per cent of the vote. The STV system takes the voters' preferences nicely into account and awards one seat to party $A$, the minority viewpoint, and one seat each to $B$ and $C$, thus giving the majority viewpoint two seats to the minority's one.

\section{Multiple Alternative Vote}

Instead of looking at the 51 per cent required by the AV system as being the minimum required to warrant a place, one can look at it as an absolute majority. One can then extend this concept to require that all candidates in a multimember constituency must get such an 
absolute majority. This is the system the Commissioners have chosen. They call it the Alternative Vote system, but there are at least two ways in which the absolute majority-oriented AV system can been applied to such constituencies: the Multiple Alternative Vote (MAV) and the Repeated Alternative Vote (RAV). One has to conclude from their Recommendation 268a (Fiji CRC 1996: 329) that it is the MAV system that the CRC has in mind.

The CRC's use of the term 'Alternative Vote (AV)' to refer to both the single-member version of $A V$ and the multimember version is confusing. The two systems are very different in their effect. Singlemember AV (hereafter SAV) is a very reputable system, and in certain circumstances the best, whereas multimember AV (whether MAV or $\mathrm{RAV}$ ) is a disreputable system.

Voters in the CRC's MAV system indicate their preferences as they would in SAV, or STV. It is in the counting that the difference lies. Since there are three candidates to be elected, the first three preferences on all votes are counted as effective votes 'the first, second and third preferences given to each candidate should be added together' (Fiji CRC 1996:329). If nobody reaches 51 per cent of the total votes cast, the lowest candidate is eliminated and the total of first three available preferences is again assessed. If somebody is elected, the lowest candidate is likewise eliminated, but all votes are reassessed only as to their first two available preferences-and so on until all three places have been filled. ${ }^{5}$

What is particularly bad about this system is that 51 per cent of the electorate can get all three of their candidates elected, while 49 per cent get none. This is not just a possibility, it is a probability, if voters tend to vote for their party as a block. This feature is not merely understood by the CRC but actively encouraged, as it proposes (Fiji CRC 1996:329) to have an 'above-the-line' (or 'ticket') option on the ballot paper. Instead of writing out all the preferences number by number, voters may just tick the particular order of preferences their chosen party has suggested.

The MAV and MV systems differ from each other in the same way as the SAV and FPP systems. The MAV system (like SAV) requires an absolute majority whereas the MV system (like FPP) requires a relative majority in order to have candidates elected. It can nevertheless be unfair to as much as 49 per cent of the electorate. In our original example when the MV system was applied to it, gave a 
result where party $A$ with 40 per cent of the votes won all three seats. In this MAV system, Party A will not win all three seats, but Party B (or possibly $\mathrm{C}$ or $\mathrm{D}$ or a combination of them) will. This is better in that at least the majority ( 60 per cent) get representation, but it is nevertheless not fair to the 40 per cent who do not get represented at all. The STV system, on the other hand, is fair to both groups.

The MAV system is much more ruthless on the minority than the SAV system (just as the MV system is, compared with the FPP system). MAV constituencies are three times the size of SAV ones. Three SAV constituencies could, for example, have the following divisions of voters: 1) A 60, B 40; 2) A 44, B 56; 3) A 70, B 30 . In this case Party A would win 2 seats, Party B would win 1 . But if these same three constituencies were combined into one MAV constituency, Party A would have 174 votes and Party B 126. Party A would more than likely take all three seats, leaving Party B without any representation.

Thus the two multimember systems MAV and MV are even worse in their effects than the SAV and FPP systems (respectively) when these latter are used for several constituencies. The CRC seems aware of such possible distortions. It reports how in Mauritius no Opposition candidates at all got elected in two national elections (Fiji CRC 1996:285). Mathur's chapter shows how this happened under the Mauritian MV system. It is even more likely to happen under an MAV system, which is even harder on minorities. In spite of this alarming precedent, the $\mathrm{CRC}$ recommends $\mathrm{MAV}$.

\section{Two houses and their seat distribution}

The CRC has also proposed the SAV system for use in the Lower House reserved seats, for the Rotuman seat of the Upper House, for the Presidential team, and for certain positions requiring only one person. As indicated earlier, it is as good a system as there is for filling just one position. It is suitable therefore for the latter tasks, but not for the election of members to the reserved seats of the Lower House. These seats should be filled using a system suitable for multimember constituencies. However, an exception can be made in both Upper and Lower Houses where it is felt that a particular constituency cannot reasonably be multimember. In that case, use of the SAV system is called for. For all multimember constituencies, the STV system is strongly recommended. 


\section{Upper House}

The CRC has proposed that there be an Upper House consisting of 35 members: 28 members representing the 14 provinces (two each), one member representing Rotuma, and six members appointed by the President (Fiji CRC 1996:302). There is a gap, however, in the CRC's explanation of the Upper House electoral system. Each of the 14 provinces is to elect two representatives. But are they to be elected singly, or are they to be elected together treating each province as a two-member constituency? This proposal could be realised by dividing each province into halves except that it is ruled out by paragraph 10.117 (Fiji CRC 1996:331), which says there is no need for boundaries to be set for the Upper House elections.

The CRC states that the revised arrangements...should comply with the international standards by applying the principle of equal suffrage' (Fiji CRC 1996:290). However, it justifies using the provinces as the basis for representation in the Upper House in this way

Where the Upper House is designed to allow the representation of particular territorial units of unequal geographical size and population, there is a recognised freedom to depart from the principle that every vote should be of equal value (Fiji CRC 1996:296).

However the provinces are of very different sizes so the representation will be far from equal, and the arrangement clearly favours Fijians. ${ }^{6}$ There is no need to represent the provinces in this unfair way. In a PR system the provinces could get much more meaningful as well as fair representation-a fact the CRC chooses to ignore. While the CRC supports provincial representation in the Upper House, it is prepared to question it in the Lower House

the use of the provinces as constituencies for the election of the Fijian members...had led to divided loyalties. It was not always clear whether members represented their parties or the Provincial Councils which had often been instrumental in their selection. In addition, the old inter-provincial rivalries had tended to come to the fore, to the detriment of a focus on national issues and interests. For these reasons, we consider that the provinces should no longer be the constituencies for the Fijian reserved seats [in the Lower House] (Fiji CRC 1996:296). 
The CRC fails to point out that, even though more people than Fijians will be electing the Upper House candidates, the same 'divided loyalties' and 'inter-provincial rivalries' will exist and exert their influence.

The main reason for having presidential appointees is the unrepresentative electoral system which the CRC has advocated for both the Upper and Lower Houses. The CRC says 'there should be provision for the appointment to the Bose e Cake [Upper House] of a limited number of members to represent communities and groups that would otherwise be under-represented in Parliament' (Fiji CRC 1996:298). If a PR system were employed, under-representation of smaller groups would be minimal, and occasional. The presidential appointees exist specifically to make up for smaller groups' underrepresentation but cannot be expected to do so adequately or consistently. In addition, there is, obviously, the disadvantage that these representatives are the President's choice, not the choice of the minority groups themselves.

\section{Lower House}

The CRC has suggested that 45 of the total 70 seats of the Lower House be elected on a common roll. This is a major change both from the present and previous electoral systems in Fiji. It is an expression of the idea that all citizens are equal partners in electing the leadership of the country.

The CRC proposes dividing the country into 15 three-member constituencies ( $15 \times 3=45$ seats) with an approximately equal number of constituents in each. It is not possible, however, to do this and retain existing provincial designations as supplied in the Report (Fiji CRC 1996:334). For instance, Bua and Ra are barely half the size of either of the proposed Ba constituencies. Boundaries are going to have to become highly unnatural, not just to get the heterogeneity the Report desires, but to get constituencies of equal size. The Constituency Boundaries Commission (henceforth $\mathrm{CBC}$ ) will have to carve off and reattach segments of provinces in ways that do not reflect people's traditional, social, or political connections.

By not presenting any figures, the CRC avoids confronting the ungainliness of the system it has proposed. For the reserved seats too, there is not enough specificity. The CRC does provide some good 
principles that would help the $\mathrm{CBC}$ in drawing constituency boundaries (Fiji CRC 1996:330-31). However, before agreeing to such a system, politicians would need to have a much clearer idea of how the constituencies would look concretely.

Regrettably, in the case of the 25 reserved seats of the Lower House, the CRC has again built in unfairness. The breakdown of seats is given as: Fijians 12, Indo-Fijians 10, General Voters 2 and Rotumans 1 . However, the ethnic breakdown of possible electors for 1999 (the date of the next regular election) shows percentages of 50.7 per cent, 74.4 per cent, 3.4 per cent, and 1.5 per cent respectively. To get the proper ratio for the 25 communal seats, all one has to do is divide these figures by 4 . This gives $12.7,11.1,0.8$ and 0.4 . The seat ratio therefore should not be $12-10-2-1$, but $12-11-1-1 .^{8}$ The CRC says the following

We consider that the allocation should be based on population figures. Without creating imbalancing, it should also take account of historical and other factors that have affected the present and past allocations of communal seats (Fiji CRC 1996:294).

What the last sentence means in plain English is: 'We will maintain the traditional pro-General-Voter and anti-Indian bias'. Even though the population of Indo-Fijians is projected to drop in the future, that of General Voters are projected to drop even more. In any event, the reserved seats are supposed to be a temporary arrangement.

We must also consider the rationale for the 25 reserved seats that the CRC has proposed as a transitional measure. It is an understandable concession made to help the populace-especially Fijians perhaps-to accept the new arrangements more readily. The CRC is also right in claiming that any more reserved seats would tend to defeat the purpose of the open seats. It must be pointed out, however, that the need to retain any reserved seats at all in the Lower House is brought about by the electoral system the CRC has proposed. If the STV system were employed, such reserved seats would not be necessary. The desired transitional guarantee could be achieved in another and much more reassuring way.

The transitional guarantee I will suggest to go along with STV can be straightforwardly withdrawn when its usefulness has expired. Not so the reserved seats proposed by the CRC. There is the grave 
danger that the transitional arrangements will remain permanent. This is Fiji's experience, with the 1970 arrangements and the shelving of the Street Commission's report. All the more so with the CRC's electoral system, since it will soon be obvious that it does not guarantee fair ethnic representation. It will likely be insisted upon that the reserved seats remain in existence indefinitely so as to give at least some assurance in this regard.

\section{The CRC's electoral system arguments}

Chapter 10 of the CRC's report commences by considering the main kinds of voting system. Its criticism of FPP is accurate, and its claim that $A V$ is a refinement of FPP is true. The CRC argues that 'like PR systems, AV mitigates the winner-take-all aspects of FPP and generally achieves better proportionality of seats to votes than the FPP system' (Fiji CRC 1996:306). However, as I have argued above, when used over a number of constituencies, neither is proportional in effect, nor can they realistically be compared with proportional systems.

The CRC here implicitly acknowledges that proportionality is a desirable object. It does so again when it professes to want a voting system which 'is likely to bring about the representation of different ethnic communities and give them the opportunity to participate in government ${ }^{\prime 10}$ (Fiji CRC 1996:308). By its own admission (Fiji CRC 1996:322) PR systems are superior in this respect to the AV system it recommends. The CRC also points out that South Africa's Constitution requires 'that the electoral system must result, in general, in proportional representation', though details are to be left to national legislation (Fiji CRC 1996:318). Under these circumstances, the CRC should have evaluated PR systems much more fully.

The CRC does not point out that List-system PR is used by many countries, several of which have an excellent history of democracy and some being multi-ethnically constituted. ${ }^{11}$ The CRC does admit that a List-system 'gives better opportunities than most systems to include women and members of minority groups sufficiently high on the list to win a seat' (Fiji CRC 1996:307), but it criticises it for giving too much power to the party and for using constituencies that are too large. These criticisms are true for some types of List-systems, but remedies exist. On this point the CRC says 'Measures to reduce the 
size of the constituency represented through the list, or to open the list to variation by individual voters deprive the system of the simplicity and proportionality it would otherwise have' (Fiji CRC 1996:307). This criticism is not well-founded. Any loss of simplicity or proportionality in such systems is minimal. The only question is where to keep the proportionality more exact-at constituency or national level. From a voter's as well as a scrutineer's point of view, there is nothing in it more complicated than what the CRC itself suggests.

The CRC states that 'under STV, the underlying principle is the distribution of fractions of a single vote' (Fiji CRC 1996:307). This is untrue. The vast majority of votes are not fractionalised at all, but remain with their first preference at full value, or are transferred at full value. The distribution of fractions is in no way 'the underlying principle', and only occurs for some votes. Indeed some versions of the rules do not employ fractions but deal only with whole votes ${ }^{12}$ The underlying principle of the STV system is to make each vote as effective as possible for the highest choice possible as registered on that vote.

\section{The CRC's criteria}

The CRC next goes on to consider the criteria for choosing a voting system in ethnically divided societies. Here I group them together for discussion.

Encouragement of multi-ethnic government; recognition of the role of political parties; incentives for moderation and cooperation across ethnic lines. Being a majority system, MAV, in the CRC's view, will provide an incentive for parties to come together. If they do so, they will be part of the government. If they do not, they will not. But what the CRC does not go on to say is that failure of a party to be part of the government is likely to lead to its being grossly under-represented in the Lower House, or not represented at all. This is certainly a strong incentive to be in the winning team, but will it not drive some politicians to desperate ends? As one renowned electoral expert says

The second ballot and alternative vote are clearly often responsible for unhappy effects on the relations between the parties...[and] may involve party combinations that are quite incongruous and dictated by nothing more than political opportunism (Lakeman 1970:68). 
Fiji has already had experience of incongruous combinations and their effects, such as the Labour Party's support for Major-General Rabuka's prime-ministership in 1992. While this could take place under any electoral system, Fiji's experience should make it wary of adopting a political model which actively encourages deals of this kind. Desperate deals are too easily reneged upon, with consequent accusations of misinterpretation or betrayal, which in turn may even embitter inter-ethnic relations.

The CRC's assumption is that in order to get a majority, parties will run a wider range of candidates, formally unite, enter into coalition, or agree to trade preferences (or even not contest seats), on multi-ethnic grounds. ${ }^{13}$ However, it is important to consider alternative scenarios.

Over the past 30 years, parties could have joined together on multi-ethnic grounds. There was nothing stopping them. Surely we must learn from that experience. The vast majority of people are likely to vote on ethnic grounds. The Fijians do not need the IndoFijians in order to form a government. They form almost 50 per cent of the electorate on their own (Fiji CRC 1996:791). The Rotumans alone would bring the total above 50 per cent-not to mention citizens of Pacific island origin and General Voters, the vast majority of whom have supported Fijians politically over the years.

The MAV system, instead of shutting out some of the more extreme groups in favour of multi-ethnic combinations, may well have the opposite effect of driving the various parties of one ethnicity together (as in 1977 and post-coup 1987). And of course a new voting system is going to make all groups feel threatened until they see how it works. The CRC is aware that an ethnically based party could win the election outright, but points out that Fiji's ethnic groups have factionalised in the past and can be expected to do so again in the future (Fiji CRC 1996:316). But what happens in the meantime? The AV electoral system, which is supposed to promote multi-ethnic government could provide instead a mono-ethnic government and, because of the lopsided nature of the system, could well leave the other major community grossly under-represented. How can this be preferable to PR where, at the very least, ethnic balance will be maintained?

A not unlikely MAV scenario is the re-emergence of an Alliance type mega-party, basically Fijian in composition but with a sprinkling 
of other support, including the odd Indo-Fijian. It would not really be multi-ethnic government any more than was the Alliance party's period of rule from 1970 to 1987. Other parties, mainly Indo-Fijian, would languish in opposition, but because of the extreme unproportionality of the MAV system, their numbers could be very small. The system is likely to maintain the one party in government for a long period-like the Alliance of yore, and like the situation in Malaysia where, as the CRC notes, 'the ruling National Front, formerly known as the Alliance, has been in power since before independence' (Fiji CRC 1996:285). But Fijians should not get too overjoyed at this. Just as the Alliance did eventually lose in Fiji, so any new coalition could ultimately lose. Such loss is likely to be far worse than 1977 or 1987, because at least then, the number of Fijians in the Lower House remained constant. With the MAV system their numbers could drop severely.

It may be felt that I am being unduly pessimistic, but such alternatives must be considered. A new spirit of multi-ethnic cooperation could take hold, and a sincere undertaking to follow the spirit of the Compact could push some major parties in the direction of true multi-ethnic government. But if so, there is no need for the MAV system. If the right spirit is there, a PR system, with all the various groups (including multi-ethnic parties) fairly represented, will produce a government of those parties who are genuinely prepared to work together for this end. PR will produce what might be called a 'love-marriage' of parties freely committing themselves to working together. MAV will produce a 'shotgun-marriage' of parties forced by the system to enter liaisons they are not serious about.

The CRC's explanation of its so-called incentives, though at first sight lengthy (Fiji CRC 1996:315-17), is meagre. The main point from a voter's perspective is that the CRC expects parties to get voters to trade preferences-that is, to give high preferences to this or that party with similar policies. It says 'only moderate parties with conciliatory policies will agree to trade preferences and be able to persuade their supporters to honour the agreement' (Fiji CRC 1996:316), and draws the conclusion that multi-ethnic parties will therefore triumph. But there is no evidence that only moderate parties will agree to trade preferences. Fiji's experience has shown that even unlikely extremes are willing to enter into political deals in pursuit of advantage. ${ }^{14}$ 


\section{The CRC declares}

The overall effect of proportional systems, compared with AV or even FPP, is that, if people vote communally, ethnic parties can expect to succeed in getting a number of candidates elected in proportion to the number of their community members in the constituency, and therefore the country. This is irrespective of whether they are moderate and seek to reach accommodations with the ethnic parties of other communities (Fiji CRC 1996:317).

But surely that is only fair? What better recommendation for PR? The CRC, however, is fully prepared to deprive these parties and their supporters of due representation by using the AV system.

Some supporters of majoritarian systems (such as AV) maintain that what people want when they vote is influence, not representation. Nevertheless, many people vote knowing full well their vote will not elect anybody, and many parties (and candidates) run knowing they will gain no real power even if elected. What such people and parties want is to express their adherence to certain principles, and to be counted.

The electoral system cannot be expected to do everything. The first task is to choose an electoral system that will represent the people fairly according to their wishes-a PR system. The next task is to ensure that these representatives have sufficient by setting up suitable structures for governance. One could have, for example, a Government of National Unity, a formal power-sharing arrangement, a more informal arrangement on Swiss lines, or a GovernmentOpposition model where the Opposition has the means, as well as the clear right and obligation, to contribute constructively to the development of policy. The CRC has opted for the GovernmentOpposition model. While one could question whether this is really the best model for Fiji's circumstances, the CRC has nevertheless made worthwhile suggestions for greater inter-ethnic cooperation. They are not part of the electoral system however, and hence beyond the scope of this chapter. The point to be made, though, is that solutions to the quest for multi-ethnic government can be found outside the electoral system. The electoral system chosen should (unlike the present one) be fully open to such developments. Forcing too many issues into the electoral system corrupts the system itself, and creates as many problems as it solves. 
The CRC's conclusion that 'AV is greatly to be preferred to PR' (Fiji CRC 1996:317) is at variance with the facts. If the CRC's hopes are not realised the results could be disastrous. If the government turns out to be ethnically based and in addition the Lower House has lopsided representation, Fiji's political situation could become very bitter. With PR, however, an ethnically based government would at least be accompanied by fair representation, politically and ethnically. On the other hand, if things worked out for MAV and multi-ethnic government were achieved, the chances are great that they would have worked out just as well under PR. Consideration of Fiji's history is instructive. The Alliance and NFP parties did make some efforts towards multi-ethnicity, and the Bavadra coalition government was a substantial further move towards multi-ethnic government. All Fiji needs is a voting system that, unlike MAV, the 1970 or the 1990 systems, is fair, non-threatening, and responsive to the people's wishes. It is then probable that multi-ethnic government would develop rapidly.

Effective representation of constituents. Although the CRC sets up 'fairness to political parties' as a separate criterion it does not mention 'fairness to voters'. Because the AV system elects people, it does not make them representatives. If 51 per cent of the people can elect all three 'representatives' of a constituency, who represents the other 49 per cent? Where is the 'effective representation'?

The objections made to the List-system by the CRC regarding constituencies (Fiji CRC 1996:318) do not stand up to examination. The objection made to the STV system is also unsound. While the CRC is critical of parliamentarians neglecting parliamentary duties for constituency work, it never takes up the wider question of the accountability of members of Parliament.

The CRC has repeated the stock objection to the STV system without looking at the weighty counter-arguments which have been made. It does not consider, for instance, how party candidates are selected by their parties. Are they selected democratically or not? Is it not often enough the case that an élite group decide on the party candidate, and the 'election' is in fact a matter of 'ratification' by the people of a choice already made? A system like STV re-inserts some democracy into this process of selection. Even where there is a good 
process, it is the MP's task to represent the voters, not just the party faithful, so it is fitting that the voters should have some choice in the matter of who is to be their candidate. What the CRC sees as a fault in STV is in fact a considerable virtue.

Nor does this competition work against a party's interests. Party regulations can keep it within certain bounds. Backbenchers are likely to be all in favour of enabling talent and hard work to triumph over cronyism and élitism within the party. Party leaders see its advantage too as it serves to weed out slackness in the party. True, there may be very able potential MPs who may not be great on the hustings but would be valuable in Parliament. The party would not want to see them eliminated by more 'popular' candidates. Nevertheless, STV does provide some reasonably safe seats where the party can place such people and thus promote their chances of election to Parliament. If even this fails, then it has to be concluded that such talented candidates should be in the civil service, not in politics.

Effective voter participation. A most important consideration under this criterion is whether voters feel their vote will make a difference. The CRC points out that having voters list their preferences, as in $\mathrm{AV}$, gives them a greater chance of affecting the outcome of the poll. It depends on the rules of counting whether one's expressed preferences really have much impact. Whereas the rules of the STV system clearly go out of their way to make people's votes have full and equal effect, the rules of the MAV system frustrate it.

As was shown in the example above, a majority in the electorate can take 60 per cent of the vote leaving the 40 per cent without any representation. In many constituencies it can be obvious which party is going to win by such rules. Many voters may therefore feel that voting is a waste of time, even if they do show up at the polls. This is true for the majority side as well as for the minority. For instance, as many votes are wasted when a candidate gets 75 per cent of the total poll ( 25 per cent more than necessary) as when he or she gets only 25 per cent. In either case the 25 per cent has been ineffective, that is, has not contributed to the election of anybody. The STV system, on the other hand, transfers votes as soon as it is clear that they are not necessary to elect a particular candidate, or that a particular candidate cannot win. 
Allocating surplus votes under STV is indeed a complex procedure not carried out in MAV, but MAV has complexities of its own. Whereas in STV each count consists of transferring the ballot papers of just one candidate, in MAV each count requires the rechecking of all ballot papers (or an extremely complex sorting of them in the first instance).

Most of the discussion under voter participation is given to providing details as to how the voter fills out the ballot paper. ${ }^{15} \mathrm{~A}$ negative feature here is that the CRC provides an 'above the line' (or 'ticket') option. This should not be allowed in either the AV or STV systems. First, when one objective is to keep the ballot paper simple, the 'ticket' serves to needlessly complicate it. Second (and more seriously), it is a deliberate attempt to frustrate the very purpose for which the AV and STV system were devised: to encourage people to make responsible individual choices.

\section{Effective representation of minority and special interest groups} and fairness between political parties. The CRC candidly admits that 'AV does not have the same capacity as proportional systems to secure the election of representatives of every group in the country which chooses to organise politically and can win a minimum share of the votes', but goes on to argue that 'the need for a candidate to achieve an absolute majority means that no candidate can afford to neglect any small pocket of voters. Just as AV encourages appeals across ethnic lines, so also it encourages appeals to women and to minorities with special interests' (Fiji CRC 1996:322). These latter assertions are unsubstantiated. SAV has been used in Australia for some time but has shown no special merits that benefit 'women or minorities with special interests'. Nor is it likely to even in theory, as it is by definition a majoritarian system. When a majority and minority viewpoint conflict, politicians will simply discard the minority one. If a particular minority group has backed the losing side, it can miss out on any representation. If it has backed the winning side, some accommodation to its interests may indeed be made-but no more than, and probably not as much as, could be achieved by a post-election coalition. This is true also for MAV. A minority person may indeed get elected within a party, but the overall benefits will be no more substantial than for SAV. In addition, the MAV system actually works against minority parties-to the extent that it is called 'perverse' by Newland (1982:31). 
In order to work towards gaining a majority or at least to gain some representation, two minorities, $A$ and $B$, may negotiate a compromise and enter some sort of coalition. The problem then is that neither of the two valid viewpoints may get representation, but only some sort of middle ground which the voters may not be very happy about, but which is the only viewpoint on offer. Because the agreements are made pre-election, no one really knows the breakdown of support for viewpoint $A$ versus viewpoint $B$.

The problem for the CRC, however, is not just one of generating a multi-ethnic government. They strongly desire a version of the twoparty system (Fiji CRC 1996:322). An alternative and much more democratic view is one that provides the people with the choice of whether or not they want a two-party style parliament.

A PR system handles both pre and post-election coalitions well. It puts in place representatives who have the people's mandate to do what is necessary to govern for the good of the country. Both STV and List-system PR have provided majority governments frequently enough. What PR does not do is artificially create a majority government where there is not true majority support, which is what the AV system often does.

The CRC maintains that 'it would be virtually impossible for a party to win an election without obtaining a majority of the overall votes' (Fiji CRC 1996:323). However, in Australia in 1954, 1961 and 1969 (using SAV), the Liberals won the election though polling fewer votes than Labor.

A worrying factor is the role of the Constituency Boundaries Commission ( $\mathrm{CBC}$ ). What principles will be used? Will the CBC take its lead from the CRC and draw boundaries that will disadvantage ethnic parties? For instance, by splitting off parts of a province like Rewa, they could divide Nationalist support among a number of constituencies and thus bring about the defeat of the Nationalists at the polls. That would be unfair, but if unfairness is a 'small price to pay' (Fiji CRC 1996:324) for the CRC, why not for the CBC?

Fijians being the majority population, the $\mathrm{CBC}$ can be expected to try to design constituencies so that a majority of Fijians will win in the MAV seats. If we look at Table B of the Report (Fiji CRC 1996:791), the comparative percentages of electors can be summarised as follows: Fijians plus all others 55.6 per cent, IndoFijians 44.4 per cent. This means that Fijians plus all others should 
get 25 of the 45 seats available, and Indo-Fijians 20, (if the voting remains ethnic, as it almost certainly will for some time). ${ }^{16}$

This way of thinking is against the multi-ethnic concept the CRC is trying to develop. But you can be sure that the CRC has not neglected-nor will the $\mathrm{CBC}$, the political parties, or the people neglect-to look at how the seats are likely to divide up ethnically. If then, 25-20 is a fair distribution of seats as between Fijians and IndoFijians, the total Lower House ethnic composition will likely be: Fijians 37, Indo-Fijians 30, General Voters 2 and Rotumans $1 .{ }^{17}$ This looks to be a tidy enough victory for the Fijian group. If the General Voters and Rotumans side with them as they have to date, the balance in the House would be 40-30. Indo-Fijians would hardly feel aggrieved as their representation would certainly be fairer than at any stage heretofore.

But consider if just one open constituency changes hands in an ethnically based election. The Lower House ratio then becomes 37-33 rather than 40-30 (for, because of the MAV system, the high probability is that all 3 seats will change hands, not just 1 or 2 ). If two constituencies change hands (as in 1987), the ratio becomes 34-36. How acceptable will this sort of scenario be to many Fijians, and indeed to the $\mathrm{CBC}$ ? Could there not be an effort to further strengthen the Fijian position? But if this is done by designing another constituency in their favour, the Lower House ratio will likely become 43--27.

Let us say, however, that multi-ethnic parties are formed. What would the ethnic breakdown likely be then? Well first, if the populace rejects the multi-ethnic concept and split their votes to vote ethnically, the result will be the same as above. If on the other hand they accept it and vote according to the party slate, the situation will nevertheless be very similar. The constituencies being three-member ones, the constituency slates for such multi-ethnic parties will almost all be of the form: one Fijian, one Indo-Fijian, and one extra-the extra most likely being a Fijian or Indo-Fijian depending on which ethnic group is preponderant in the electorate. ${ }^{18}$ The CBC's balancing act will thus be quite similar to that described above. Instead of working in threes, however, it will need to compute the proper ratio for each ethnic group as derived from a mixture of ones and twos.

A particular difficulty will arise if the main electoral division is between a multi-ethnic party and an ethnically based party, 
especially if it turns out that the multi-ethnic party is supported much more seriously by one ethnic group rather than the other. The result will be that the 'more tolerant' ethnic group will have considerably less representation than its numbers warrant. If the multi-ethnic party lost the election, this would be a death-knell for that party, and politics would revert to being ethnically based. If it won the election, the disproportions could nevertheless have a negative effect. The 'more tolerant' ethnic group could well have a majority in the governing multi-ethnic party, but a minority in the Lower House. Resentment could rise as this ethnic group is numerically dominated not just in the Lower House itself, but in Sector Standing Commmittees and so on. This problem could arise, of course, under any voting system, but its effects could be much more sharply felt under MAV, since, unlike a PR system, it can notably distort ethnic proportions.

No matter what the scenario, it seems the $\mathrm{CBC}$ is expected to gerrymander the constituencies to better facilitate a multi-ethnic result. The Commissioners themselves say

The design of constituencies deliberately to improve the chances of success of a particular party, or to exclude the effective representation of a particular community is widely condemned as 'gerrymandering'. But it is wrong to suppose that constituency design cannot also be a legitimate element of a voting system specially in an ethnically diverse society. Everything depends on the purpose for which constituencies are designed in a particular way (Fiji CRC 1996:313).

The argument here seems designed to justify gerrymandering. But it is wrong to gerrymander ${ }^{19}$ and that is explicitly what the Commissioners have advocated by - to requote the above words'deliberately improving the chances of success' of multi-ethnic parties (to the detriment of ethnic ones) and 'excluding the effective representation of a particular community' (indeed more than one) (See Fiji CRC 1996: 317, para 10.62), 322, paras 10.81 and 10.82, 323, para 10.86 , and 324 , para 10.88 ).

The whole question of heterogeneous constituencies is overplayed. The CRC is prepared to tolerate an ethnic imbalance of up to 90 per cent to 10 per cent (Fiji CRC 1996:315, para 10.51). How heterogeneous is that? Even constituencies with a ratio as low as 60 per cent to 40 per cent are hardly likely to generate, of themselves, much cross-ethnic appeal. On the other hand, constituencies that are 
divided about 50 per cent to 50 per cent, while looking the fairest, can under the AV system be the most dangerous of all. If all constituencies were divided such that Fijians had the national average of about 52 per cent, ${ }^{20}$ they could not only win the election, but take all 45 seats! If, however, due to inclement weather or acute political apathy a good number of Fijians failed to vote, they could likewise lose, not just a few seats, but all 45 .

Of course, the constituencies will not be so evenly divided, but the fact is the division will depend on the $\mathrm{CBC}$, and anywhere between the extremes is a possibility. Furthermore, with even just a few 50 per cent to 50 per cent constituencies in existence, the potential is there for a huge switching of power (ethnically and/or politically) on the basis of just a small swing of votes. If on the other hand the $\mathrm{CBC}$ designs most of the constituencies so as to be ethnically lopsided (say 60 per cent to 40 per cent or more), many voters are likely to lose interest in elections, in the valid belief that their vote is not going to matter much. There is the problem too of trying to design constituencies for multi-ethnic parties in such a way that if the parties go mono-ethnic instead, the national ethnic ratio will not be too distorted. ${ }^{21}$

In effect the $C B C$ is a team of three people which will decide the composition of the Government. In a PR system on the other hand, the degree of support for the various parties is tied strictly to what the voters have expressed. It does not depend on electoral boundaries. PR provides virtual certainty that in an election where ethnic considerations will be very high, the ethnic proportions in Parliament will be fair. If it were used for the suggested 45 seats with the parties ethnically based, one could confidently predict there would be a $25-20$ divide (give or take one or two seats) between the two major communities regardless of their party affiliation. If the parties were multi-ethnically based, the divide might be a little less exact-perhaps out of balance by another seat or two, but nowhere near as unpredictable as with AV.

Even if the CBC gets the ethnic part right and provides an ethnically balanced parliament, the AV system can still give extraordinary political results. By gerrymandering constituencies, the $\mathrm{CBC}$ might be able to get the ethnic mix it wants, but it will not be able at the same time to guarantee a fair party mix. Even if the AV system yields a multi-ethnic government, Fiji could end up with a 
politically lopsided Lower House. One multi-ethnic party could win all the seats, perhaps with a slim majority of the votes, while other parties could win none at all, even though holding 49 per cent of the vote! The range of percentages and the way they work-discussed above mainly for ethnicity-apply in the same way to parties representing other social or ideological interests.

Effective government and effective opposition. It is not necessary to have an official Opposition..$^{22}$ Fiji could operate on a 'Government of National Unity', for example. The idea that government by a party holding a majority is more effective than one, say, formed by a post-election coalition is also unproven.

Government and Opposition will be effective if the people elect good people to the posts, and provided the structures of government are well organised. The former, one must leave to the decision of the people. The latter is something for which the CRC can make, and has made, very useful suggestions, but it is outside the electoral system.

Proven workability. This criterion is interpreted very narrowly to mean that the system has in fact been used somewhere. The CRC mentions the use of 'multimember constituencies in Nauru' (Fiji CRC 1996:326) but does not follow it up. The CRC also mentions that MAV was used in the Australian Senate from 1919 to 1946. It was a dismal failure. It has not been used elsewhere for national elections and has no proven suitability for promoting multi-ethnic governments.

Legitimacy. This criterion serves as a good heading under which to summarise my very strong objections to the CRC's proposed system. It is not a legitimate system because

- its basis is objectively and ethically unsound. An electoral system is meant primarily to ascertain the will of the people, not produce willy-nilly a multi-ethnic government. To distort the people's will so as to achieve a particular end is unethical.

- the system itself is clearly unfair. Up to 49 per cent of the people may remain totally unrepresented. This unfairness also leads to instability, since just a small swing in votes can achieve a large transfer of power.

- the system is totally untested in multi-ethnic situations, has been used very little generally, and even then with poor results. It is quite inappropriate to propose a system of such dubious record for Fiji's problematic situation. 
- the system has not been well argued. In discussing AV and other systems, the CRC has made errors of fact and judgement. An AV election could have a totally different outcome from what the CRC hopes for a multi-ethnic government. Even should those hopes be realised, the system could be disastrous in effect, leaving a large group grossly unrepresented.

\section{Counterproposals-the STV system}

In view of my very negative assessment of the CRC's electoral proposals, it would be desirable for this chapter to make some positive suggestions. The CRC has said that its entire Report needs to be read as a whole if it is to be understood properly. This is because many of its parts are dependent on one another, and because what is said in one place helps to explain what is said in another. It does not mean, however, that the Report must be accepted as a whole.

Choosing a suitable voting system is a vital part of the whole Constitution Review. Nevertheless, replacing the CRC's system, whether partially or totally, does not mean that its entire Report is put in doubt. On the contrary, so much of it is excellent. Furthermore, there is a lot of material in the Report which actually provides the basis for choosing a different electoral system from the one the CRC has proposed. Changing the CRC's system can be seen as a modification or development of the Report, not so much a contradiction of it. I propose that a system of PR, and specifically the STV system, be used for government elections in Fiji. ${ }^{23}$ The main advantages of this system can be summarised under the following headings.

\section{The will of the people and neutrality}

The STV system is a neutral system that strives to reflect as impartially and as accurately as possible the will of the people. Being a preferential system, it allows people to express and nuance their will fully. It provides voters with a variety of options (including ethnic ones) while in no way pushing them one way or the other.

This last point has particular relevance for multi-ethnicity. AV allows one to express preferences in an identical way to STV, but since the quota for election is so high (51 per cent), a much greater percentage of voters are pushed away from their first, second or even third preferences before any candidate reaches the required total. By 
having a lower quota for election (26 per cent for a three-member constituency) the STV makes it easier for voters to get somebody they really want elected. This, of course, is of great benefit to minorities who can thus get separate representation if they so wish. Genuine majorities do not suffer, as two or three of their candidates may reach the 26 per cent quota and thus get elected. Where the party is multi-ethnic, the votes of some voters may well contribute to electing a candidate of different ethnicity from their own. Where the party is not multi-ethnic, the voter may nevertheless have been prepared to give some later preference to a candidate of different ethnicity. Having got a candidate elected of the voter's own ethnicity (or having had him or her eliminated if he or she could not make the 26 per cent), the voter may in fact help someone of a different ethnicity by this later preference.

Obviously, one wants to use the higher preferences of voters as much as possible, not the lower, if one is serious about seeking the will of the people. There is little point in having a great range of choice if in fact the voter's preferred choices are bypassed. This is what tends to happen in AV. Note, for instance, that in order to reasonably guarantee a clear election result, the $C R C$ requires voters to fill in 75 per cent of the preferences on their AV ballot papers (Fiji CRC 1996:319). This is because the AV system brings it about that a substantial number of voters have their votes utilised for candidates who are very low preferences for them. The STV system, on the other hand, leaves people free to enter as many or as few preferences as they like, since in STV the lower preferences come into play only for a few ballot papers. Clearly, STV enables people's votes to be used more faithfully according to their wishes.

\section{Fairness and proportionality}

To truly respect all people equally, every body of opinion must be allowed to play its part. It follows that every body of opinion should be given due representation according to the number of people who support it - that is, there should be Proportional Representation (PR). This seems so obviously fair that some find it hard to understand how people can really be opposed to PR. The reason for their opposition usually lies in their own political agenda. They are not in accord, perhaps, with the presumed political consequences of a PR system. They concede it may be fair to have all viewpoints 
represented, but having all these differing viewpoints clamouring for a say, will, they reckon, lead to indecisive and unstable government. PR has, however, been around for a long time and in many countries. There is no general tendency in these countries towards stalemate or instability. Even if there were, such a negative feature would still need to be measured against the negative features of an unjust and unrepresentative system.

The problem lies not in the electoral system, but in the style of governance. A system of government that presumes on a majority taking all power and doing as it likes with it, will naturally be wary of a PR system. Basic fairness requires that even smaller parties be allotted their due proportion of seats. One sometimes hears people proclaiming the virtues of $P R$, but then trying to cut back on the proportional principle for smaller parties by setting a minimum threshold in order to exclude them. The argument is that smaller parties are bad for politics: the political system gets too fragmented leading to instability and ineffective government.

The case against small parties is grossly exaggerated. The classic example given is that of a hung government which can swing this way or that on the the discretion of an Independent MP. This one parliamentarian is regarded as wielding too much power. But his or her vote has no more power than anyone else's. What has happened is that the other MPs have abdicated their duty of making a responsible choice and are simply towing a party or ideological line. Any one of them could have as much power as the Independent MP but they have abdicated their freedom to do so-quite often under party duress.

The inordinate fear of Independents and of smaller parties stems from subservience to majoritarianism. ${ }^{24}$ The target is seen to be a 51 per cent vote in Parliament. Independents and small parties are seen as making this target more difficult to achieve. But concern for the whole community would surely demand that a sincere effort be made to appeal to more than just 51 per cent.

\section{Accountability and responsibility}

If the will of the people is so important, there needs to be a means whereby the elected representatives can be held accountable to their electorates. The constituency is the place where this accountability resides. The CRC asserts the importance of the constituency, but is 
critical of the fact that regional interests can interfere with national ones. Representatives, however, should have the freedom to represent local interests. Contrary to what the CRC implies in paragraph 9.170 (Fiji CRC 1996:296), it is not desirable to blur traditional boundaries to provide nondescript constituencies that have no natural cohesive principle. Feeling that a representative is one's own, and accountability to the electorate, are much more easily accomplished when the electoral constituencies stick to natural or traditional boundaries. This is what STV (as a PR system) does, and where it is so superior to a system like AV. Variations in constituency size are taken care of by having a different number of representatives elected according to the size of the constituency. Under PR this works out fairly. Under other systems it does not.

It may be felt that larger constituencies will make things too impersonal. It requires only straightforward decisions by the $\mathrm{CBC}$ to decide which geographical divisions need be constituted as threemember constituencies (because of their far-flung nature), and which should be seven-member (because of their high concentration of population). Modern transport should enable candidates to visit all parts of their constituencies as desired. Having more than one representative is a distinct advantage to electors as they can go to the one they feel will be most responsive to their needs, whether because of personal charisma or a party affiliation.

\section{Effective votes and effective choice}

A very important facet of a voting system is to ensure that people's votes do, as far as possible, contribute equally and meaningfully to the election. The STV system has very little vote wastage. What is more, all votes in the system have equal weight. It is the most effective system in terms of respecting the voters' expressed choices, and provides a wide range of choices in the first place. By having the vote transferable, voters can indicate their will in a very complete way. If a party is what is important to them, they can give all their top preferences to the members of that party. By putting them in order, they show which of them they prefer. If ethnic background is what is important, they can vote for people of one ethnic background. If religion, they can vote for co-religionists. If a particular issue (for example women's rights, a nuclear-free Pacific), they can vote for supporters of this position. When all these concerns 
are mixed up together, STV is better than any other system in the cross-section of representation it provides.

Of course, voters vote for their choices in several electoral systems. Where the vote is non-transferable, if that person misses out, the vote is 'wasted'. Even if it is transferable as in AV, the vote may well be wasted as the candidates are unnecessarily required to get 51 per cent instead of a lower figure, and thus many voters will have their votes end up electing nobody. Furthermore, even if a voter's choice is elected, such a vote may be wasted as the candidate may have many more votes than really needed. The STV system gets over both these drawbacks by having the vote transferable and by having a low quota (not an absolute majority). If one's first choice is out, the vote moves on to the next choice (as in AV). If one's first choice is already elected and does not need the vote, the vote likewise moves on (which does not happen in AV) and is not 'wasted' on that candidate (which it is in AV). As a result, a very large percentage of the electorate has their votes contribute to the electing of someone they are happy about. For the majority party each vote is vital because it may lead to a clean sweep for the party. For the minority party it is no less vital, for, the system not being winnertakes-all, the minority party may get one of the seats if it has sufficient support.

Nevertheless, the STV system does not force the voter to vote in party terms. A person's vote is not counted towards a party total as in List-systems of PR. For very many people party considerations are uppermost, but those with a different approach should be free to express it. The STV is undoubtedly superior in the freedom it gives in this respect. The voters have a single vote, but they can direct it to have maximum effect according to their will. Parties having nothing to lose from this. The fact that some voters are not committed to a particular party means that the party will lose those voters' support even as early as the second preference, but the party will also pick up as much support in the same way.

Integration and consociation. A final important attribute of a good voting system, especially in a multi-ethnic country like Fiji, is that it generates consciousness among the people that they are voting together as citizens of one country. It should facilitate the various political, cultural, religious, and other groupings in their deciding together on national leadership. There are two approaches to this 
problem: the integrative approach and the consociational approach (Sisk 1996:34-45). The integrative approach tends to bring groups together by blending them, by mixing individuals together from different groups, or by forming new joint groups. The consociational approach tends to retain the separate identity of groups, but encourages them to respect each other and to work together. Both of these approaches can be positive, but care must be taken also against their excesses. The bad side of integration can be a tendency towards uniformity, the smothering of valuable distinctions, and preoccupation with the whole. The bad side of consociation can be a tendency towards divisiveness, a failure to appreciate what is held in common, and preoccupation with the communal unit. The electoral system needs to be one that is fully open to the positive dimensions of both approaches. It must help generate unity in diversity, giving the people the facility to decide in what areas they will integrate, in what areas they will consociate, and to what degree.

Any system where the voters make only one entry is not likely to do this. It is all too easy for the voters to simply vote for the knownfor their own group, or traditional candidate. A system, however, where the voters make a number of meaningful entries as in STV (though AV likewise does this), stimulates voters to think outside predetermined categories and to consider the merits of candidates that may be quite distantly removed from their spontaneous choice. This can only contribute to greater bonding and understanding between Fiji's different groups as well as to more informed voting habits.

\section{Basis for STV in the CRC's report}

There is material in the CRC's Report which provides a good basis for choosing the STV system. In considering its objectives, the CRC pointed out that 'there are two schools of thought about the best way of encouraging moderation and cooperation across ethnic lines'. It continued: 'One view is that, in order to come together in stable multi-ethnic coalitions or perhaps a multi-ethnic party with broadlybased support, political parties must have strong electoral incentives to take real account of the interests of other communities' (Fiji CRC 1996:311). This is one form of the integrative approach. But as I have shown at length, the particular way the CRC applies this approach is unsound. 
The STV system is, I believe, an ideal voting system for Fiji as it incorporates both the integrative and consociational approaches, and will allow the future development of these approaches in the way and at the pace the people and their politicians want. Much of what the CRC says about making cross-ethnic appeals and trading preferences (Fiji CRC 1996:311) applies perfectly well to STV. At the same time, STV makes good and fair provision for those groups that want separate representation.

The CRC is also of the view that it is desirable to maintain a uniform electoral system for all government elections' (Fiji CRC 1996:633). ${ }^{25}$ If the STV system of PR is chosen for Fiji, this condition is still fulfilled. Firstly, STV and AV are both 'preferential' systems. Indeed, STV and MAV are both daughters of SAV. This can be put the other way round. STV and MAV are both typically thought of as systems for multimember constituencies. When their respective rules are applied in single-member constituencies, however, they have identical effect. In other words, the STV for a single-member constituency and the SAV system are one and the same. It would be thoroughly advantageous, then, for STV to be used for all government elections in Fiji. Whether one-member, two-member, three-member or multimember constituencies are involved, the ballot papers are the same, as are the rules for counting. Government elections in Fiji would thus be uniform.

There are other features of the CRC's proposals that STV promotes. For example, the CRC recommended multimember constituencies. Though I have shown that these work disastrously under MAV, they are a very positive dimension of STV.

\section{Drawbacks to STV}

Before concluding, it would be well to consider some of the possible drawbacks to STV, both real and imagined. It can occasionally happen under the STV system that a party or grouping (of any size) gets less than its due proportion. This is because there is a slight wastage of votes in each constituency. For instance, if there are five representatives being elected, five-sixths of the vote in that constituency will have elected them. The other sixth may be quite happy with those representatives. On the other hand, they may not. In any election of course, some voters will be disappointed. But if the people in each constituency who miss out on their choice (under a 
sixth, on average) all belong to the same party or grouping, then some disproportion can creep into the representation.

The problem here is akin to the problem in FPP, SAV, or MAV constituencies. It was pointed out that in these systems up to 49 per cent of the electorate (more in the case of FPP) may have no representation at all due to the fact that the same party can be winning in all constituencies. That can happen too for STV, but in this case the maximum amount of distortion is only 16 per cent, ${ }^{26}$ not 49 per cent. It is also much rarer in STV that that maximum would be realised, because usually a good number of the 'wasted' votes-those not resting with an elected candidate-have been moved on from a higher preference candidate who has been elected. Such voters, then, will not be unrepresented.

It is a defect which occurs comparatively rarely. It occurs more frequently and in a much worse form in the AV (and FPP) systems. Some List-systems of PR overcome the problem altogether but unfortunately have defects of their own.

Other 'defects' of the STV system are hardly real defects at all. We have already discussed the matter of candidates of the same party competing with one another. We also briefly considered the complexity of counting. As the CRC said for the AV system: 'Voters do not need to concern themselves with the mechanics of counting and distributing the preferences... We foresee no great difficulty in training the requisite number of electoral officers' (Fiji CRC 1996:2022). The principles of STV are clear and recommend themselves to the voter as being fair. This, plus an easy-to-fill-in ballot paper, are all that is required. There is the problem of non-transferable votes (votes that are in some way incomplete), but methods have been found to handle these fairly. The accusation that STV brings about too many coalition governments is also unfounded.

One alleged defect is that STV provides only a single vote. It does not allow voters to vote for more than one person at once, thereby restricting them to one choice out of many, and not allowing them to vote for two or more candidates whom they actually support. What is more, a system that allows a multiple vote will better allow people with multi-ethnic interests to show that on the ballot paper. However, by being preferential systems, both STV and AV do allow multiethnic interests to be indicated. The idea of voting is to have one's will taken due note of. While MV and MAV give a voter more than 
one vote, the end result of these extra votes is that some voters are notably over-represented and others notably under-represented. By restricting everybody to just one vote, but making it preferential, STV ensures that as many people as possible get represented and also that they get represented by the person they want. Some List-systems of PR that provide a multiple vote do not misrepresent the electorate like MV or MAV, but they fail in this latter point. Voters' ability to elect a particular candidate from the list, and to register their opinion about issues across party lines, is most uncertain.

One further genuine defect of STV, however, is the fact that at various stages of the election the lowest candidate is eliminated. This may seem fair enough, but it could happen, for instance, that a person who got practically nobody's first preferences was everybody's second preference, yet would be eliminated before this fact would emerge. In practice, however, this problem is of rare occurrence and is generally felt to be a very tolerable one. AV, obviously, has the same problem. While other systems do not, this is not to their advantage. The only reason they do not is that they do not go as far as the STV and AV systems in trying to find out the voter's will.

\section{Conclusion}

The electoral system recommended by the CRC is seriously defective. The STV system is demonstrably far superior to it. What defects the STV system has are very minor, especially when compared with the defects of the 1970,1990, or the CRC's systems. STV builds on much of what the CRC itself has proposed. Furthermore, it was also advocated for open seats by the Street Commission, using excellent argumentation. STV is a transparently fair system which would operate very well in a multi-ethnic country like Fiji. It is a system that demonstrably seeks out and respects the people's will. Fiji's people deserve that much.

\section{Notes}

1. It is not done for the Indian or General Voter seats-a further unfair differentiation that has been little commented on.

2. Third preferences, because those 4 votes have already had both their first and second preferences considered but excluded. 
3. A contender for serious consideration along with $\mathrm{AV}$ is the Condorcet system, (Newland 1982:15-8).

4. Strictly speaking, all that is required is more than 50 per cent, not 51 per cent. The figure 51 per cent (and other approximate percentages) will be used throughout the paper for ease of reference.

5. Fuller details of counting, including a sample count, can be found in Newland (1982:31). See also Ben Reilly's chapter in this volume.

6. This is in fact admitted by the CRC in 9.180 (Fiji CRC 1996:299).

7. This figure is gained by summing the totals for Fijians and Other Pacific Islanders in Table B of the Report (Fiji CRC 1996:791). The $\mathrm{CRC}$ proposes that these groups be joined together for purposes of voting.

8. Strictly speaking, the Fijians are more entitled to an extra seat than the Rotumans are entitled to even one! It does seem fitting, though, that if there is insistence that the Rotumans be given a separate seat, the 'cost' would be borne mainly by the Fijians. Both are indigenous peoples and have tended to support each other strongly politically; furthermore the Fijians do not have sufficient numbers to warrant a thirteenth seat as of absolute right.

9. This may seem a harsh criticism for the misallotment of just one seat, but in politics-as the CRC well knows-every seat is important.

10. Note, however, that it is not a mere 'opportunity' that's involved here, but a right: 'Everyone has the right to take part in the government of his country, directly or through freely chosen representatives' (Universal Declaration of Human Rights Act 21/ 1). Nor does $A V$ promote 'freely chosen representatives' when it pressures voters to vote for some larger party that may (or may not) take care of their interests rather than enable them to elect the representatives they really want.

11. The following are just some of the countries that use List systems. Those in bold print are multi-ethnic-Argentina, Austria, Belgium, Brazil, Costa Rica, Denmark, Finland, Israel, Netherlands, Norway, Spain, Sweden, Switzerland, Turkey.

12. Such versions of STV are not as accurate as those employing fractions, but are still fairer than most other voting systems. 
13. These 'incentives' are in fact but a linear progression of just one incentive: parties must strive to be in the majority group (ultimately the government) and voters likewise must vote for such conglomerates; otherwise parties and voters risk being grossly unrepresented!

14. Two examples are the agreement between Major-General Rabuka and the Labour Party already mentioned above, and the fact that Ratu Mosese Tuisawau and Sakeasi Butadroka ran on the same Rewa ticket in 1992.

15. The presentation is clear and user-friendly, but there is no comparable explanation of the AV system itself, especially the MAV version. Many readers of the Report will not fathom how the system works.

16. Traditionally, the 'all others' group has tended to side with the Fijians politically, but it would be unfair to claim that all have. It could be claimed that the fairest distribution would be: 24 for Fijians and others, 21 for Indo-Fijians and others. This would make it easier for the $\mathrm{CBC}$ to plan an electoral outcome where parties remained ethnically based, as the constituencies are threemember ones and it would be difficult to set up a 25-20 situation, such numbers not being divisible by three.

17. This total is gained by adding together the communal (SAV) and open (MAV) seats. There is always the possibility, of course, that a General Voter or Rotuman might win one of the open seats as well.

18. In one or even two constituencies, a General Voter or Rotuman might take the third spot.

19. The Pocket Oxford Dictionary defines 'gerrymander' as 'manipulate boundaries of (constituency etc.) so as to give undue influence to some party or class'.

20. This percentage would included Rotumans and Pacific islanders.

21. This will be a most daunting task, since the $C B C$ will have to draw up the constituencies before party alignments and voting patterns develop.

22. Indeed the MAV system could result in no Opposition being elected, just as the MV system has done in Mauritius.

23. In an earlier version of this paper, I also proposed a List-system as a possible (though less preferred) alternative, providing much 
detail as to how it could be fairly applied in Fiji even using small multimember constituencies ( 3 to 7 people). This material has been omitted from this version of the paper both for reasons of space and because a List-system is, at this juncture at least, much less likely to be seriously considered than STV.

24. Having said that, it must not be thought that PR invariably proliferates Independents and small parties. There are various kinds of PR. The STV system recommended here (and also some List systems) show no tendency to excess in this dimension. Indeed the STV system can be criticised as having quite a high threshold (see below).

25. In 10.24 (Fiji CRC 1996: 309) it goes further and claims that the system has to be suitable for all these purposes'. This statement is wrong. There is absolutely no need for different government elections to be run according to one and the same system, although, other things being equal, a uniform system would obviously have some advantages.

26. That is, a sixth, if the average constituency has 5 members. The percentage will increase or decrease inversely to the increase or decrease of average constituency size. This is why larger-sized constituencies were recommended above.

\section{References}

Fiji Constitution Review Commission 1996. The Fiji Islands. Towards a United Future, Parliament of Fiji Parliamentary Paper 34 of 1996, Government Printer, Suva.

Lakeman, E., 1970. How Democracies Vote, Faber and Faber, London.

Newland, R.A., 1982. Comparative Electoral Systems. The Arthur McDougall Fund, London.

Royal Commission [Street], 1975. Report of the Royal Commission. Parliamentary Paper 24, Parliament of Fiji, Government Printer, Suva.

Royal Commission on the Electoral System, 1986. Towards a Better Democracy, Government Printer, Wellington, New Zealand.

Sisk, T.D., 1996. Power Sharing and International Mediation in Ethnic Conflicts. Carnegie Corporation, New York. 


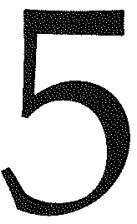

\section{Party cooperation and the electoral system in Mauritius}

\section{Raj Mathur}

The tiny Republic of Mauritius, of an area of $1,865 \mathrm{sq} \mathrm{km}$ and a population of 1.1 million, is situated in the Indian Ocean, $850 \mathrm{~km}$ east of Madagascar. It was first successfully colonised by the French (1715-1810) then by the British (1810-1968). On 12 March 1968 Mauritius became a sovereign democratic state but chose to keep the British Queen as the Head of State, represented in Mauritius by a Governor-General. Exactly 24 years after independence from Britain (on 12 March 1992), Mauritius became a republic, thus breaking one of the last umbilical links with Britain.

The Republic of Mauritius is a parliamentary democracy based on the Westminster model. It is one of the rare former British colonies which has retained the political system inherited from colonial times, 27 years after her independence and five years after becoming a republic. Of course, the Westminster model (winner-takes-all), had to be adapted to ensure power-sharing, a sine qua non for the survival and growth of multi-ethnic societies.

Before power-sharing amongst the various ethnic groups could become a reality in Mauritius, the country underwent some traumatic experiences in the 1950s and 1960s, the pre-independence period. Hence, we see the pertinence of the Mauritian experience to the Fijian problem. Successive constitutional conferences ${ }^{1}$ held in 
London before independence were preoccupied with devising an electoral system for Mauritius which would ensure the following conflicting goals

- a safe and adequate representation of the various ethnic groups comprising the Mauritian people

- majority rule but at the same time respect for the rights of the minorities.

These goals were to be reconciled by

- encouragement of voting which would cut across ethnic lines

- inter-party, and therefore, inter-ethnic collaboration at the level of government

- the imperative of power-sharing amongst the various parties, thus killing any notion of politics as a zero-sum game

- the growth of 'national parties', that is, parties which would represent the interests of all the various ethnic groups and would, therefore, necessarily seek genuine cross-ethnic support.

The Mauritian social structure is not dissimilar to Fiji's. Mauritius is a multi-ethnic, multi-lingual, multi-religious and, therefore, multicultural society. However, there is one major difference-while the Mauritian population is totally an immigrant one, Fiji has an indigenous population. Mauritius was first peopled in the 18th and early 19th centuries by African slaves to labour in the sugar plantations and to work in the households of the French and British colonisers. Following the abolition of slavery in 1835, French sugar magnates turned to the Indian subcontinent for labourers to work in the sugarcane fields. By 1881 the Indian immigrants and their dependants already constituted two-thirds of the inhabitants of Mauritius. $^{2}$

\section{The different communities}

According to the Constitution of Mauritius

The population of Mauritius shall be regarded as including a Hindu community, a Muslim community, and a Sino-Mauritian community, and every person who does not appear, from his way of life, to belong to one or other of those three communities shall be regarded as belonging to the General Population, which shall itself be regarded as a fourth community. ${ }^{3}$ 
Thus, there are only four main communities. The weight of each community, as a percentage of the total population is as follows ${ }^{4}$

$\begin{array}{lr}\text { Hindu } & 50.3 \text { per cent } \\ \text { Muslim } & 16.1 \text { per cent } \\ \text { General Population } & 30.7 \text { per cent } \\ \text { Chinese } & 2.9 \text { per cent }\end{array}$

It is significant to note that if the Hindu population is added to that of the Muslim, the weight of the population of Indian descent is 66.4 per cent.

There are divisions inside each of the four communities. The Hindus are divided along caste, religious and linguistic lines. There are several linguistic groups within the Hindu community: Telegu, Marathi, Tamil, Hindu and also many castes, such as Brahmin, Babouji, Vaish, and Rajput. There have always been attempts by extremist politicians to foster divisions by encouraging each one of the subgroups to demand parliamentary representation commensurate with its numerical strength. The extremists claim that Marathis, Telegus and Tamils should not be categorised as Hindus, that their cultural rites are different and that they have different religious traditions. Like the Hindu community, the Muslim community is also divided along caste, linguistic, economic lines but probably in a less pronounced form. The General Population for its part consists of Franco-Mauritians (less than one percent of the population), persons of mixed blood (Europeans and Africans, Europeans and Indians, Africans and Indians), and persons of African and Malagasy descent. The General Population is further divided along colour, social status and class lines. The Chinese community is also divided along religious (Xian or Buddhists), economic (big business or small shopkeepers), and political (Communist or Nationalist) lines.

\section{Parties and ethnicity in the 1950s and 1960s}

In the 1950s and 1960s the Mauritius Labour Party, which controlled a majority in the legislature and which had cross-communal support, rightfully claimed to be a national party, representing the interests of the various ethnic groups. The Opposition party, the Parti Mauricien Social Democrat (PMSD) which overtly claimed to represent the 
interests of the minorities-that is the Muslims, the Chinese, and, lastly but most importantly, the General Population-pressed for a system of Proportional Representation to ensure that the 'minorities' would have seats in the legislature, proportionate to their numerical strengths in the country. The opponents of the Mauritius Labour Party taxed the party for being communal, defending only the interest of the Hindu community. The Mauritius Labour Party, founded in 1936, preached class warfare in the late 1930s and 1940s against the sugar oligarchy. The party successfully aroused the class consciousness of the workers and was able to rally under its umbrella workers of all denominations and ethnic groups to press for a better deal with the sugar barons-mainly white Franco-Mauritians-in order to improve their desperately low living and working conditions. It became a major political force in the late 1930s and pressed for an extension of the vote to the working classes.

Fearing that political power would slip from their hands if the workers remained united, the sugar oligarchy instilled the poison of communalism to divide and arrest the working class movement. This is how politics became communal and ethnically based in the 1950 s and 1960s. Since the PMSD claimed to represent the minorities, the Mauritius Labour Party (already perceived by the population as being pro-Hindu) ${ }^{5}$ had no alternative but to turn to the latter to consolidate its votes. In the 1960s while the Labour Party and other progressive forces pressed for the Independence of Mauritius, the PMSD-representative of the minorities-demanded an Integration or Association with Britain, ostensibly because of their fear of Hindu hegemony after independence. The propaganda of the PMSD against Hindu domination scared the minorities, and led to an exodus of its population just before and after independence to Britain, France, and Australia. Fifty-four per cent of the population voted in favour of independence (that is, for the Labour Party and its allies) in the critical election of August 1967, while 44 per cent of the population (mostly people belonging to the General Population) voted for the PMSD, against independence (Mathur 1991:268).

From independence onwards both major parties made a big effort to become 'national', that is, embracing all ethnic groups. The PMSD accepted the offer of Sir Seewoosagur Ramgoolam, the Labour leader and Prime Minister, to join a government of national unity in 1969. 


\section{The electoral system}

Throughout the 1950 s and 1960 s, the electoral system and the mode of election to the legislature was the main bone of contention between the two main parties. Successive constitutional conferences held in London were haunted by the need to ensure a 'safe and adequate representation' to all sections of the Mauritius community. It is undoubtedly an achievement that this 'safe and adequate representation' has been made possible without the imposition of a Proportional Representation system which would probably have polarised the divisions along communal, caste and linguistic lines, thus rendering the process of nation-building more difficult.

For the purpose of elections to the National Assembly the country is divided into 21 constituencies, 20 for mainland Mauritius and 1 for Rodrigues (a smaller island). Each constituency in Mauritius elects three representatives whereas Rodrigues elects two representatives to the legislature. ${ }^{6}$ The present electoral boundaries of the various constituencies of Mauritius were drawn by British electoral experts in pre-independence days, to ensure 'adequate representation' to the two most important sections of the Mauritian population, namely the Hindus and the General Population. Ten constituencies are in the rural areas where Hindus predominate with the remaining ten in the urban areas. ${ }^{7}$ Thus the Hindus who constitute 50 per cent of the population would get adequate representation if, as has always been the practice, the national parties would field Hindu candidates in the rural areas. The General Population which constitutes 30 per cent of the population is the most important 'ethnic group' 8 in the majority of the urban constituencies. With the support of the other minority groups, it can muster a majority in urban constituencies, ensuring that it would always get a fair number of seats. Like the Hindu community, it would get 'adequate' representation in the National Assembly.

There is, however, a problem regarding the representation of the remaining two communities, the Muslim (16 per cent) and the Chinese (three per cent). National political parties do sponsor Muslim candidates in areas where that community constitutes a sizeable section of the population and one or two Chinese candidate(s) in a Port Louis constituency where the Chinese 
represent an important ethnic group. ${ }^{9}$ Parties, however, go much further in their choice of candidates for particular constituencies. They do not merely look at the ethnic configuration of a constituency but also consider the sub-groups-caste, cultural and linguistic appurtenance-of the voters, ensuring in the process that the several caste, cultural and linguistic groups of the Hindu community would be represented in the Legislature.

The electoral system is based on the Westminster First-Past-thePost system (FPP) with the important difference that whereas Britain has some 659 single-member constituencies, Mauritius has 20 threemember constituencies. It is a simple majority system. Candidates do not require an absolute majority ( 50 per cent of the votes +1 ) to be elected. The first three candidates, regardless of the percentage of votes obtained, are declared elected.

\section{Distortions caused by FPP}

Under the one-round elections prevalent in Mauritius, a party with only 35 per cent of the vote evenly distributed may get, in a threeparty contest, a majority of seats in Parliament. In theory that party may even get 100 per cent of the seats, if the strength of the other two parties are 33 and 32 per cent in every one of the 20 constituencies. At the 1982 elections the Mouvement Militant Mauricien/Parti Socialiste Mauricien alliance obtained 100 per cent of the seats with 64 per cent of the vote (see Mathur 1991:282). The 33 per cent of the electorate who voted for the Opposition had no representative at all in the Legislature. The Opposition was completely wiped out, thus jeopardising the workings of the British-based parliamentary system..$^{10}$ However the legitimacy of the Government was not challenged as it had the support of 64 per cent of the population. One may wonder what would have happened had total victory for one party or party alliance come with less than 50 per cent of the vote!

General elections were again held in 1983 and this time the winning alliance obtained 52 per cent of the vote and 41 of the seats (out of 60) that is, 68 per cent of the seats, leaving the Opposition with 19 seats ( 32 per cent) for 46 per cent of the vote. In 1987 the winning alliance with slightly less than 50 per cent of the vote obtained 65 per cent of the seats. In 1991 again the distortion was more pronounced, the winning alliance obtaining 95 per cent of seats for 56 per cent of the vote, leaving the Opposition with only 5 per 
cent of seats for 40 per cent of the vote. However the distortions were to become alarming when at the 1995 election, the winning alliance, repeating the performance of 1982, won all the seats for 65 per cent of the vote, leaving the Opposition, smaller parties and Independents with no seats at all for 35 per cent of the vote!

\section{Table 5.1: Votes and seats in General Elections, 1982-1995}

$\begin{array}{clcc}\text { General Elections } & \text { Alliance } & \% \text { Vote } & \text { \% Seat } \\ 1982 & \text { MMM/PSM } & 64 & 100 \\ & \text { LAB/PMSD } & 33 & - \\ 1983 & \text { MSM/LAB/PMSD } & 52 & 68 \\ & \text { MMM } & 46 & 32 \\ 1987 & \text { MSM/LAB/PMSD } & 50 & 65 \\ & \text { UNION } & 48 & 35 \\ 1991 & \text { MSM/MMM } & 56 & 95 \\ & \text { LAB/PMSD } & 40 & 5 \\ 1995 & \text { LAB/MMM } & 65 & 100 \\ & \text { MSM/Others } & 35 & -\end{array}$

Notes

1. The two seats of Rogrigues are normally contested by Rodriguan parties and are, therefore, not included.

2. MMM: Mouvement Militant Mauricien, founded in 1969 and led since its foundation by Paul Berenger.

3. PSM: The Parti Socialiste Mauricien a party founded by H. Boodhoo in 1979. The party is now defunct.

4. LAB: the Mauritius Labour Party founded in 1936 and at present led by Navin Ramgoolam, Prime Minister (Dec 1995-to date).

5. PMSD: the Parti Mauricien Social Democrates led by Sir Gaëtan Duval from 1966 until his death in 1996. At present the party is led by Sir Gaëtan's brother Hervé Duval.

6. MSM: the Mouvement Socialiste Militant was founded in 1983. It was the ruling party from March 1983 to December 1995. It is led by Sir Anerood Jugnauth, Prime Minister from 1982 to 1995 (1982 as the MMM party leader, then from 1983 as leader of the MSM).

7. UNION: the official name of the alliance of MMM along with two small political formations namely, the Mouvement Travailleurs Democrates, led by A. Baichoo and the FTS, the Front Travailleurs Socialiste, led by S. Michel.

8. Others: include the very small political formations and the Independents. At the 1987 elections, the MSM/LAB/PMSD alliance won 65 per cent of the seats with only 49.6 per cent of the vote. The figure has been rounded up to 50 per cent.

Under FPP, a small swing from one party to another may lead to a disproportionate percentage of seats changing hands. If this is true 
for countries with single-member constituencies, the distortion between the percentage swing in votes and seats may be three times as much in a country like Mauritius where the three-member constituencies prevail (see Rae 1971). In 1983 the results were so clear-cut with the winning alliance obtaining an average of 64 per cent in practically all constituencies, that it would have required an enormous swing from the winning party to the losing alliance for seats to change hands. In 1987 a four per cent swing in favour of the losing alliance and against the winner would have meant that the losing alliance would have obtained 37 seats with 50 per cent of the vote and, therefore, form the Government! In 1987 the losing side would have gained office with only two per cent swing in its favour against the winner. It would have obtained 32 out of the 60 seats $!^{11}$

Political parties, with the exception of the ruling Labour Party, are seriously considering a mixed system which would incorporate FPP and a form of Proportional Representation.

\section{Best losers}

Over and above the direct election of 62 members to the National Assembly, the Constitution of Mauritius also provides for the allocation of eight additional seats to ensure a 'fair and adequate representation' of each community. ${ }^{12}$ These additional seats are known as 'Best Loser' seats. Thus, the Mauritian Parliament is made up of seventy members -62 directly-elected (60 in Mauritius and 2 in Rodrigues) and eight Best Losers. The first four Best-Loser seats are allocated to under-represented communities (resulting from the results of the direct elections) regardless of the candidates' political affiliations. However the candidates must obtain the highest score amongst other defeated candidates belonging to the same community. The under-represented community is determined by dividing the number of persons belonging to that community by the number of seats that the community has obtained plus one. The community with the highest quotient is the appropriate community and MPs belonging to that community represent a greater number of persons than MPs belonging to other communities. A separate exercise is done for each seat to determine the under-represented community.

The second set of four Best Losers is awarded on a party and community basis. The emphasis is first on party because the balance 
of political power which existed soon after the general election must not be offset. In a close election, if such a rider were not laid down, the Opposition might become the majority party by winning a greater number of Best Loser seats. The candidates chosen must belong to the under-represented community. However the score obtained by candidates must be the highest in relation to other candidates of their party belonging to their community.

Following the 1982 and 1995 elections there has been a massive popular movement in favour of the abolition of the Best Loser system, and therefore doing away with the vestiges of communalism in Mauritian politics. It is argued that the electorate in the successive elections held from 1976 to 1995 did not vote along communal lines. Instead the electorate's choice was more motivated by the program of the parties, the competence of the team presented by the various parties, the choice of a Prime Minister, political principles and ideology rather than by race, caste or religion. The movement contends that it is high time for the Mauritian Parliament to pass a Bill abolishing the constitutional provisions for Best Loser seats. This would in effect mean the abolition of formal ethnic representation and, hopefully, put an end to ethnically based politics.

\section{Party cooperation and sharing of political power}

The Mauritian electoral system encourages bipolarisation of the political system. The FPP favours the formation of two major political alliances confronting each other. A third party, or still less smaller political formations, has no chance at all to have their candidates elected unless the support is concentrated in one or two constituencies. There is either a pre-electoral alliance of two parties perceived by the population as representative of the two major ethnic groups (Hindus and General Population) or a post-electoral coalition formed by parties perceived as representatives of the two major ethnic groups after the election results are known. There is, therefore, a real sharing of political power by all the different constituents of the Mauritian nation. This sharing of political power ensures that the several ethnic groups and sub-groups have their share of the national cake, in particular the appointment to top positions in the civil service, parastatal bodies, municipalities, and in the private sector.

Since independence, Mauritius has been governed by a coalition formed after the results of the elections are known or by an alliance 
concluded before the elections. It is conceded that no party on its own can expect to win a parliamentary majority. Pre-election alliances and coalition governments are the rule. Politics in Mauritius has never been conceived as a zero-sum game.

Democracy in multi-ethnic societies does not merely mean majority rule, governing with 50 per cent plus 1 seats. Rather it means a readiness to share political power with other parties which are perceived to be representatives of other communal or ethnic interests. All the important communal, linguistic and economic groups must be represented in Parliament and in the Cabinet. Since the introduction of the Ministerial system in 1958, the British colonial power had assured that the governments formed were governments of national unity, encompassing all the various ethnic groups and political parties. ${ }^{13}$ Successive governments formed after independence have always consisted of ministers from all the major ethnic groups.

In their bid to win political power, the two major parties strove very hard to be perceived by the electorate as 'national' parties. They would field candidates from all the major communities. These candidates are not 'puppets' but rather important personalities capable of seeking and obtaining cross-communal support. The main political parties in Mauritius have learnt a very important lessonnamely that to win political power a party cannot be perceived as being solely ethnically based, defending the interests of only one community. Rather it must obtain cross-communal support. This stark reality has sunk so much in the minds and hearts of the political élite that today there is no major party which is ethnically based. All the major parties can claim to be truly national parties.

\section{Notes}

1. These constitutional conferences were convened by the colonial power to pave the way for self-government and eventual independence.

2. In 1881 there were 249,064 Indians out a total population of 360,847 (Mauritius 1891:1:7).

3. Schedule 1, para 3(4) of the Constitution.

4. The population figures, from which the percentages have been worked out, are based on the 1972 population census-the last 
census when the population was required to indicate their communal appurtenance. There has not been any significant change in the ethnic distribution of the population (Ministry of Economic Planning and Development 1974).

5. Up to the end of the 1950s, the Mauritius Labour party was supported by workers of all denominations. The Parti Mauricien Social Democrat's propaganda that the Labour Party was a proHindu party was successful in convincing the non-Hindu 'minorities' only in the 1960s.

6. Schedule 1, para 1 (1) of the Constitution of Mauritius.

7. See Trustram-Eve Report in Sessional Paper 1 of 1958, Report of the Mauritius Electoral Boundary Commission and also the Banwell Report in Sessional Paper 5 of 1966, Government of Mauritius, Port Louis, Mauritius.

8. However, the Community General Population has an absolute majority in only one constituency.

9. This practice which encourages inter-ethnic collaboration was initially recommended by the British Electoral Commissioner Trustram-Eve in 1958. It has since then been followed scrupulously.

10. The allocation of 4 seats to the Opposition through the Best Loser system provided a skeletal parliamentary opposition.

11. For the effect of swings, see Mathur 1991.

12. Schedule 1, para 5 to the Constitution of the Republic of Mauritius.

13. During the colonial era, it was the British Governor who formed the Council of Ministers. He appointed as ministers persons whom he considered to be representatives of the various communities. These appointments would be carried out regardless of whether the appointees were elected members or nominees of the then Legislative Council.

\section{References}

Mathur, Hansraj, 1991. Parliament in Mauritius, Editions de l'Océan Indien, Rose Hill.

Mauritius, 1992. The Constitution of the Republic of Mauritius, Port Louis.

Ministry of Economic Planning and Development, 1974. Mauritius Population Census of 1972, Port Louis. 
State, society and governance in Melanesia

Mauritius 1891, Census of Mauritius and its Dependencies April 1891, Port Louis.

Rae, Douglas W., 1971. The Political Consequences of Electoral Laws, Yale University Press, New Haven. 


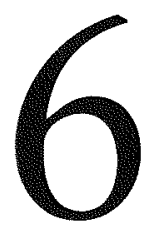

\section{The recommendations on the electoral system: the contribution of the Fiji Constitution Review}

\section{Yash Ghai}

In order to assess the electoral proposals of the Fiji Constitutional Review Commission (CRC), it is necessary to place them in the overall scheme of constitutional reform recommended by the Commission. The Commission states that its report is like a 'seamless document', whose component parts are inextricably linked and that 'its full import will be grasped only if it is read in its totality' (Fiji CRC 1996:3). This approach to the recommendations of the CRC is particularly important in view of the 'social engineering' orientation of its report, whereby constitutional rules are deliberately designed to achieve particular results (as opposed to, for example, a 'liberal' constitution which theoretically seeks merely to establish a 'political market place' where different ideas and options may be freely and equally pursued). Indeed a social engineering approach was required by the terms of its commission. It was the task of the CRC to recommend a constitution that would 'promote racial harmony and national unity and the economic and social advancement of all communities', paying attention to 'Fiji's needs as a multi-ethnic and multi-cultural society' (Fiji CRC 1996: 754-5).

The CRC decided that these goals would be best achieved through the emergence of multi-ethnic governments. The Commission also set out the broad framework within which a multi- 
ethnic government would be established. It supported the concept of the paramountcy of Fijian interests, so long as the concept was understood in its 'protective function' and did not 'involve the relegation of the interests of other communities'. It recommended that the Westminster parliamentary system should continue. At the same time the 'important role of the Bose Levu Vakaturaga', or Great Council of Chiefs, should be constitutionally recognised. The system of representation should move away from communal seats. There should be an increased role for backbench members of all parties. The Constitution should protect individual human rights and the rights of groups, including rights to land. It also recommended programs for social justice and affirmative action for the Fijian and Rotuman communities 'as well as for other disadvantaged communities and groups'. (These points are set out in chapter 2 of the report).

The rest of the lengthy and detailed report of the Commission sticks clearly and consistently to these objectives, and establishes a close connection between the various parts of its constitutional proposals. The report is admirably clear and well argued. It is by far the most sophisticated review of a constitution that has been undertaken in the South Pacific. However, there is not necessarily an internal coherence to its proposals. The role of the Bose Levu Vakaturaga and the constant emphasis on 'Fijian and Rotuman interests' (bracketed often with the 'interests of other communities'), the singling out of Christianity from other religions in Fiji in the proposed Preamble, and frequent genuflections to the paramountcy of Fijian interests are out of tune with its otherwise even-handed and humanistic approach. It would, however, be unfair to blame the Commission for these aberrations, for it was weighed down with the burden of history, and had to try to produce not only a fair set of proposals but also those which had some prospects of acceptance by the ruling élites in Fiji. Nevertheless, when assessing the proposals, these features cannot be ignored, since the report is a 'seamless web'.

\section{Proposals of the SVT and the NFP-FLP}

In order to understand and evaluate the recommendations of the $\mathrm{CRC}$, it is useful to provide a summary of the submissions of the major political parties. This will help to establish the ideas that were circulating in the country, the difficulties facing the Commission in 
establishing common ground, and insights into its own thinking in so far as it deviated from the submissions made to it.

The position of the Soqosoqo ni Vakavulewa ni Taukei (SVT) was that arrangements for power-sharing should be voluntary but made within a constitutional framework which recognised the political supremacy (and majority in parliamentary representation) of indigenous Fijians (SVT 1995:45). Otherwise it had little to say on coalitions or power-sharing, being concerned largely with castigating Indo-Fijians and accusing them of all manner of nefarious intentions and activities. Its general approach was scarcely that of a community looking for inter-racial cooperation and amity. Under its proposals, the decision whether to form a multi-ethnic party would effectively depend on the dominant indigenous Fijians' party, although that decision would be influenced by its strength in the legislature and consequently whether it had sufficient members to establish a government by itself. Nor did the SVT say much about the electoral system, but in so far as it wished to retain the 1990 Constitution, it supported a disproportionately large representation of indigenous Fijians and opposed any form of non-racial seats or parties. However, it was not clear how far this position represented the views of the leadership of the government, as it was rumoured that only a small group had drafted the submission and that it did not enjoy the support of some senior politicians. Certainly both its tone and content were at variance with the position adopted by ministers in their discussions with the opposition leading up to the establishment of the CRC and the drafting of its terms of reference.

By contrast, the position of the National Federation Party (NFP) and the Fiji Labour Party (FLP) clearly favoured a constitutionally mandated sharing of power. They had given much thought to the desirability and feasibility of power-sharing and constitutional provisions that would facilitate both a coalition type of government and its accountability to the legislature-which is reflected in their submission to the CRC (NFP-FLP 1995). The two parties claimed that the justification for some form of power-sharing at this stage of our history is overwhelming' (NFP-FLP 1995:54). They referred to the effect of the 1970 and 1990 constitutions of excluding a major ethnic group from any share in state power, or influence in its exercise, and argued that this had served to worsen race relations. They saw several advantages in power-sharing. 
Under it the cabinet would provide a framework for inter-ethnic negotiations and would facilitate the resolution of many outstanding problems of the country which requires accommodation of competing ethnic claims. It would ensure that no vital interests of any community would be disregarded. It would help to develop a national outlook on major issues facing us. It would lead to increased responsiveness to public needs. It would ensure greater stability in government and strengthen the party system. A particular advantage in Fiji would be that an agreement on power-sharing would facilitate an agreement on the electoral system - which is the most controversial decision your Commission would have to make-since every major community and party would be confident of participating in government and precise numbers of parliamentary seats would be of less moment than at present (NFP-FLP 1995:54).

Their submission also discussed possible shortcomings or negative consequences of power-sharing but considered that the 'advantages of power-sharing outweigh them-at least for now' (NFP-FLP 1995:55). However, in their proposals on power-sharing, they were concerned 'to maximise the advantages and minimise the drawbacks'. They realised that their proposals were not consistent in all respects with the Westminster system (although they were concerned to ensure that government remained accountable and that backbenchers would have an active role in policymaking and the supervision of administration). Their basic position was that the Westminster system as it had been constitutionally established and practised in Fiji had not served well the interests of the country.

The principal part of their proposal was that power-sharing should be constitutionally mandated, not voluntary. It would be inter-party rather than inter-ethnic. Any party which obtained more than 20 per cent of seats in the lower house would be entitled to a similar proportion of seats in the cabinet. The expectation clearly was that this proposal would result in leaders of all ethnic groups joining in government but also that it would not inhibit the development of inter-ethnic parties which might result from a formula which based power-sharing on ethnicity. Nevertheless, there would be an obligation on the part of the Prime Minister and the Deputy Prime Minister (drawn respectively from the largest and the second largest parties) to ensure a racially balanced cabinet (the minimum portfolios recommended were 40 per cent each for indigenous Fijians and Indo-Fijians and 5 per cent for others). 
The proposals of these parties on the electoral system were likewise determined by the objective of racial harmony and national unity-in contrast to previous systems which had 'pitted one community against another' (NFP-FLP 1995:57). The ultimate goal was non-communal voting of all members. However, as an interim measure, a certain number of communal seats would be retained. The recommendation was for 40 non-communal ('national') seats and 31 communal (14 each for indigenous Fijians and Indo-Fijians, and 3 for others). Communal seats would be elected from single-member constituencies on the alternative vote system to ensure a real majority, while the other seats would be contested on a system of Proportional Representation based on party lists, with the whole country as one constituency (with voters free to change the order of preference in relation to candidates of the party for which they vote). It recommended a threshold of seven per cent of the national vote in these elections before a party would become eligible for any seats.

The NFP and the FLP expected that the system of national seats would act as incentives towards the formation of non-racial or interracial political parties. There would be several incentives for the formation of such parties: national seats constitute the majority of seats; a party has to achieve seven per cent threshold to be eligible for a seat; a party qualifies for a seat in the cabinet only if it has at least 12 members in the legislature; and the largest party supplies the prime minister. It also recommended that no party would be allowed to contest elections unless its membership was open to all races.

\section{The Commission's approach to multi-ethnic government}

The Commission's assumptions about, and framework for, multiethnic government are quite specific. The first assumption is the retention of the Westminster system, which it regards as having served the South Pacific well (Fiji CRC 1996:22). Its scheme for multiethnic government had therefore to be fitted within the broad parameters of that system, which has not traditionally been hospitable to coalitions. The second assumption of the Commission is that multi-ethnic government has to come about through the choice and decisions of political parties, rather than be constitutionally required or mandated. However, it realised that a multi-ethnic government was unlikely to come about purely through voluntary means. Consequently, it was willing to skew the electoral system in favour of 
multi-ethnic government by creating incentives for parties to seek cooperation with other parties, especially across racial boundaries. Its preference for voluntary over constitutionally mandated multiethnic government was motivated by its assessment that, in so far as a multi-ethnic government would arise out of a coalition, it needed a stronger foundation than a post-election pact-as such coalitions tend to be unstable. Of course in so far as a coalition is mandated by the constitution, it has greater prospects of survival than a purely voluntary arrangement, but the Commission may have been concerned about the deadlocks that may ensue from such a 'forced marriage', and the consequent delays in decision-making and administrative inefficiencies (Fiji CRC 1996:20, 279). The Commission had great faith in the capacity of political parties to respond to electoral incentives and to negotiate and fashion deals. It stated that 'the party system is deeply embedded in the [Fiji] political culture. Power-sharing should be achieved through the voluntary cooperation of political parties, or increased support for a genuinely multi-ethnic party' (Fiji CRC 1996:19). The Commission was therefore concerned to devise an electoral scheme in which the prospects for the formation and stability of multi-ethnic coalitions or the development of multi-ethnic parties would be high.

The key to that scheme was the electoral system. The Commission believed that it would be impossible to establish multi-ethnic government unless there was a change in the electoral system. The electoral system had to create incentives for cooperation among ethnic parties or lead to the formation of ethnic parties (Fiji CRC 1996:279). Essential to that purpose was the abolition of communal representation which had led to ethnic parties and prevented cooperation among them (Fiji CRC 1996:19-20, 279). However, the Commission recognised that it was unrealistic to expect at this stage to do away altogether with communal representation. The Commission's recommendations on the allocation of seats were a compromise between its preferred policy of no communal seats and the reality in which most parties supported or were willing to accept some communal representation, and that of the ruling SVT party which opposed any form of non-communal seats.

There are two elements to the Commission's proposals for the electoral system. The first relates to the allocation of seats in the House of Representatives. It recommended that in a House of 70 
seats, there should be 25 communal seats and 45 non-communal ('open seats'). The communal seats would be distributed as follows: Fijians (including Pacific islanders) 12; Indo-Fijians 10; General Voters 2 and Rotumans 1 . The crucial part of the recommendations was the system of constituencies and of voting for the open seats. The Commission recommended single-member constituencies for communal seats, and three-member constituencies for the open seats. The reason for choosing three-member constituencies will become apparent after the system of voting is explained.

For both types of seats, the system recommended for voting.was the Alternative Vote (AV). This system of voting has been described elsewhere in this volume. The essence of this system is that a candidate has to obtain an absolute majority (rather than plurality) of votes to win the elections. Voters cast their votes among the candidates in an order of preference. In order to determine the winner, the first preferences of all the candidates are counted to begin with. If a candidate obtains an absolute majority, he or she is declared elected, but if no one has enough votes, the candidate at the bottom is eliminated, and the second preferences of the voters of those voted for such a candidate are distributed accordingly among the remaining candidates. The process of elimination and redistribution is carried on until a candidate obtains the majority.

This system is used in single-member constituencies in preference to plurality voting in order to ensure that the winning candidate enjoys the support of the majority of voters. The system has the effect of encouraging parties and candidates to broaden their appeal to their electorates. If an electorate consists of two or more ethnic communities (none of which is in a majority), the chances are that the candidate who appeals to and beyond his or her community would win. This may also lead to cooperation among parties (especially in agreeing to urge their members to cast their second preferences for the candidates of their 'partner' parties). It may even lead to multiethnic parties. In communal seats the system would of course not work like this. Therefore the importance of AV for the purposes of the Commission lay in open electorates. However, if constituencies for open seats tended to have a clear majority of one community, AV would not work in the way desired by the Commission. Fearful that single-member constituencies would indeed be of this kind, the Commission recommended that open seats be contested in three- 
member constituencies to increase the likelihood of their being significantly ethnically heterogeneous, so that no one party could expect to win the elections on the strength of the votes of one community only. However, the Commission failed to explain clearly what the system of voting within the constituencies would be. The impression being that there would be one composite constituency, returning three candidates, as the Commission specified that the first, second and third preferences given to each candidate would be added together before the elimination of the candidate with the lowest votes (Fiji CRC 1996:329).

There was considerable confusion among the readers of the recommendations as to how precisely the elections for open electorates would be conducted. This was one of the major reasons that almost all political parties (and other commentators) were critical of the proposals. The system of AV is associated with singlemember constituencies - the consequences of its adoption in threemember seats were uncertain, and could indeed act to operate against minorities.

\section{A critique of the Commission's recommendations}

The impact of the recommendations was undoubtedly dented by the confusion about the method of voting proposed for open seats. It was impossible for political parties to establish how votes would be cast or its consequences, or how they might affect their strategies for political organisation or cooperation with other groups. Not surprisingly, they tended to disregard the recommendations. It is not my purpose to comment on the recommendations from the point of view of the mechanics of the recommendations or the feasibility of their implementation. I wish to examine some of the assumptions of the recommendations instead.

The Commission was at one with most parties and individuals who made representations to it on the necessity of multi-ethnic government. It departed from them in two important respects. First, its commitment to the Westminster system meant that it was not always prepared to accept the logic of some proposals for powersharing made to it, which implied a significant modification of that system. It would have been difficult for the Commission to take on the Westminster model in the absence of any large-scale opposition to it, but it is unfortunate that it did not examine (but assumed) that the 
model had worked well in the South Pacific. In fact it has not worked well and many problems such as the lack of political stability, incoherent policymaking, and a large measure of corruption in public life, can be attributed to it (Chan 1988; Ghai 1988, 1997). In any event, the Commission could have made more of an attempt to recommend modifications of the Westminster system in order to accommodate the general support of multi-ethnic governments expressed in most of the submissions to it. It was also mistaken in its observation that those supporting power-sharing had not tried to fit it within the Westminster model. In fact the NFP-FLP had gone to considerable lengths to examine and deal with some of the issues that might arise from its accommodation within Westminster.

The more important departure, partly (but only secondarily) aimed at preserving the 'purity' of Westminster, was in the method advocated to achieve multi-ethnic government. Most proposals assumed that political parties represented in the legislature would qualify for the membership of the cabinet in some proportion to their parliamentary seats. Most of them also specified the ethnic proportions that must be represented in the government. The Commission opposed this method, arguing that there was no realistic prospect of multi-ethnic government unless there are strong incentives within the electoral system for cooperation within what, for the time being, would continue to be mainly ethnic parties (Fiji CRC 1996:20). It was also influenced by the view that such coalitions, formed after elections, tend to be unstable. It supported a system which would lead to cooperation or partnership between political or ethnic groups before the elections-in fact, would constitute an essential element in their election strategy. For this reason it focused instead on the electoral system and came up with the specificities that I discussed above. It wanted the electoral system itself to provide incentives for cooperation between ethnically-based parties or preferably the formation of inter-ethnic parties. The success of this strategy depended on various assumptions that the Commission made. I argue that several of these assumptions were unjustified.

It was central to the recommendations of the Commission that parties are well established in Fiji and that they are able to take advantage of incentives offered by electoral rules. It is true that for a long period politics in Fiji were dominated by parties, with two large and relatively well-organised parties. However, the situation 
changed with the formation of the Fiji Labour Party. Its major impact was on Indo-Fijian politics and party organisation. The coups of 1987 and the promulgation of the 1990 Constitution had an equally significant impact on political organisation among the Fijian community, with the SVT replacing the Alliance as the dominant party. Its claim as the party of the chiefs and its close links with the Council of Chiefs affected the configuration of party organisation among indigenous Fijians. It was neither as well organised or representative as the Alliance. Since these developments, parties have been less firmly anchored among their supporters and there is considerable fluidity in their membership and leadership.

Another precondition for the success of the scheme recommended by the Commission is that there should be two or more parties in each community. This would facilitate cooperation or alliances between parties with different ethnic bases for the purpose of trading or polling votes. One could say that the existence of multi-parties in each of the major communities is an essential condition for the achievement of the goals of the Commission. It may be questioned whether the communities would remain politically divided. There was some incentive under the 1970 Constitution for the existence of more than one party in each community due to the existence of national seats. The community which dominated in a constituency could effectively determine the results of the election to the national seats, and each party had an incentive to field candidates for all national seats. So there was a role for a minority party within each community and, indeed, for multi-ethnic parties. However, the sense of communal competition for power so dominated the political system that, effectively, each community had one party only.

The situation changed under the 1990 Constitution for two reasons. The first was the abolition of national seats. The second, more important, was the provision of a built-in Fijian majority representation and domination. Not only did each community become inward-looking (under a system where there were only communal seats), but the huge Fijian majority representation eliminated a sense of competition for power from other communities. Consequently there emerged different claimants to power in the Fijian community, while the pre-coup divisions within the IndoFijians consolidated with the disappearance of the coalition that had 
formed government under Bavadra. It is likely that with the introduction of open seats, which would be the key determinants of access to power under the recommendations of the Commission, the sense of communal rivalry would re-emerge. It is hard to predict its effect on the pattern of party organisation. I want merely to suggest that the solidity within each community, especially the indigenous Fijians, is at least as likely as bifurcation or the emergence of multiethnic parties. It is conceivable that the Council of Chiefs or provincial councils would attempt to close Fijian ranks (just as there may be 'fundamentalists' among the Indo-Fijians). Ironically, it was the existence of a system in which seats were contested purely on a communal basis that produced divisions within each community, and created the situation which the Commission perceives is essential to the success of its proposals rejecting the dominance of communal seats.

A further assumption is that parties have effective control over their supporters and can direct them on how to cast their preferences. It remains to be seen whether voters would overcome a natural tendency to favour candidates of their own ethnic affiliation. The more complex the system of seats and voting, the less likely is it that voters would understand the implications of multi-ethnic cooperation. In this respect the continued existence of communal seats might work against the logic of open seats. It is possible that given a majority of communal seats, the tendency towards internal communal divisions may persist. There is therefore considerable irony that the effective working of the recommendations of the Commission in favour of open seats would depend on the logic of communal seats!

Yet a further assumption is the feasibility of the ethnic heterogeneity of constituencies. The Commission realised that a deliberate act of 'gerrymandering' would be necessary to establish heterogenous constituencies-and that such heterogeneity would be difficult in single-member constituencies. There are very considerable dangers in a deliberate design of constituencies. It would tend to politicise the process of their delimitation, which fortunately has been avoided hitherto. It would be most undesirable if the neutrality of the Constituency Boundaries Commission were undermined. 


\section{Conclusions}

I do not want to suggest that the scheme proposed by the Commission would not work in the way the Commission expects it to. I want to suggest that it may not work like that. There are too many assumptions and uncertainties about the system. If so, we have to assess whether it is desirable to put all one's eggs of multi-ethnic government in the electoral basket. The Commission's agenda is bold and eminently sensible and desirable-if it works. The negative side is that if it does not, the prospects for multi-ethnic government may become even more remote. The impression one gets on reading the $\mathrm{CRC}$ report is that it has made what one might call doctrinal objection to post-election coalition. In the search for its alternative proposals, it paid insufficient attention to the proposals for a constitutionally mandated power-sharing (even on a temporary basis). There is no doubt that the political integration through the electoral process that the Commission envisages is better than the alternatives it rejected-if it works. However, a close analysis of the NFP-FLP proposals (which the Commission does not undertake in its report, although it may have in its internal deliberations) would have demonstrated that the primary concern is integration through the political process.

In the end the choice may lie between a constitutionally mandated power-sharing, hopefully on terms that would encourage multiethnic parties, and a system which relies only on the electoral system to achieve that goal. In the realities of Fiji, the Commission may have underestimated the difficulties of persuading political parties and communities, particularly but not only Fijians, to move away from the essentials of the old system of representation. By placing so much weight on an untried electoral system (and it must be remembered that it is untried anywhere else, not only in Fiji), it has provoked acute anxieties about the electoral system. The Commission thereby gave up an immediately more feasible alternative-that of a constitutional mandate. Ironically, the provision of constitutionally mandated power-sharing would have facilitated agreement on the electoral system that the Commission has recommended. Perhaps in the end the Commission was too much influenced by textbook arguments against coalitions, and an unspoken prejudice against consociationalism-notwithstanding that its other recommendations 
are replete with the consociationalism of Fiji's past. However, even if they are not accepted, the Commission's bold and innovative approach and recommendations have opened up a lively debateand concentrated the minds of decision-makers in their search for multi-ethnic government.

\section{References}

Chan, Sir Julius, 1988. 'Experience with Papua New Guinea's Constitution: a Prime Minister's Reflections,' in Ghai, Yash (ed.), Law, Politics and Government in the Pacific Island States, Institute of Pacific Studies, Suva.

Ghai, Yash, 1997. 'Establishing a Liberal Political Order Through a Constitution: the Papua New Guinea experience,' Development and Change 28:303-30.

Ghai, Yash, 1988a. 'Political Consequences of Constitutions', in Ghai, Yash (ed.), Law, Politics and Government in the Pacific Island States, Institute of Pacific Studies, Suva.

Ghai, Yash (ed.), 1988b. Law, Politics and Government in the Pacific Island States, Institute of Pacific Studies, Suva.

National Federation Party and the Fiji Labour Party (NFP-FLP), 1995. Towards Racial Harmony and National Unity, Submission of NFP-FLP, Suva.

Soqosoqo ni Vakavulewa ni Taukei (SVT), 1995. Respect and Understanding: Fijian sovereignty, the recipe for peace, stability and progress, submission by the SVT, Suva. 